\title{
A new genus and eight new species of Amazonian cosmetines (Opiliones, Laniatores, Cosmetidae)
}

\author{
Adriano B Kury ${ }^{*}$ and Carla ML Barros
}

\begin{abstract}
Background: The taxonomy of family Cosmetidae is in as unsatisfactory state. The genera have been historically erected based on trivial features and do not represent natural groups. A new taxon is here for the first time recognized and named.

Results: The new genus Taito is described to include eight new species - Taito galaga, Taito honda, Taito kakera, Taito kawaiikei, Taito medinae, Taito osmari, Taito rorschachi, and Taito spaceinvaders (type species) - plus six recombined from Eucynortella, Cynorta, and Cynortula - Taito insperatus (Soares 1970), Taito juruensis (Mello-Leitão 1923), Taito litteratus (Soares 1970), Taito oblongatus (Roewer 1928), Taito serriperna (Mello-Leitão 1932), Taito unapunctatus (Goodnight and Goodnight 1943). This totals 14 South American species, distributed in the Upper Amazon Basin. The combined distribution of species of Taito is Brazil (Acre, Amazonas, and Rondônia states), Colombia (Amazonas and Meta department), Ecuador (Zamora-Chinchipe province), and Peru (Amazonas department). Cynortula serriperna Mello-Leitão 1932 is revalidated from the synonymy of Eucynortella juruensis Mello-Leitão 1923 (currently Cynorta juruensis), and type localities of both species are interpreted to be in Acre state, Brazil instead of Amazonas. The hitherto unknown male of Eucynortella juruensis is described. Three new structures are characterized and named: (1) a pattern of $\mathrm{H}$-shaped or easel-shaped white markings on dorsal scutum - the equuleus, (2) a dorso-basal cluster of coarse granules on male coxa IV - the groin warts, and (3) a special type of dorsal scutum coda - the free tergite zero.

Conclusions: A hitherto undetected group of Cosmetidae is recognized and formally described, along with some morphological characters which are proven useful for systematics of the family Cosmetidae.
\end{abstract}

Keywords: Neotropics; Harvestmen; Rainforest; Variation; Genital morphology

\section{Background}

The Neotropical family Cosmetidae of Opiliones Laniatores with more than 700 species is nearly as diverse as Gonyleptidae (Kury 2003; Kury 2013). But the higher homogeneity of cosmetid morphology caused phylogenetic relationships among species of this family to go largely unrecognized. We estimate that about $50 \%$ of the cosmetid genera are meaningless by being monotypic or defined only by combinations of trivial meristic features such as tarsal counts and area armature, not taking into consideration any possibly useful additional feature.

In the present project, a presumed natural group of cosmetids from Upper Amazon Basin is for the first time recognized and characterized, based on the study of Brazilian material from Amazonas State in the collection

\footnotetext{
* Correspondence: adrianok@gmail.com

Departamento de Invertebrados, Museu Nacional/UFRJ, Quinta da Boa Vista, São Cristóvão, 20.940-040, Rio de Janeiro, Brazil
}

of Museu Nacional in Rio (complemented by scarce material from other institutions), as well as a fine collection of Opiliones from Acre State made in 2009 to 2010 and kindly sent by Osmar Torres (Universidade Federal do Acre - UFAC). This group, here described as the new genus Taito, may be recognized by a combination of easily seen (though not exclusive) features such as an equuleus, a free tergite zero (terms defined below), sexual dimorphism in elongation of dorsal scutum in male, armature of coxa IV, femur IV, and anal operculum.

Some species, earlier located in Eucynortella Roewer 1912 and Cynortula Roewer 1912, are here transferred into Taito as the diagnoses of these genera, based on trivial characters, matched those of Taito, while the true Eucynortella and Cynortula are not especially closely related to it. Another two species, originally described in Cynorta C.L. Koch, 1839, during the 70s, when the name 
Cynorta has an astonishing wide range are also considered to belong in Taito.

\section{Methods}

Abbreviations of depository collections are as follows: IAvH-I (Instituto de Investigación de Recursos Biológicos Alexander von Humboldt, Villa de Leyva, Colombia curator Dr. Claudia Medina), IBSP (Instituto Butantan, São Paulo, SP, Brazil - curator Dr. Antonio Brescovit), ICN-AO (Universidad Nacional, Instituto de Ciencias Naturales, Bogotá, Colombia - curator Dr. Eduardo Florez), INPA (Instituto Nacional de Pesquisas da Amazônia, Manaus - curator Dr. Ana Lúcia Tourinho), MNRJ (Museu Nacional, Universidade Federal do Rio de Janeiro - curator Dr. Adriano Kury), MNRJ-HS (former Helia Soares Private Collection, now in MNRJ), MZLQ (Museu de Zoologia Luiz de Queiroz, Piracicaba, SP, Brazil), MZSP (Museu de Zoologia, Universidade de São Paulo - curator Dr. Ricardo Pinto-da-Rocha), SMF (Senckenberg Museum, Frankfurt am Main, Germany - curator Dr. Peter Jäger).

Exploded representations (Figure 1) of the dorsal and ventral terminal segments of opisthosoma of some species are used here as more convenient to visualize armature of anal operculum, free tergites, and sternites than the ordinary posterior view (e.g., Figure 2d), which is more adequate to convey other information. The section 'distribution' within each species heading for shortness summarizes the second-order administrative divisions (municipalities, provinces or districts) containing the localities. Measurements are in millimeters. Localities are referred to WWF Eco-regions (abbreviated as WWF) to contribute to their biodiversity inventory. Abbreviations used are CL, carapace length; CW, carapace width; AL, abdominal scutum length; AW, abdominal scutum width.

\section{Historical background}

Roewer (1912): 45 described the new genus Cynortula, with type species Cynorta longipes Pickard-Cambridge 1904, from Costa Rica, including also five new species from disparate places in the Americas. Roewer (1912): 52 also described the new genus Eucynortella, including three already known species, but designating as type, a fourth species, Eucynortella spectabilis, from French Guiana. He admittedly chose his species as type because he has not seen the other three, all described in Cynorta by older authors from California, Costa Rica, and Guatemala. Support for the new genera was given by combination of area armature. Both genera are relevant here because some of the species treated in this work as Taito were placed in them.

Mello-Leitão (1923) described Eucynortella juruensis from 'Upper Juruá River'. This river rises among the Ucayali highlands in Peru and flows along Acre and Amazonas states in Brazil. This species is the first described of what we are now calling Taito, and the insufficient illustration by Mello-Leitão (of the scutum only,

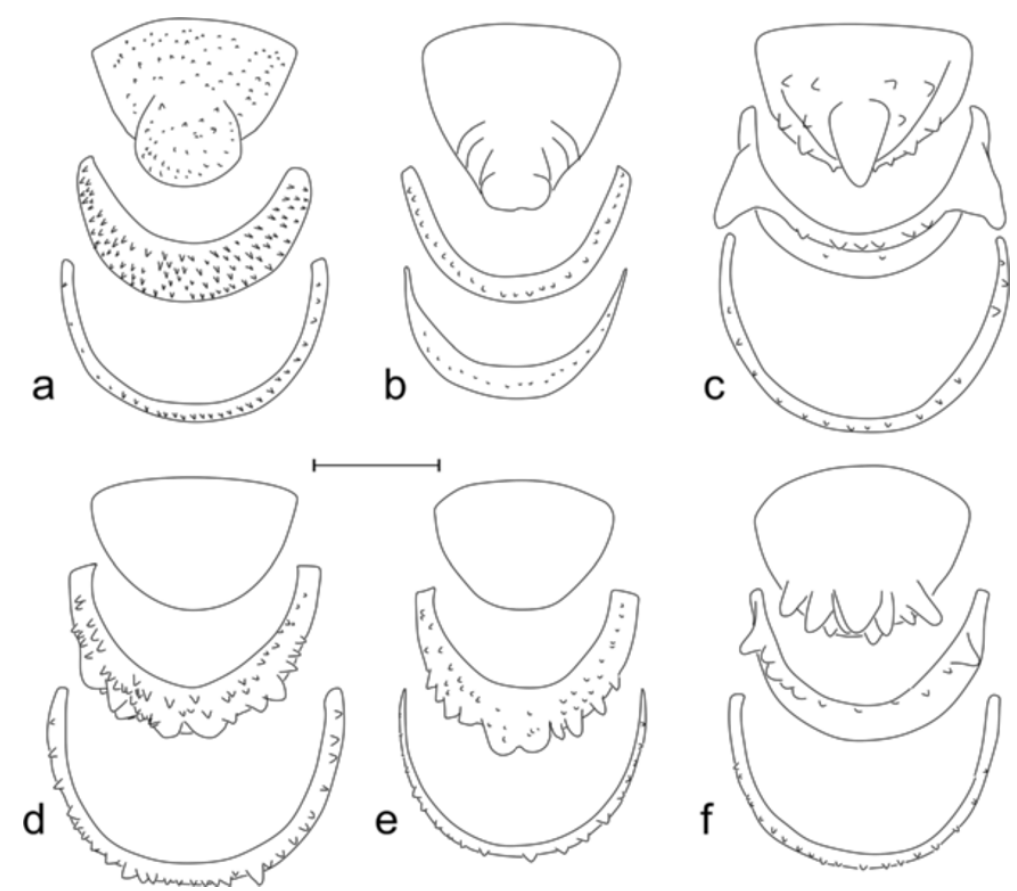

Figure 1 Taito spp., males. Exploded schematic view of the (respectively, from top to bottom) anal operculum; sternites $7 / 8$ and sternite 6. View changes gradually from posterior-dorsal to posterior-ventral, (a) T. medinae, holotype; (b) T. spaceinvaders, holotype; (c) T. galaga, holotype; (d) T. insperatus, holotype; (e) T. oblongatus (ICN-AO 213); (f) T. osmari, holotype. All figures to the same scale. Scale bar = 1 mm. 


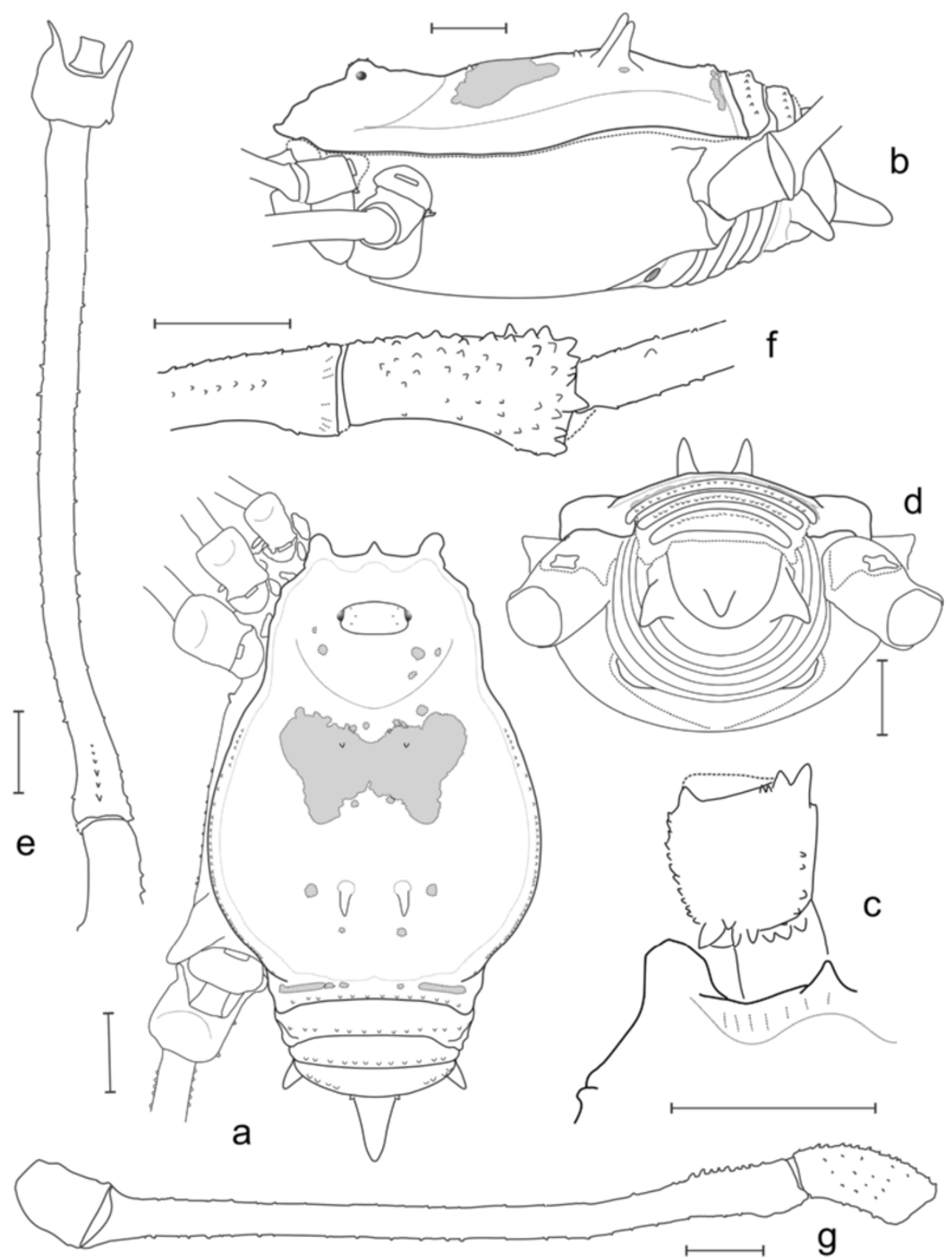

Figure 2 T. galaga sp. nov., male holotype (MNRJ 1949). (a) Habitus, dorsal view; (b) habitus, lateral view; (c) carapace, left half and left chelicera, dorsal view; (d) free tergites and free sternites, posterior view; (e) left femur IV dorsal view; (f) left patella IV dorsal view; (g) left femur-patella IV prolateral view. Scale bars $=1 \mathrm{~mm}$.

without even the stubs of legs) can be clearly seen as a white drawing on mid-area I, which he called 'crownshaped'.

Roewer (1928a) added one strange-looking Cynortula Cynortula oblongata Roewer 1928 - from Ecuador. This species was illustrated in an uncommon level of detail, showing not only a white drawing on mid-area I, which he called 'star-shaped', and an elongated posterior margin of scutum with an interrupted transverse white line, but also sexual dimorphism in scutum length, armature of anal operculum, coxa, and femur IV.
Mello-Leitão (1932): 442 described Cynortula serriperna from 'Brazil, Rio Janinana', providing a poor photograph of the habitus of the male holotype in dorso-lateral view. He mentioned an interrupted line in area $\mathrm{V}$ as well as a pair of round flecks in area III and a large 'stylized H' in the middle of area I. Piza (1938) described the new species Eucynortella pauper from Parauari River in Amazonas State, Brazil. He provided an almost useless photograph of the female holotype.

Goodnight and Goodnight (1943): 4 described the new species Cynortula unapunctata from Peruvian Amazonia. 
They noticed the similarity between this species and Roewer's Cynortula oblongata and provided poor drawings of the elongated body and the femur IV of the male with a prolateral comb of blunt spines.

Soares (1944) compared the female holotype of E. juruensis with the male holotype of $C$. serriperna and believed them to be conspecific, formally proposing a synonymy.

Roewer (1947) described the then new monotypic genus Cynortopyga Roewer 1947 containing the new species Cynortopyga h-album. His illustration of the male habitus shows a median $\mathrm{H}$-shaped fleck on area I, a blunt protuberance on anal operculum, acuminate spine on coxa IV, pro- and retrolateral combs of spines on femur, elongated area $\mathrm{V}$ with interrupted transverse white line.

Goodnight and Goodnight (1953a): 38 synonymized many cosmetid genera into Cynorta, including Eucynortella.

Soares (1970) recorded E. juruensis from Pará state, Paru de Leste River, but this record needs confirmation, as there are some cosmetid species with a similar pattern of white markings on scutum. She also described two species of Cynorta from upper Amazonas, Cynorta insperata (from Conceição Raimundo, Juruá River) and Cynorta litterata (from Benjamin Constant) using the extremely wide concept of the genus as given by the Goodnights.

Kury (2003) revalidated the genus Eucynortella and interpolated 'Amazonas state' in the type locality Eucynortella juruensis. He also (Kury 2003) repeated the type locality of Cynortula serriperna: Rio Janinana without any further comment. As interpreted here, the name Janinana is an obvious misspelling of Jaminuá, a river in the Brazilian state of Acre (latitude $-9.15^{\circ}$, longitude $-71.8^{\circ}$ ), municipality Jordão.

\section{Results}

Morphology - new terms used here

Equuleus (Figures 3, 4, 5, 6, 7, and 8). This is a new name for a white/yellowish-white spot of the dorsal scutum roughly in the shape of an easel (Latin equuleus = easel), present in many species of Cosmetidae, belonging to genus Taito and other presumably related genera such as Vononoides Roewer 1912 and Eucynortella. The basic shape (Figure 3a) is formed by an arch ('body') superimposed on the groove which marks the posterior border of area I + a pair of posterior 'legs' (projections extending to area II) and a pair of anterior 'arms' (projections extending to carapace). These arms and legs have diverse degrees of development and may appear isolated from each other and from the main body of the blot, detached from the main body of the easel, with left and right sides fused or narrowed forming horns (Figure 3a). Even with all this reported variation, the basic structure of the easel is easily recognizable as is interpreted here as a primary homology and a possible synapomorphy for Taito plus some cosmetid genera (many examples in Figure 4). The shapes of the equuleus in most species are reminiscent of the shapes of the alien attackers in Namco and Taito videogames (Figure 3b,c) or the inkblots of the psychological Rorschach test.

Free tergite zero. The posterior part of dorsal scutum, recognizable as the part with parallel straight sides, posterior to the main slope change caused by the widened convex laterals is called 'coda' (Kury 2012). In species with dorsal scutum alpha-conformed (Kury et al. 2007), recognition of a coda is trivial, but for those beta-conformed, by definition, the coda is not well-developed. However, in some beta-conformed cosmetids, a sharply defined coda may be recognized because the outline of scutum is not continuous in that region, giving the impression of an extra free tergite before the ordinary ones. This illusion is reinforced because there is a white transverse stripe across the coda which resembles the articular membrane separating the free tergites.

Dorsal scutum outlines (Figure 9). Kury et al. (2007) recognized four main shapes of the cosmetid dorsal scutum in the dorsal view, which they called, alpha, beta, gamma, and delta. Studying Cynortopyga, Vononoides, and related genera, we may say that Taito has the scutum shape roughly fitting the beta class, with varied degrees of sexual dimorphic elongation, that is, while females are typical beta, males are not. Three classes of scutum elongation are used here:

Sturdy. Ratio length/width of scutum between 1.15 to 1.19 .
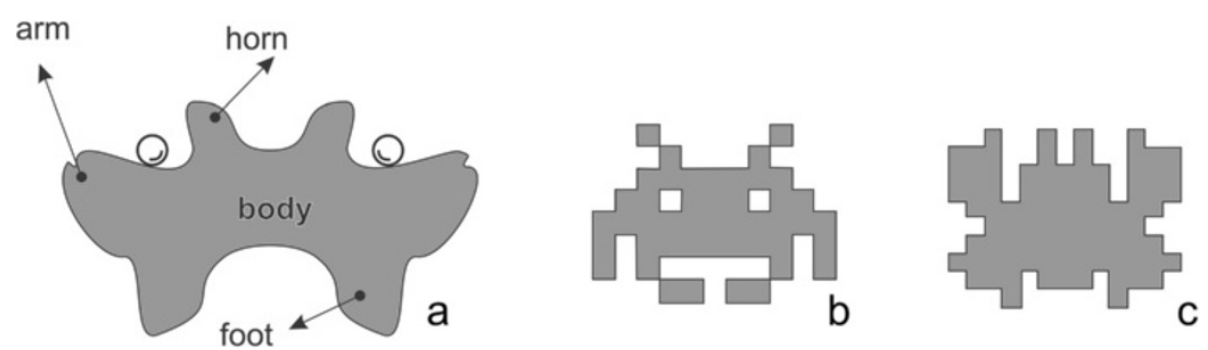

Figure 3 Equuleus and its 1980s game counterparts, which inspired some of the species names proposed here. (a) Names of component parts of the equuleus, as proposed here; (b) Sprite of Taito Spaceinvaders game; (c) Sprite of the Namco Galaga game. 
a

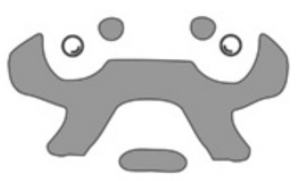

e

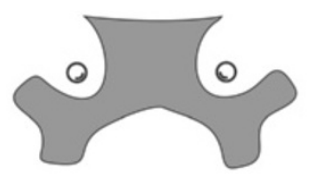

i

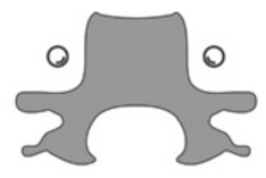

b
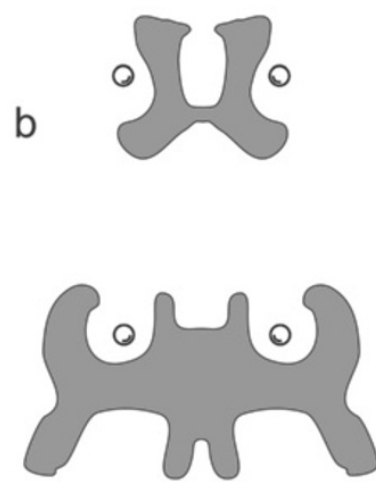

C

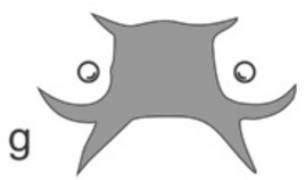

h
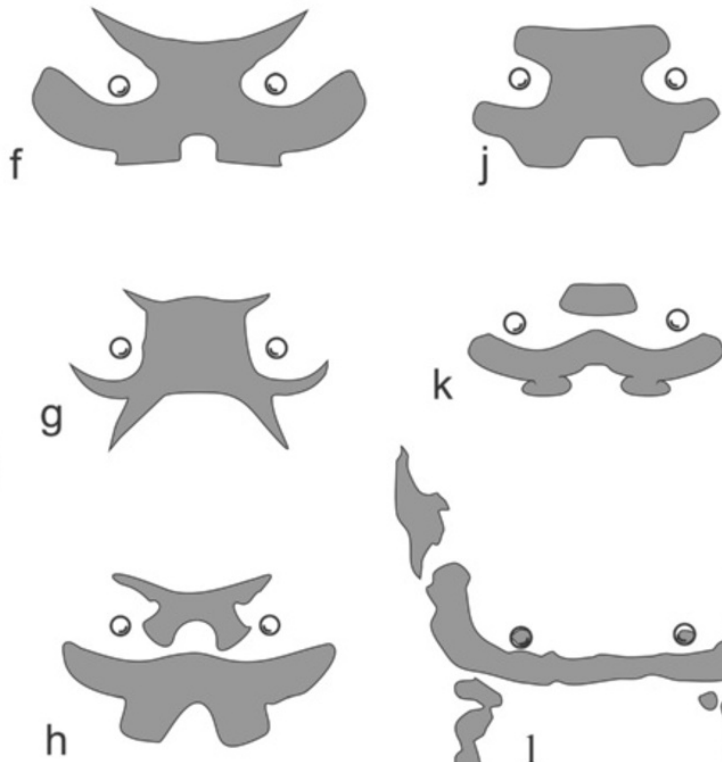
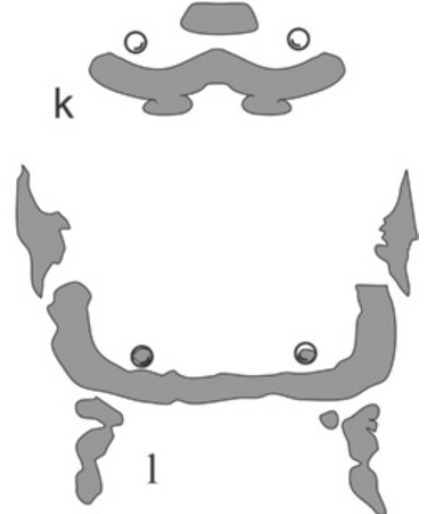

Figure 4 Shapes of the equuleus in some species of Cosmetidae. (a) Namballeus signifer Roewer, 1952; (b) Cynortula alejandra Roewer, 1957; (c) Chusgonobius weyrauchi Roewer, 1952; (d) Chirinosbius poecilis Roewer, 1952; (e) Vononoides unimaculatus Roewer 1912; (f) Pygocynorta festae Roewer, 1925; (g) Eucynortella cryptogramma Mello-Leitão, 1942; (h) Eucynortella obscurior Mello-Leitão, 1943; (i) Cynortula stellata Roewer 1912; (j) Cynortoplus albimaculatus Roewer, 1925; (k) Vononella maculata Roewer, 1925; (I) Cynortopyga pauper (Piza 1938).

Intermediate. Ratio length/width of scutum between 1.28 to 1.41 .

Elongated. Ratio length/width of scutum between 1.49 to 1.67 .

\section{Systematic accounts}

\section{Taito new genus}

Etymology. The Taito Corporation (Japanese kabushikigaisha taitō) is a Japanese developer of video game software and arcade hardware and creator of vintage fixed shooter, puzzle, and monster video games. This refers to the shapes of the equuleus in most species, which are reminiscent of the shapes of the alien attackers in Taito video games. Gender masculine as used by us by choice, in virtue of the absence of genders in Japanese nouns.

Type species. Taito spaceinvaders sp. nov.

Other included species. Taito galaga sp. nov., Taito honda sp. nov., Taito insperatus (Soares 1970), Taito juruensis (Mello-Leitão 1923), Taito kakera new species, Taito kawaiikei sp. nov., Taito litteratus (Soares 1970), Taito medinae sp. nov., Taito oblongatus (Roewer 1928a), Taito osmari sp. nov., Taito rorschachi sp. nov.,
Taito serriperna (Mello-Leitão 1932), Taito unapunctatus (Goodnight and Goodnight 1943).

Combined distribution. The 14 species of Taito occur in the Upper Amazon Basin (Brazil, Colombia, Peru), stretching to the Eastern slope of the Andes in Colombia and Ecuador (see Discussion and conclusions for more details).

Diagnosis. Dorsal scutum beta-shaped, superficial segmentation lost, outline elongated in males, virtually unarmed, only area III with meaningful armature as a pair of acuminate tubercles, rarely as a pair of spines. Coda always forming free tergite zero. White or yellow color markings of scutum as an equuleus - a single main blot easel-shaped, $\mathrm{H}$-shaped or butterfly-shaped over dark brown background. Chelicerae monomorphic, weak, with marginal rows of acuminate tubercles of varied size. Pedipalpal tibia with mesal ditch. Groin warts present. Legs elongated, weakly armed, only femur IV of some species incrassate and/or curved with variedly located spines on males. Tibia and/or metatarsus IV with retrolateral row of few small spines in some species. Males of some species have apophyses on anal operculum and/ or sternite 7/8. Tarsal counts: 6(3)/11 to $14(3) / 7-8 / 8-10$. 

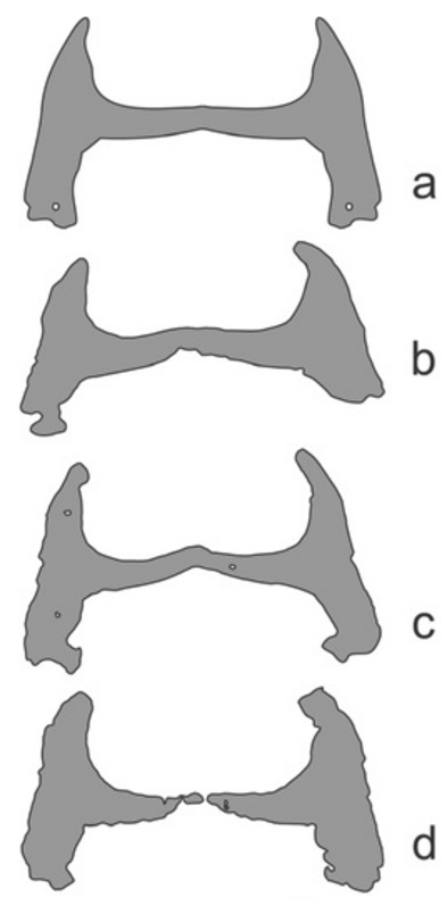

C

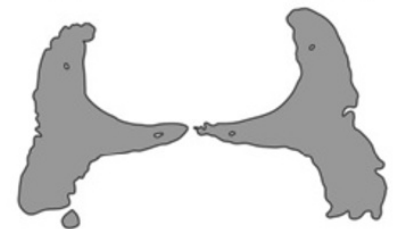

e
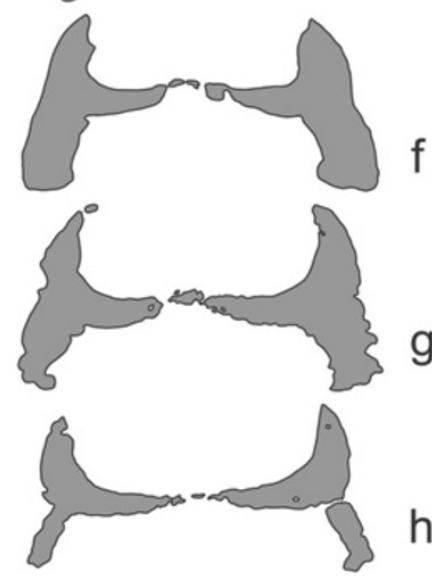

$\mathrm{h}$
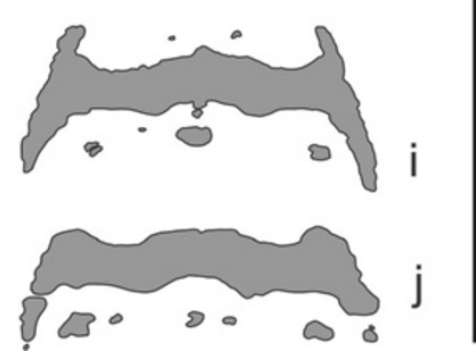
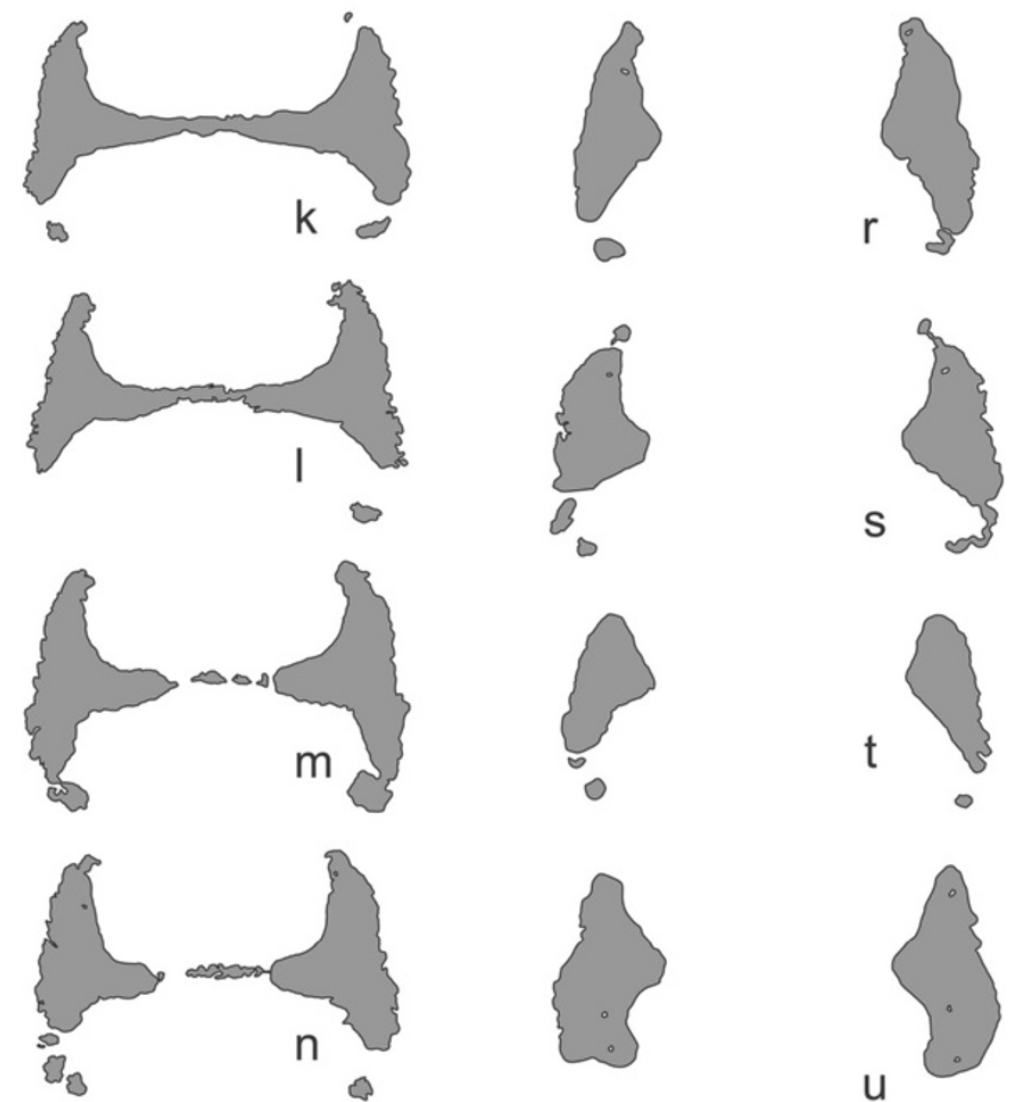

u
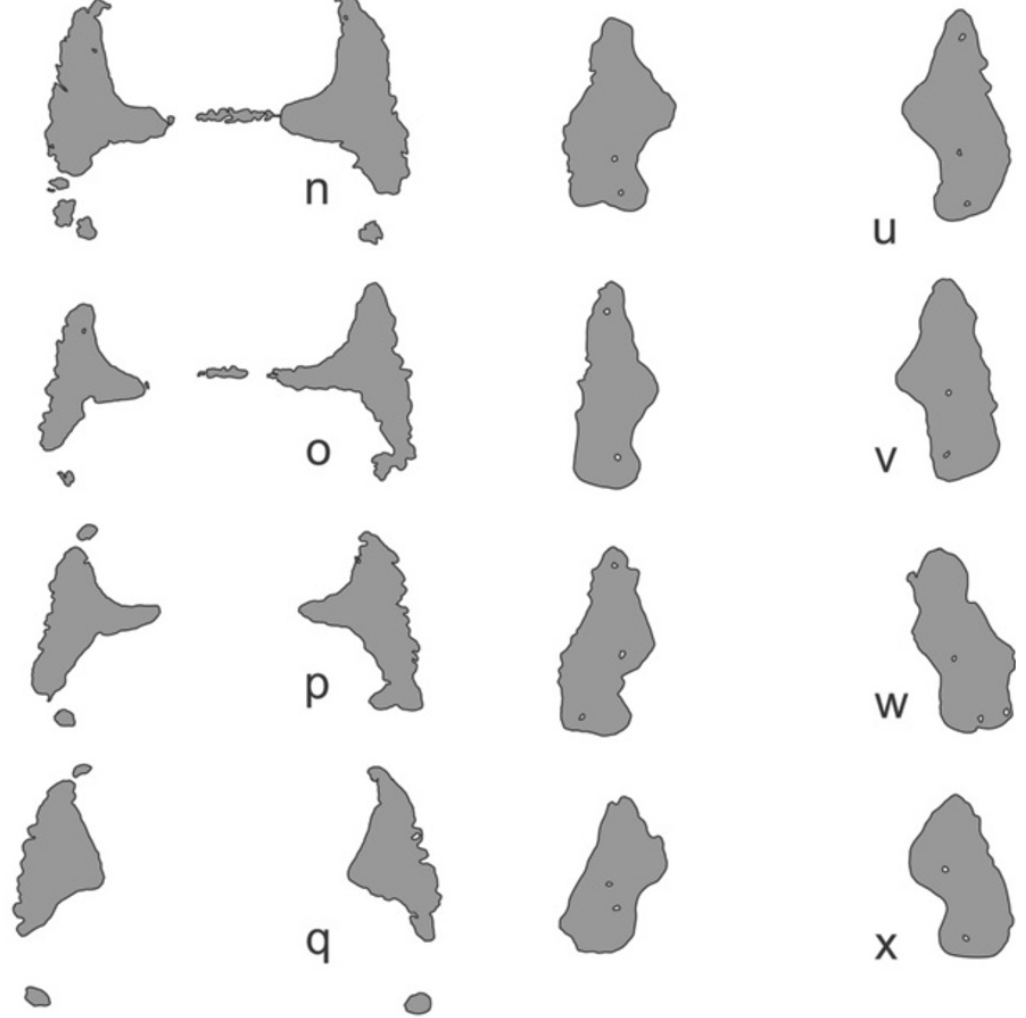

Figure 5 Shapes of the equuleus in the species of Taito, type-1, H-shaped, showing dissolution of the original blot. (a,b,c,d,e,f,g,h) T. honda (males and females MNRJ 7087, MNRJ 7085, and MNRJ 7084); (i,j) T. litteratus (females MNRJ 5061 and MNRJ-HS 0015); (k,l,m,n,o,p,q,r,s, $\mathbf{t}, \mathbf{u}, \mathbf{v}, \mathbf{w}, \mathbf{x})$ T. kakera (males and females MNRJ 2345, MNRJ 2369, MNRJ 2372, MNRJ 7548, MNRJ 7623). 

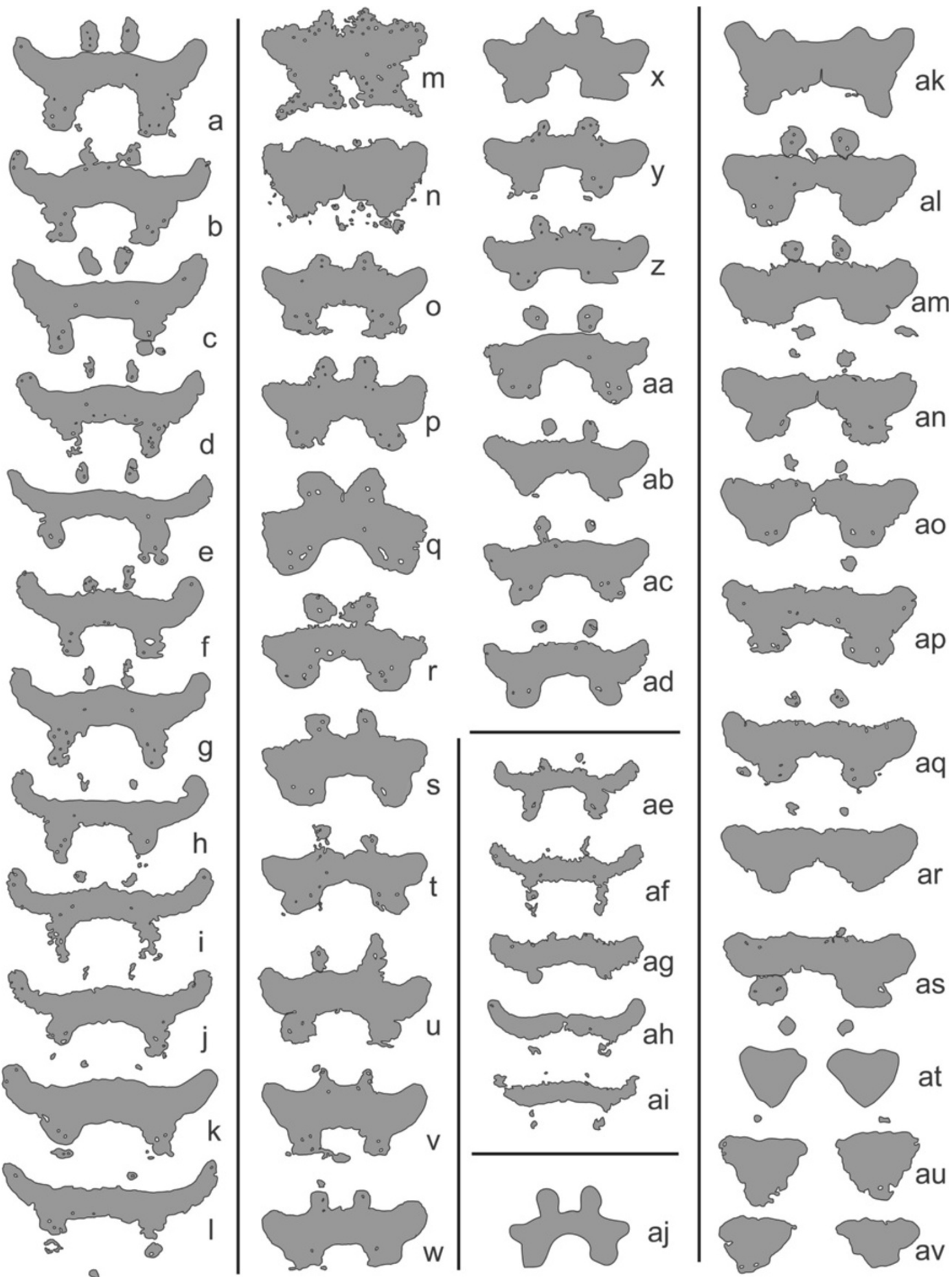

Figure 6 Shapes of the equuleus in the species of Taito, type-2, typical easel. These shapes show variations of primitive pattern by disintegration of body, fragmentation and isolation of crown. (a, $\mathbf{b}, \mathbf{c}, \mathbf{d}, \mathbf{e}, \mathbf{f}, \mathbf{g}, \mathbf{g}, \mathbf{h}, \mathbf{i}, \mathbf{j}, \mathbf{k}, \mathbf{l})$ T. oblongatus (males and females ICN AO 213). (m, $\mathbf{n}, \mathbf{o}, \mathbf{p}, \mathbf{q}, \mathbf{r}, \mathbf{s}, \mathbf{t}, \mathbf{u}, \mathbf{v}, \mathbf{w}, \mathbf{x}, \mathbf{y}, \mathbf{z}, \mathbf{a a}, \mathbf{a b}$, ac,ad) T. juruensis (males and females MNRJ-HS 0010, MNRJ 2288, MNRJ 2307, MNRJ 2313, MNRJ 2370). (ae,af,ag,ah,ai) T. insperatus (males and females INPA 007, MNRJ 8269, MNRJ-HS 0719, ICN AO 303). (aj) T. serriperna (male holotype, MNRJ 1372). (ak,al,am,an,ao,ap,aq,ar,as,at,au,av) T. kawaiikei (males and females MNRJ 2347, MNRJ 02353, MNRJ 7622). 


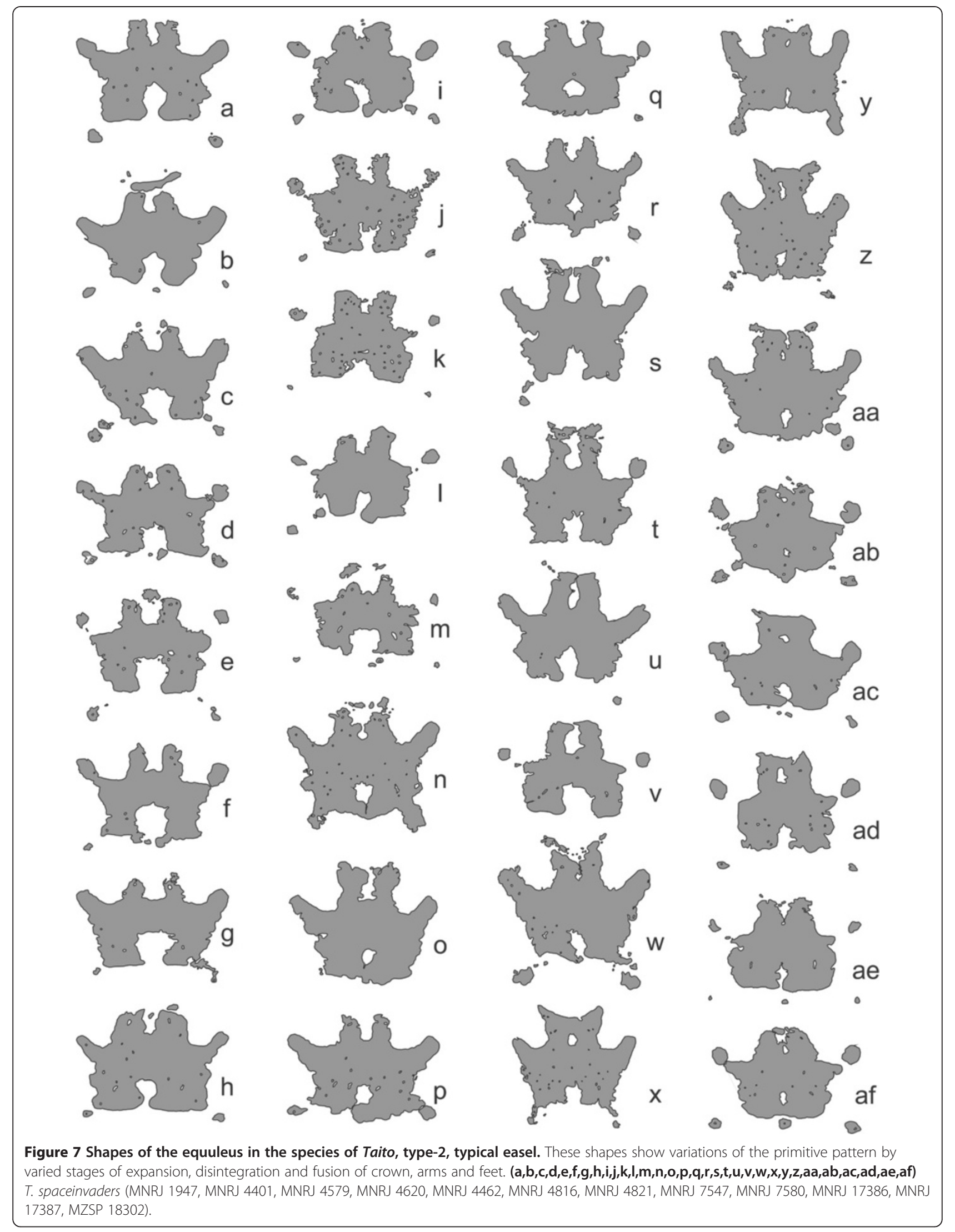




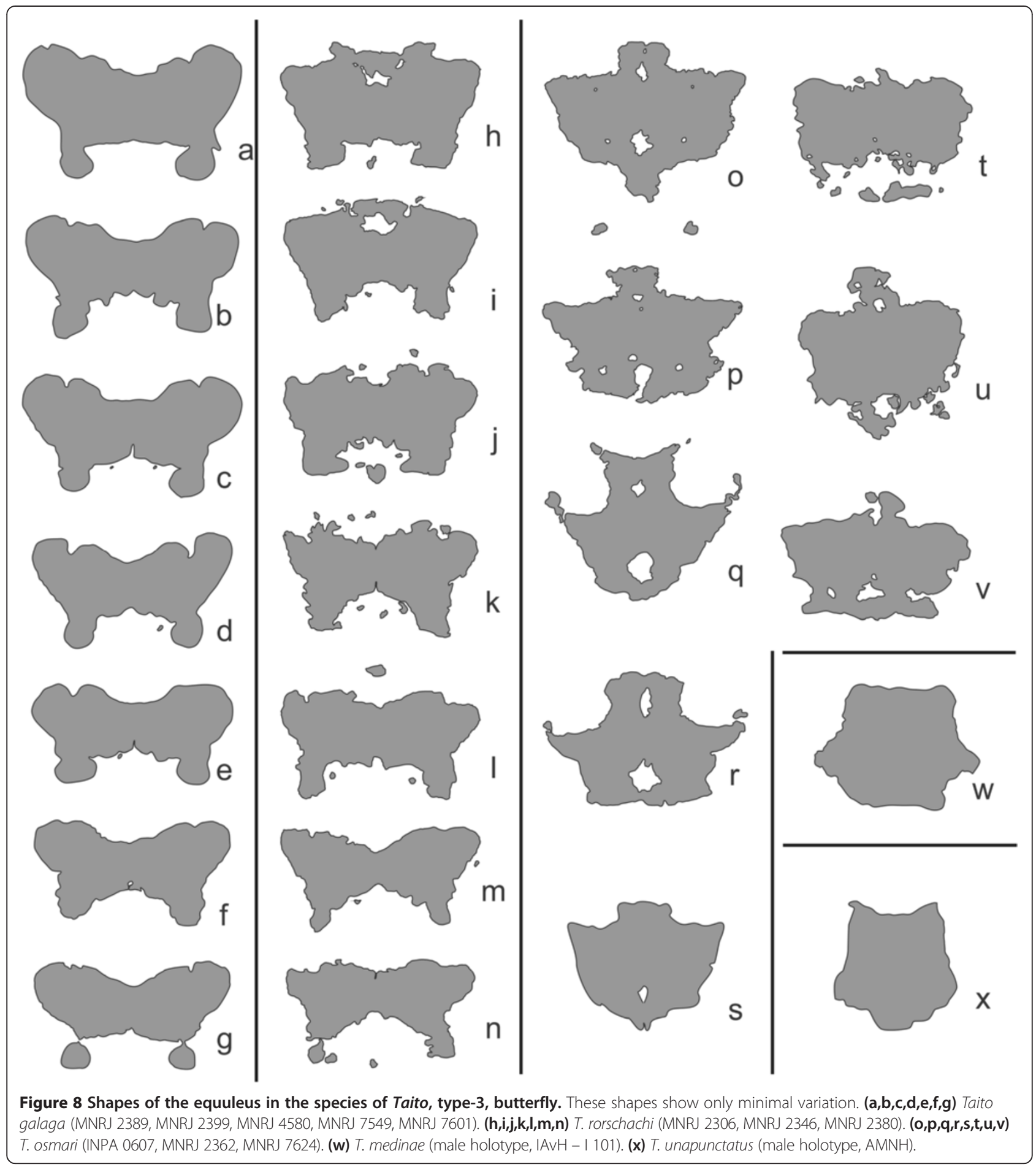

Description. Dorsum. Body strongly depressed (flattened dorso-ventrally) in lateral view. Outline of dorsal scutum beta, sometimes sexually dimorphic, elongated in male (ratio length/width of dorsal scutum ranging from 1.15 to 1.67), extremely elongated in some species (e.g., T. medinae, T. oblongatus). Anterior margin of carapace with very shallow cheliceral sockets, frontally with a small central triangular process and two very large lateral trapezoid processes. Lateral outline of scutum convex, widest at virtual area III. Lateral margin of scutum may bear a pair of large spiniform apophyses (only in T. kakera). Scutum with well-defined elongated coda (post-constriction margin of scutum) bearing a white transverse stripe (here called 'free tergite zero'). Anterior margin of carapace 


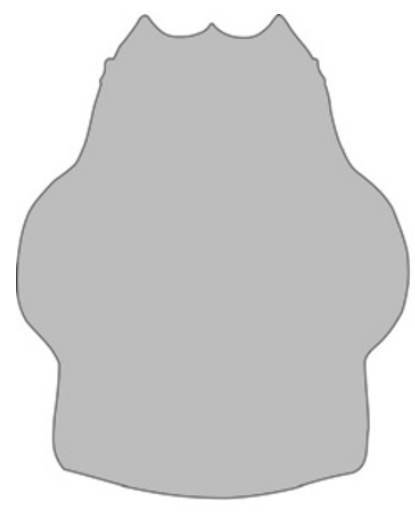

a

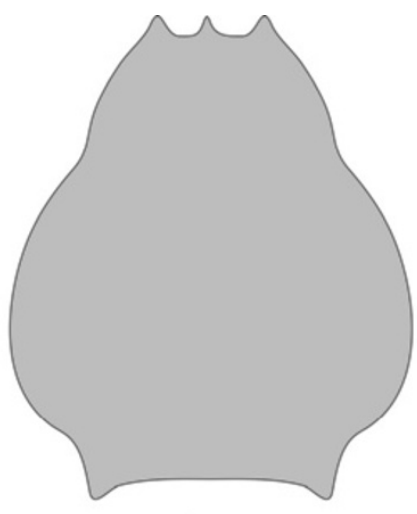

b

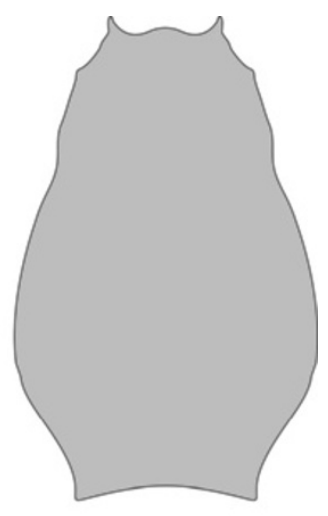

C

Figure 9 Examples of schematic outlines of dorsal scutum in Taito and related genera. These outlines show the posterior shift of convexity from (a) alpha to (b) beta, culminating in the extremely slender/elongate shape (c) beta-L.

with very shallow cheliceral sockets, three frontal processes (a small central triangular and two much larger lateral blunt trapezoids). Eye mound low, with lateral crowns of minute granules around the eyes. Scutal grooves almost completely effaced. Virtual scutal area I either unarmed or with a pair of minute tubercles, area III either with a pair of small granules or acuminate spines (T. galaga, T. honda), all other areas unarmed. Dorsal anal operculum either unarmed or with median spine/blunt protuberance or crown of tubercles. Venter. Sternal region and pedipalpal coxa deeply concave, much deeper than adjacent areas. Posterior margin of cheliceral bulla with rows of conical processes, also row on ectal surface of basichelicerite. Coxae I to III with largest axis oriented transversely to body axis. Coxa I subtriangular with anterior row of acuminate tubercles. Coxa II subtriangular unarmed, maxillary lobe as small rounded projection, connected with coxa III by tubercular bridges. Coxa III similar to coxa II, connected with coxae II and IV by tubercular bridges. Coxa IV pentagonal, almost parallel to main body axis, a little longer in situ than stigmatic area. Stigmata large, free, not sunken. Sternites 3 to 6 with transverse row of small granules. Sternites 7/8 either unarmed or varied armed with protuberances. Pedipalpus. Remarkably uniform among the species of the genus (Four species are illustrated here (Figures 10, 11, 12, 13) to widely cover the morphological diversity). Tegument scaly with sparse bristles, except femur mesal and tibia ventral which are smooth and glossy. Trochanter club-shaped, with strong ventral setiferous tubercle (Figure 10d). Femur elongated spoon-shaped, concave mesally, with ventral row of large granulous setiferous tubercles varying from 9 (T. galaga, T. honda) to 11 (T. juruensis and T. spaceinvaders). Patella cylindrical, thicker distally, with mesal keel on the distal 3/4 and meso-apical setiferous tubercle; tibia elongated spoon-shaped, with very deep ditch on mesal edge. Without notable projections or spines. Tarsus roughly triangular, with strong ventral-ectal and ventro- mesal rows of spines. Mesal edge strongly beveled, glossy, and smooth. Legs. Most podomeres smooth and unarmed. Coxae I and II surrounded by a set of large flattened anterior and posterior apophyses. Coxa IV well-developed, long, but barely surpassing dorsal scutum in dorsal view. Groin warts of coxa IV present as wrinkled tubercle (Figure 14e). Dorso-apical well-developed spiniform apophysis in coxa IV of male, sometimes double (e.g., T. juruensis, T. serriperna). Trochanters I to III each armed with a slender retro-basal curved spiniform apophysis (Figure 14c,d). Femora I to III substraight. Femur IV of some species incrassate and/or curved with variedly located spines on males. Occasionally, tibia and/or metatarsus IV with retrolateral row of few small spines. Color. Body and appendages in uniform shades of brown, with free tergites, sternites, or legs slightly darker or lighter. Main white or yellowish white blot of dorsal scutum present in mid area I as an equuleus (easel). Crown of equuleus more or less connected to easel body, shaped as two prongs (as opposed to the anvil of Vononoides). Dorsal scutum with one or more pairs of rounded satellite spots. Tibiae II and IV and metatarsi I to IV with several lighter rings. Genitalia (Figures 15, 16, 17, 18, 19, 20). Truncus penis apical with concave area caused by lack of the dorsomid-apical portion of truncus which directly supports the glans sac. Main shaft of penis (truncus) either (1) slender, abruptly growing wider at base of VP forming a pair of lateral projections here called 'calli' (T. medinae, T. oblongatus, T. spaceinvaders) or (2) less abruptly widened, with smaller calli ( $T$. kakera, T. honda) or gradually widening only a little, without projections ( $T$. galaga, $T$. rorschachi). VP either trapezoid, widening distally ( $T$. oblongatus) or subrectangular (T. serriperna). VP with two groups of macrosetae, two pairs distal, spatulate and three pairs more proximal, cylindrical, middle pair much reduced. Glans tegument covered by 'bump-scales'. Dorsal process of glans with apex either (1) smooth conical 


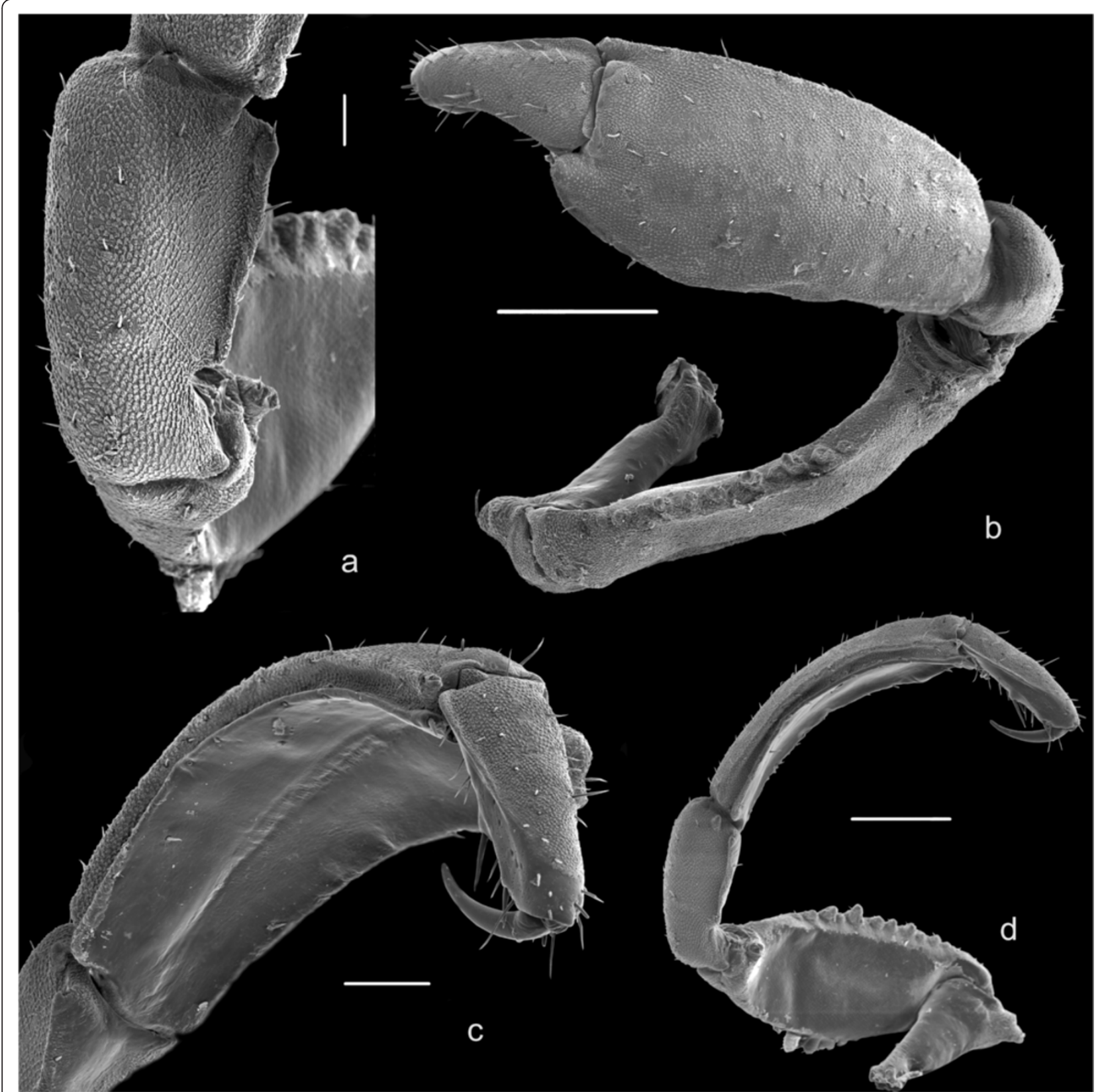

Figure 10 Taito juruensis (Mello-Leitão 1923) male (MNRJ 2370). Left pedipalpus: (a) Patella, dorsal view; (b) tibia-tarsus, dorsal view and femur, ventral view; (c) tibia, ventro-mesal view, tarsus, dorso-mesal view; (d) patella-tarsus, lateral view and femur, lateral view. Scale bars = 500 (b,d), 200 (c), and $100 \mu \mathrm{m}$ (a).

(T. galaga, T. rorschachi, e.g., Figure 18e) or (2) blunt, subsquare, bilobed densely covered by villosities (T. honda, T. juruensis, T. spaceinvaders, e.g., Figure 20e).

\section{The easel in Taito - patterns of variation}

With the study of series, displaying a sizeable variation in the drawing of the equuleus (due to dissociation or fusion of parts), the configuration of this variation may be more easily appreciated. Study of limited material, with isolated specimens might obscure this pattern. It seems that there are four basic patterns of equuleus, namely (1) the H-shaped, (2) the more typical easelshaped, (3) the butterfly, and (4) the compact shape.

(1) The H-shaped equuleus (Figure 5): It may be characterized by a thin body slightly $\mathrm{V}$-angled pointing forwards connecting a pair of elongated bottle-shaped blots. These blots are situated far away from each 




Figure 11 Taito honda sp. nov., male (MNRJ 7087). Left pedipalpus: (a) patella, dorsal view; (b) tibia-tarsus, dorsal view and femur, ventral view; (c) tibia, ventro-mesal view and tarsus, dorso-mesal view; (d) patella-tarsus, lateral view and femur, lateral view. Scale bars = 500 (b,d), 200 (c), and $100 \mu \mathrm{m}(\mathbf{a})$.

other, close to the lateral margin of scutum. It is not obvious to homologize this kind of easel with the other. There are three species of Taito which show this shape - T. honda, T. litteratus and T. kakera. In the series examined, all three species show specimens with complete body. T. litteratus (Figure 5i,j) has three groups of secondary posterior island blots and no example of body dissolving, and the bottle is always poorly developed. In T. honda (Figure 5a,b,c,d,e,f,g,h), there are no posterior island blots, the bottle is well formed and the body almost entire, even in the most fragmented specimens. In T. kakera (Figure 5k,l,m,n,o, $\mathrm{p}, \mathrm{q}, \mathrm{r}, \mathrm{s}, \mathrm{t}, \mathrm{u}, \mathrm{v}, \mathrm{w}, \mathrm{x})$, there are many degrees of body deterioration, but most specimens lack a body and have the bottle blots isolated as polygonal shards, which give the name to the species. Here, the two lateral secondary posterior island blots are sometimes present (e.g., Figure 5q), while the central island is always lacking.

(2) Typical easel (Figures 6, 7, and 8): All three remaining types are easily seen as variation of the same easel shape. This type- 2 easel has a sturdy body, much different from the rod of type-1. More or less clearly recognizable are the horns, the arms, 


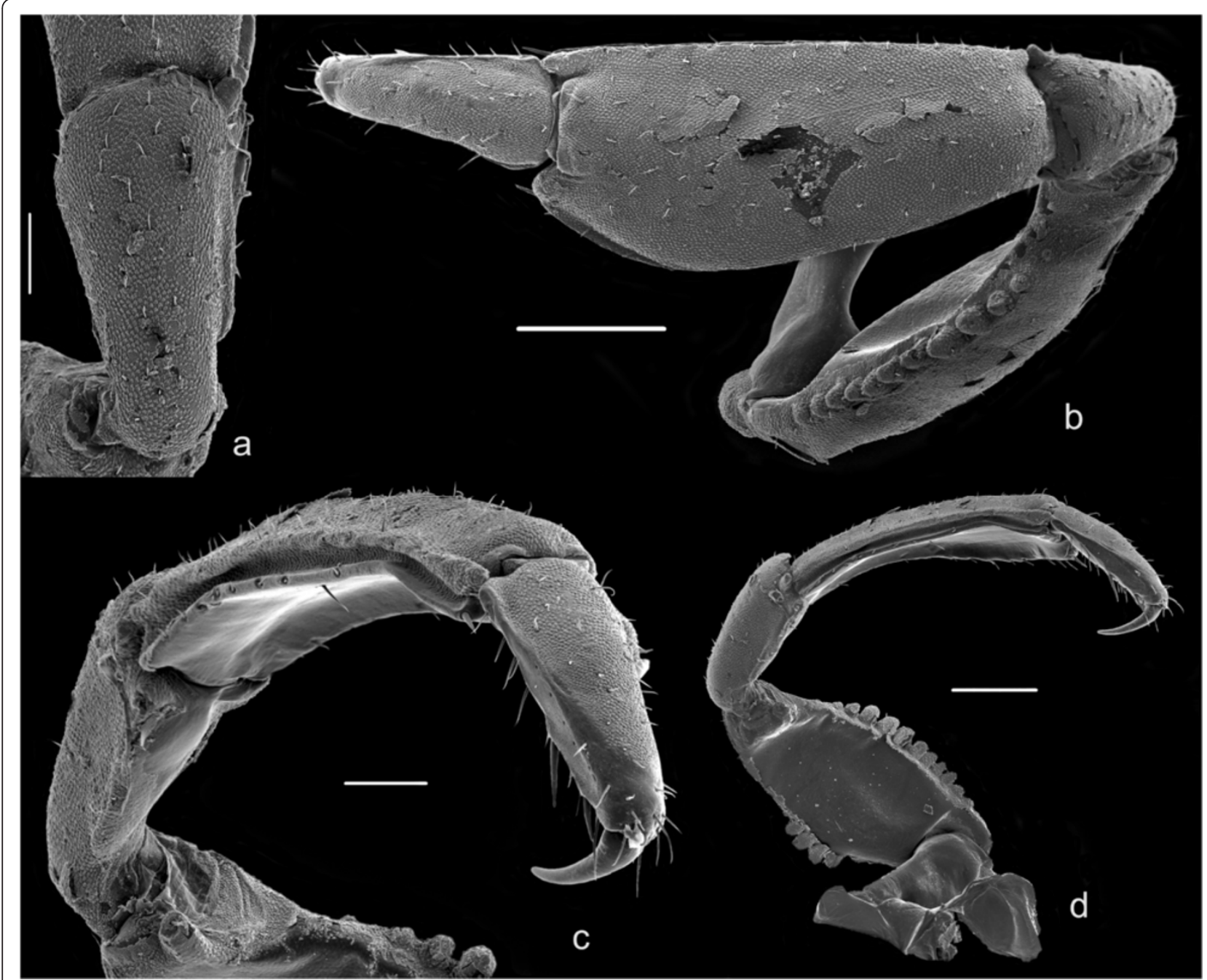

Figure 12 Taito spaceinvaders sp. nov., male (MNRJ 7547). Left pedipalpus: (a) patella, dorsal view; (b) tibia-tarsus, dorsal view and femur, ventral view; (c) tibia, ventro-mesal view and tarsus, dorso-mesal view; (d) patella-tarsus, lateral view and femur, lateral view. Scale bars = 500 (b,d), 200 (c), and $200 \mu \mathrm{m}(\mathbf{a})$.

and feet. We may consider six species as displaying this pattern - T. insperatus, T. juruensis, T. kawaiikei, T. oblongatus, T. serriperna, T. spaceinvaders. T. serriperna (Figure 6aj) is known only by the holotype. Body is integer, crown, arms and feet well-defined and all well attached to the body forming an archetypical easel.

T. juruensis (Figure $6 \mathrm{~m}, \mathrm{n}, \mathrm{o}, \mathrm{p}, \mathrm{q}, \mathrm{r}, \mathrm{s}, \mathrm{t}, \mathrm{u}, \mathrm{v}, \mathrm{w}, \mathrm{x}, \mathrm{y}, \mathrm{z}, \mathrm{aa}, \mathrm{ab}$, ac,ad) shows some variation, presenting the archetypical form similar to that of $T$. serriperna, with degrees of detachment of the horns and fusion (e.g., Figure 6q) of arm and foot of each side. Also, there are accretion arborescent shapes, expanding in lattices, with pointed feet and crenelated crowns (e.g., Figure $6 \mathrm{~m}$ ).

T. oblongatus (Figure 6a,b,c,d,e,f,g,h,i,j,k,l) has the most slender body resulting from no fusion of arms and feet into it. Arms and feet are themselves slender, not fused to each other. Deteriorating pattern can be seen in horns isolating (e.g., Figure 6c), vanishing (e.g., Figure 6k), and feet dissolving (e.g., Figure 6l). In extreme cases, the set body-arms results in an almost botuliform blot similar to those seen in T. insperatus.

T. insperatus (Figure 6ae,af,ag,ah,ai) is remarkably similar to T. oblongatus. In the available sample, however, the horns and feet are much more strongly reduced. In one specimen, even the arms are dissolving (Figure 6ai).

T. kawaiikei (Figure 6ak,al,am,an,ao,ap,aq,ar,as,at,au,av) is actually an intermediate of this type- 2 and the butterfly because the arms and feet of each side are quite fused (e.g., Figure 6ak). The horns are fairly well defined though, and mostly isolated from the 


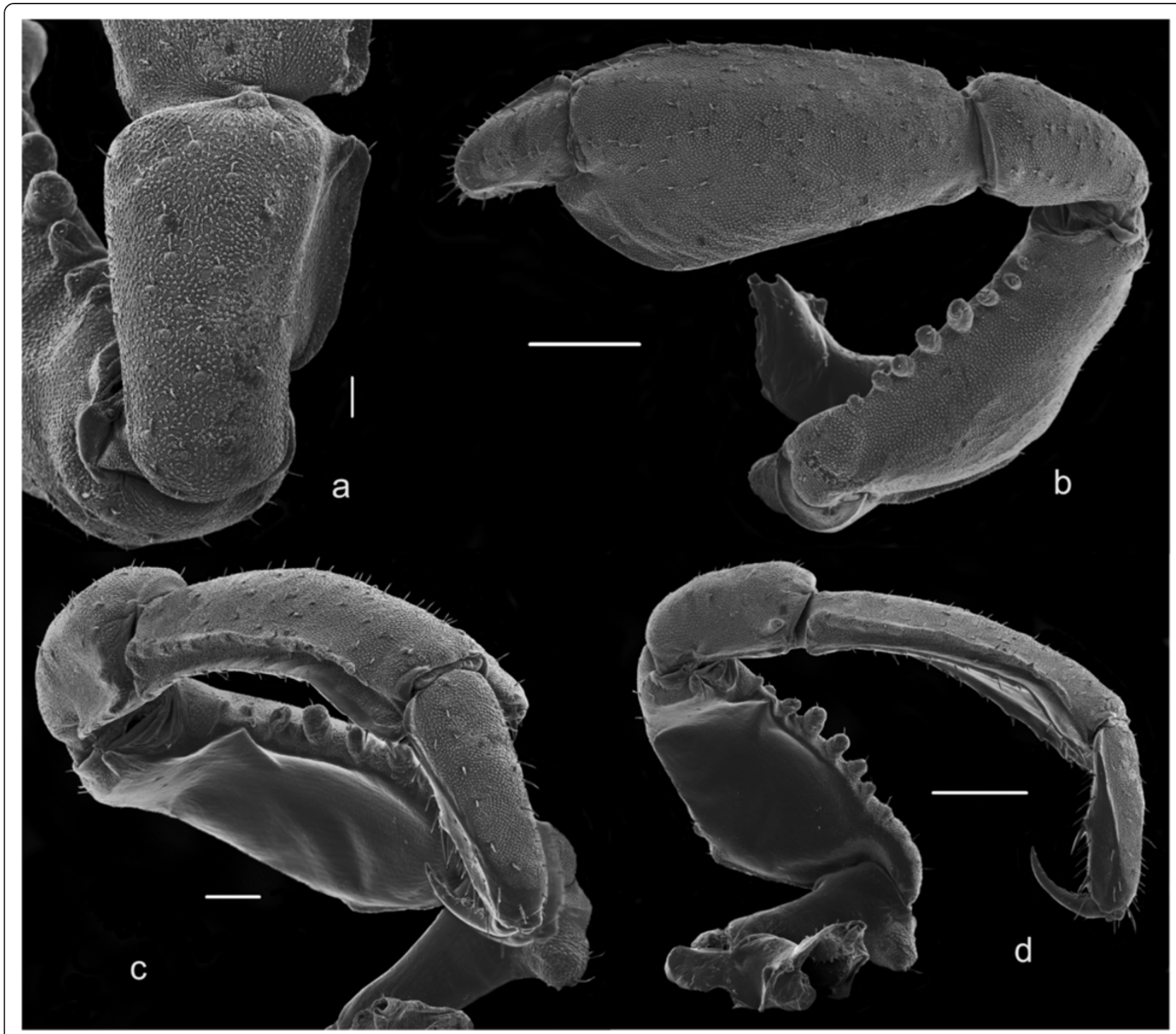

Figure 13 Taito galaga sp. nov., male (MNRJ 7601). Left pedipalpus: (a) patella, dorsal view; (b) tibia-tarsus, dorsal view, femur, ventral view; (c) tibia, ventro-mesal view, tarsus, dorso-mesal view; (d) patella-tarsus, lateral view and femur, lateral view. Scale bars = 500 (b,d), 200 (c), and $100 \mu \mathrm{m}(\mathrm{a})$.

body. The posterior cleft of the body increases while the horns decrease, resulting in a total loss of the horns and mid-cleavage of the body, isolating left and right halves of the equuleus: the two 'hearts' which give the species name (Figure 6at,au, av). This may be superficially similar to the two isolated blots of T. kakera, but a simple glance at the dissolving series shows that the elongated shard form of T. kakera and the short form of T. kawaiikei originate from different patterns.

T. spaceinvaders (Figure 7a,b,c,d,e,f,g,h,i,j,k,l,m,n,o,p, q,r,s,t,u,v,w,x,y,z,aa,ab,ac,ad,ae,af). There are specimens with well-defined and isolated horns, arms, and feet (these are expanded basally). In some, the feet are even more expanded and fused to each other (Figure 7n,o,p,q,r). Arms may decrease, detaching from body (as in Figure 7x,y,z,aa,ab,ac,ad). Extreme deterioration of arms and fusion of feet renders this easel almost into a type 4.

(3) The butterfly-shape (Figure 8a,b,c,d,e,f,g,h,i,j,k,l,m,n): exclusive of two closely related species - T. galaga and $T$. rorschachi. In this pattern, the horns of each side are fused with the corresponding arm, filling the space between them, and resulting in a much thicker body. Also arms and feet of each side are partially fused, giving a more rounded aspect. T. rorschachi (Figure $8 \mathrm{~h}, \mathrm{i}, \mathrm{j}, \mathrm{k}, \mathrm{l}, \mathrm{m}, \mathrm{n}$ ) may be distinguished from T. galaga by the feet squared and the horns further 


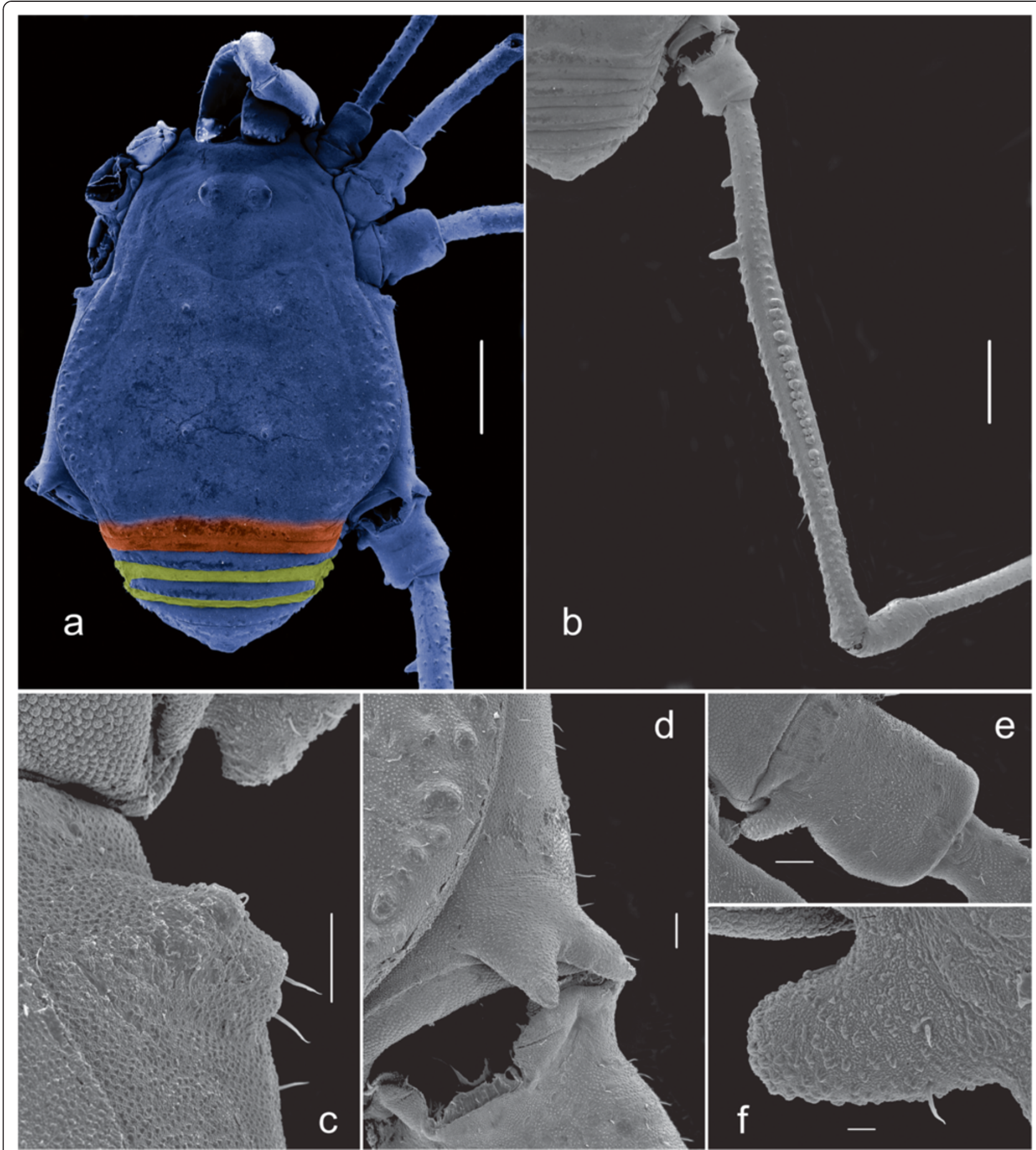

Figure 14 T. juruensis (Mello-Leitão 1923) male (MNRJ 2288). (a) Habitus, dorsal view; (b) right femur IV dorsal view; (c) right coxa IV, detail of groin wart; (d) double apophysis of right coxa IV; (e) right trochanter I, dorsal view; (f) same, detail of apophysis. Scale bars = $1 \mathrm{~mm}(\mathbf{a}, \mathbf{b})$, $100 \mu \mathrm{m}(\mathbf{c}, \mathbf{d}, \mathbf{e}), 20 \mu \mathrm{m}$ (f).

fused to each other, filling the central concavity. There are also small posterior fragments.

(4) Compact (Figure 8o,p,q,r,s,t,u,v,w,x): certainly derived from type-2. In this type-4 easel, horns and feet are fused medially, while arms and feet projections are greatly diminished, resulting in a compact square blot. There are three species with this pattern - T. unapunctatus, T. medinae, and T. osmari. The first two species are each known only by the holotype, so nothing can be said about 


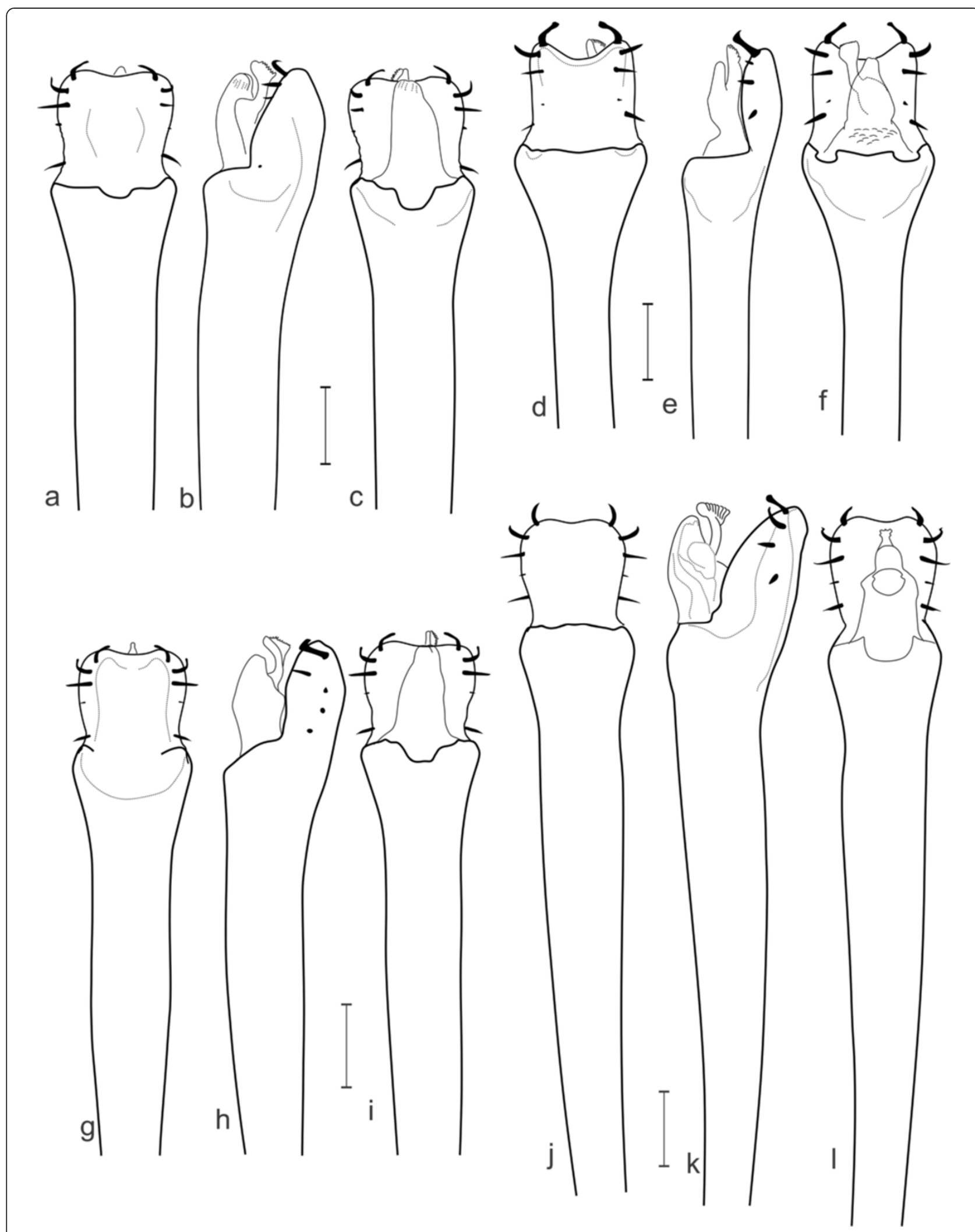

Figure 15 Taito spp., genitalia, distal part. Respectively ventral, lateral, and dorsal views; (a,b,c) T. osmari (MNRJ 7624); (d,e,f) T. kawaiikei (MNRJ 7622); (g,h,i) T. honda (MNRJ 7087); (j,k,l) T. kakera (MNRJ 7623). Scale bars $=0.1 \mathrm{~mm}$. 


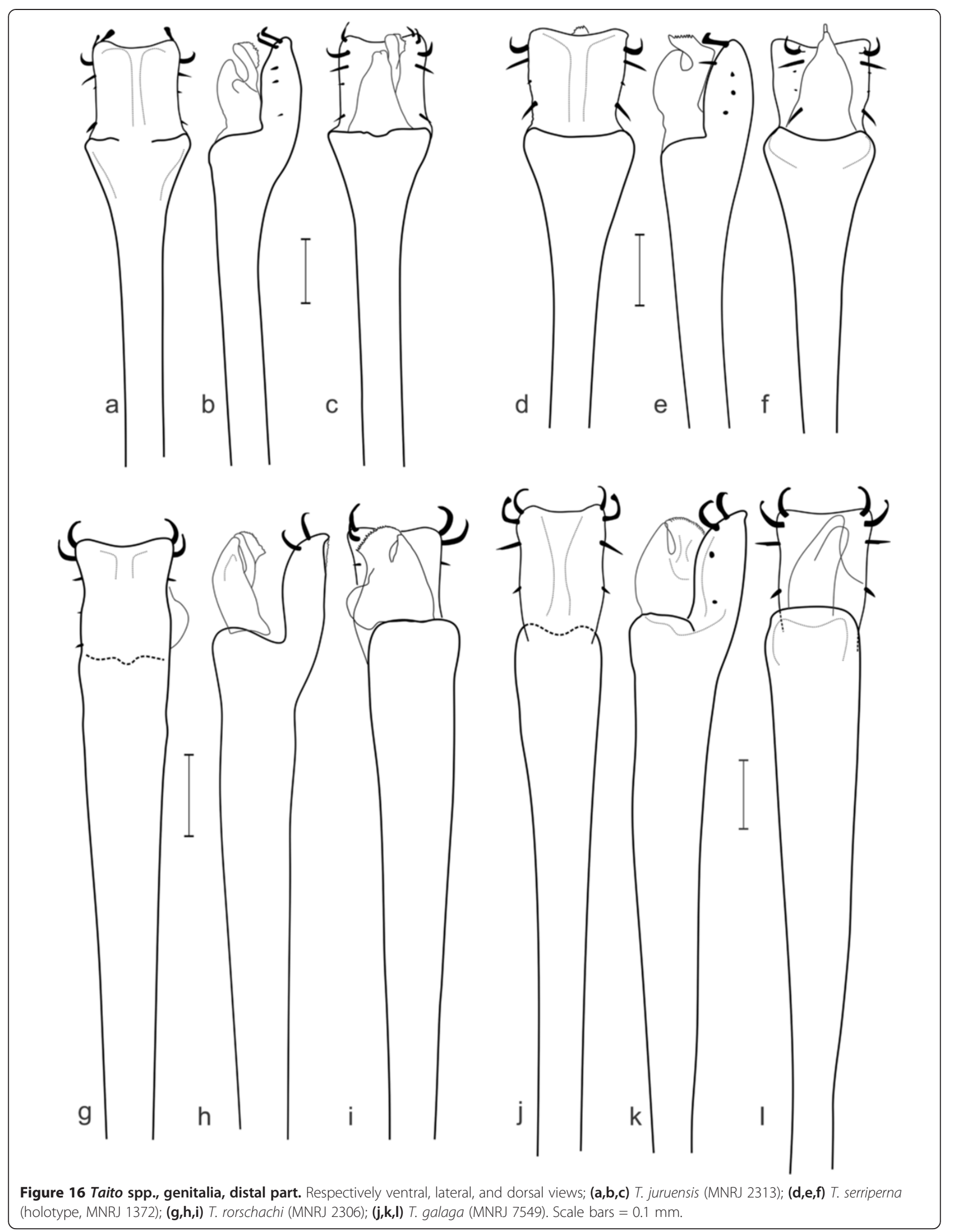




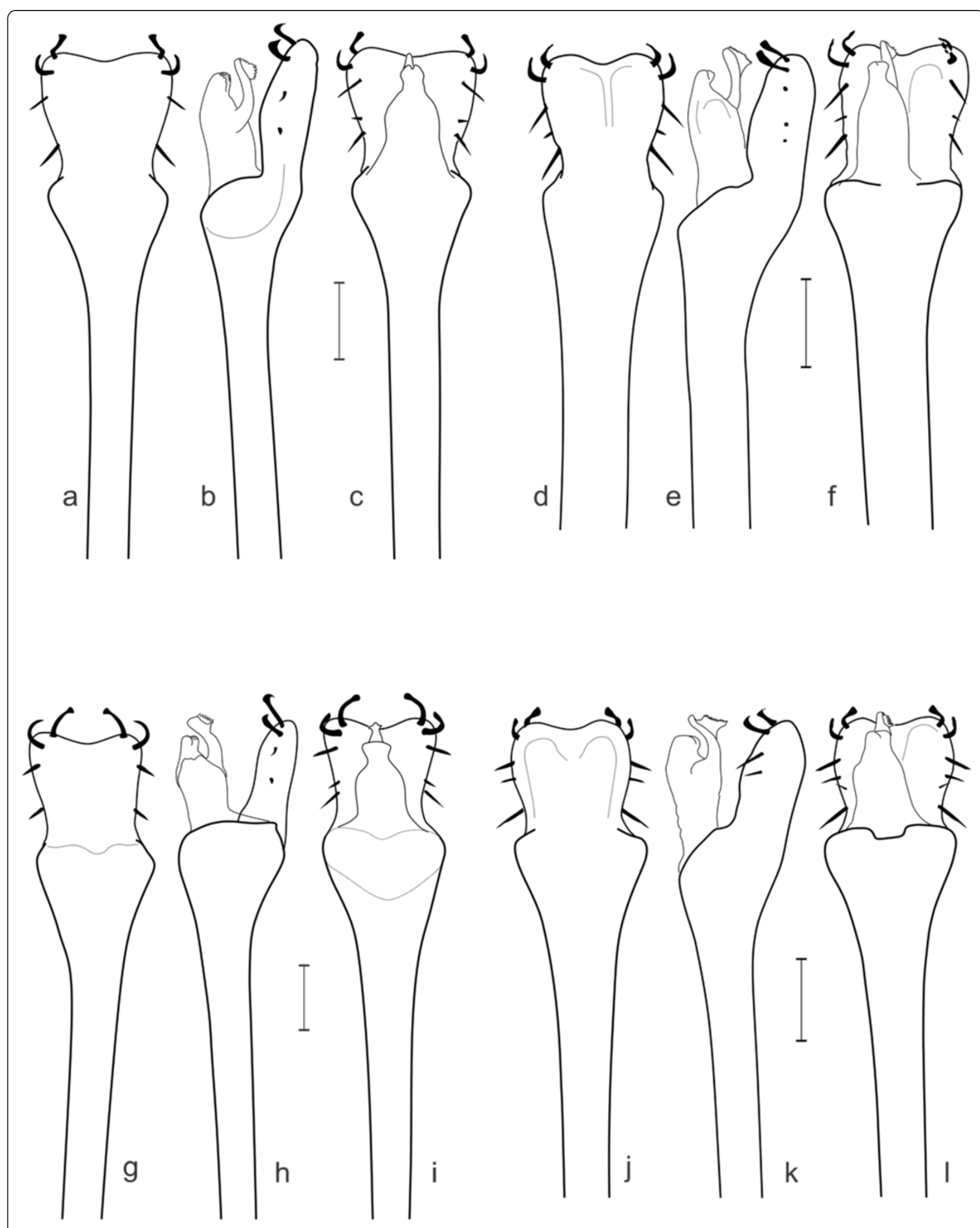

Figure 17 Taito spp., genitalia, distal part. Respectively ventral, lateral, and dorsal views; (a,b,c) T. oblongatus (ICNAO 213); (d,e,f) T. insperatus (INPA 007); (g,h,i) T. spaceinvaders (MNRJ 7580); (j,k, $\mathbf{l})$ T. medinae (IAvH - I 101). Scale bars $=0.1 \mathrm{~mm}$. 


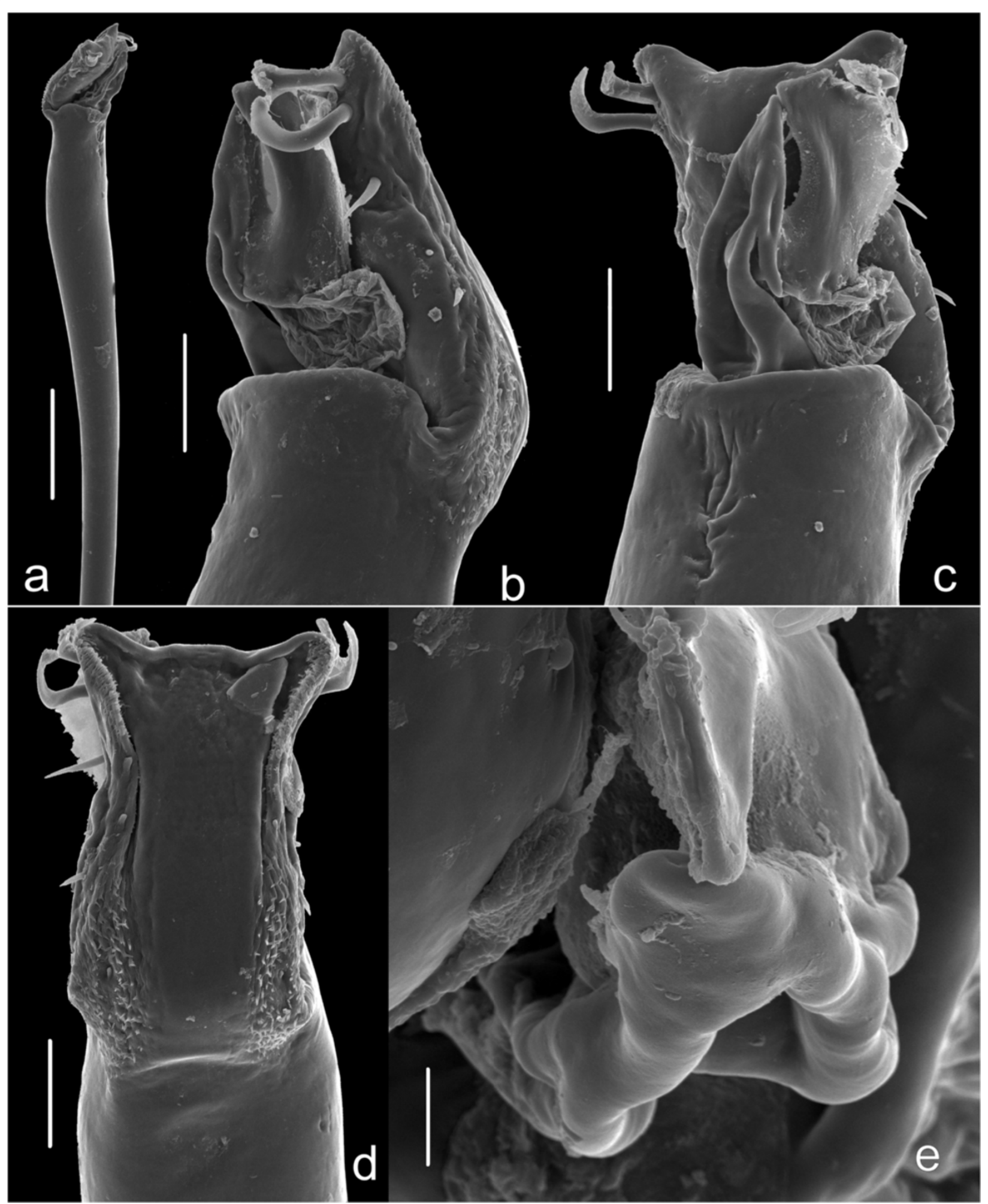

Figure 18 T. galaga sp. nov., male paratype (MNRJ 7549) from Humaitá. Masculine genital morphology: (a) Penis, panoramic, lateral view; (b) distal part of penis, lateral view; (c) same, dorsal view; (d) same, ventral view; (e) glans, detail of stylus and dorsal process, apical view. Scale bars $=200(\mathbf{a}) ; 50(\mathbf{b}, \mathbf{c}, \mathbf{d})$, and $10 \mu \mathrm{m}(\mathbf{e})$ 

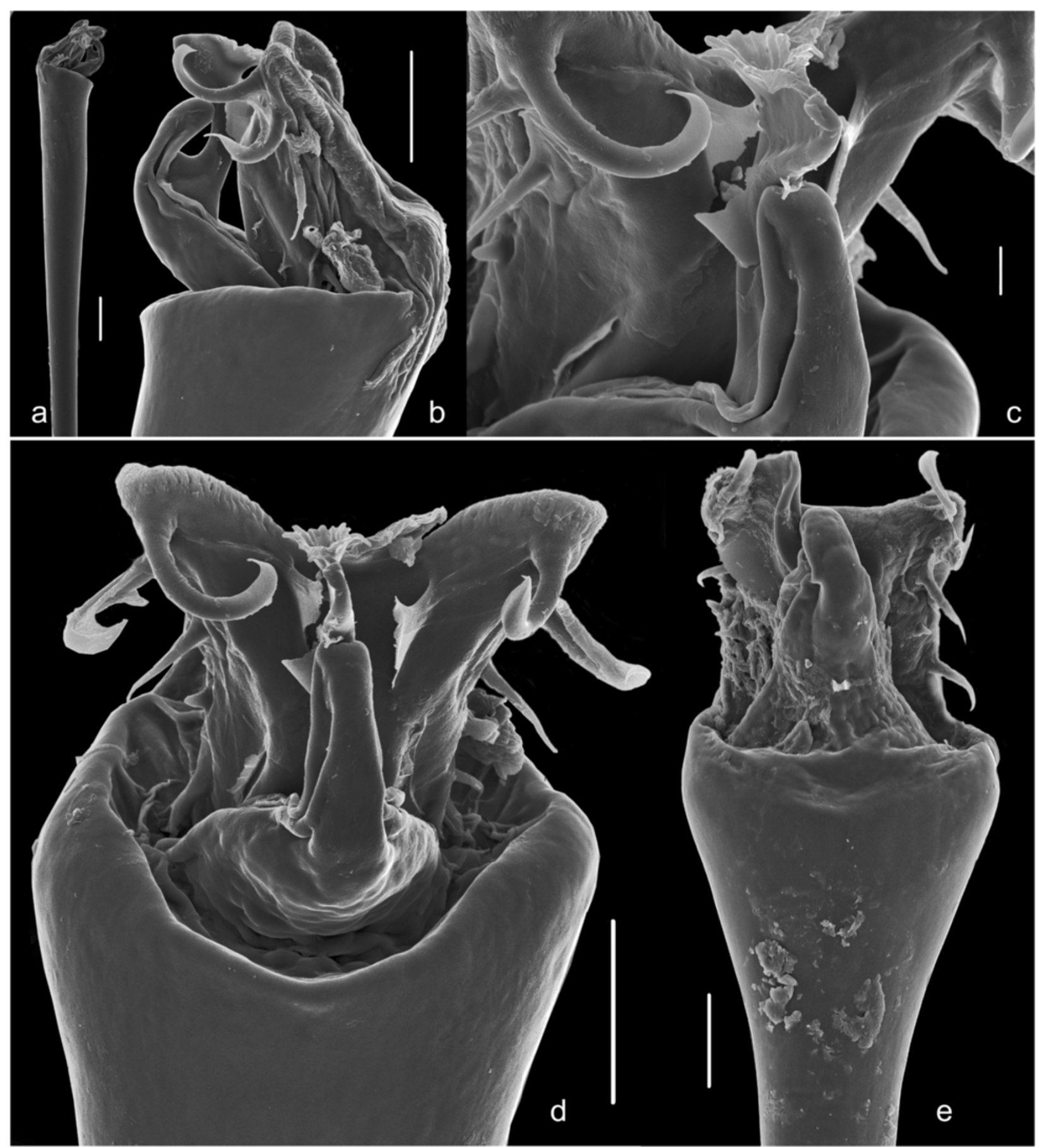

Figure 19 T. kakera sp. nov., male paratype (MNRJ 7548) (a,b,c,d) and T. kawaiikei sp. nov., male paratype (INPA-OP 1251) (e). Masculine genital morphology: (a) penis, panoramic, lateral view; (b) penis, distal part, lateral view; (c) glans, dorsal view; (d) penis, distal part, dorso-apical view; (e) same, dorsal view. Scale bars = 100 (a); 50 (b,d,e), and $10 \mu \mathrm{m}$ (c).

the variation. In both species, the equuleus is basically a square blot. T. osmari (Figure 8o,p,q,r,s,t,u,v) show drastic variation, with the feet mostly joined together, but concentrated in the middle; horns may be dissociated and lost, and arms are mostly indistinct from body.

\section{Key to 12 species of Taito (only for males)}

Distinction of females in this genus is tricky. They may be mostly recognized by the shape of equuleus, but there is some overlapping among the species as shown here. The iconography of known variations of equulei may help in this respect. 

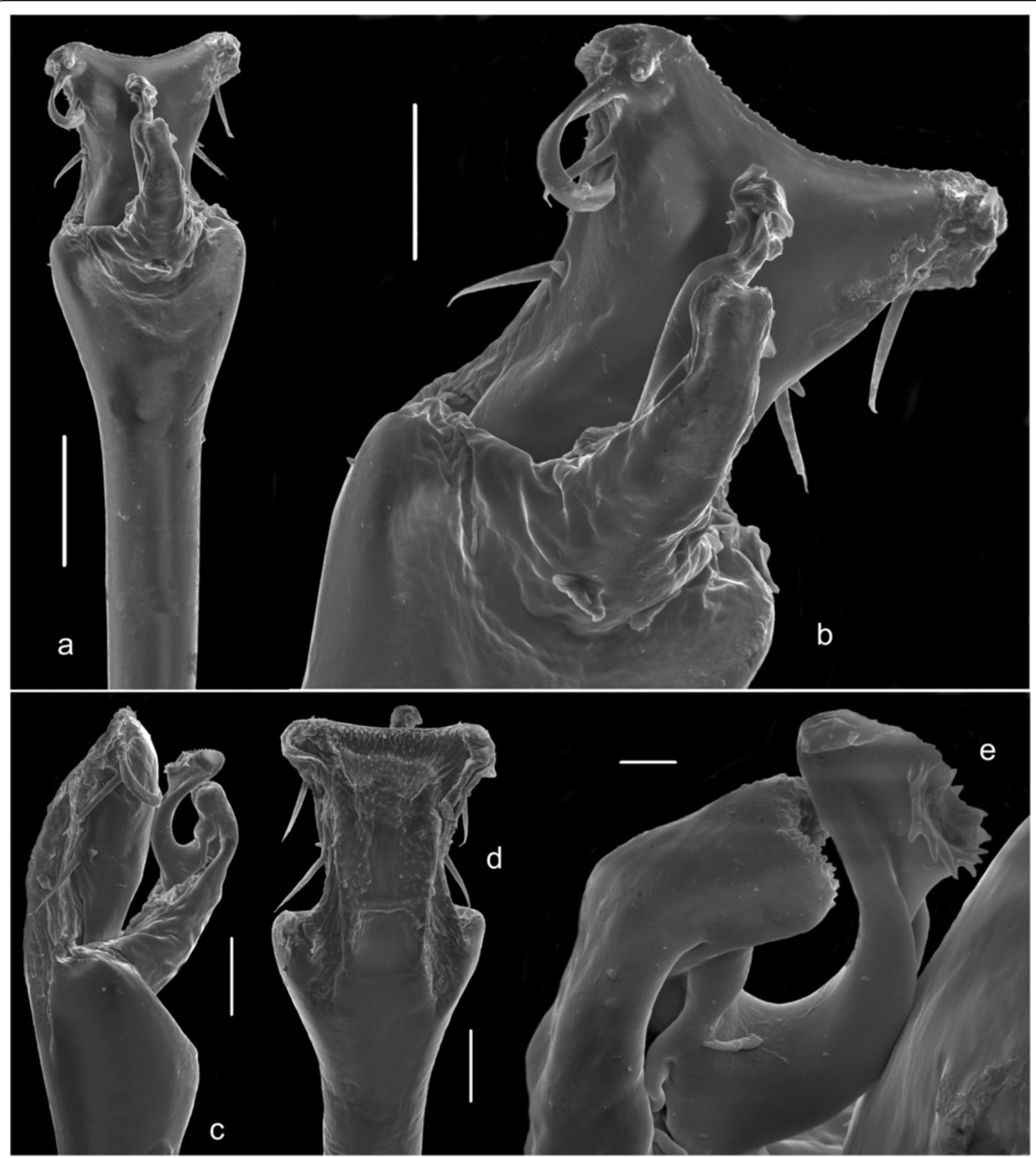

Figure 20 T. spaceinvaders sp. nov., male paratype (MNRJ 4816). Masculine genital morphology: (a) distal part of penis, dorsal view; (b) same, detail; (c) same, lateral view; (d) same, ventral view; (e) glans, detail of stylus and dorsal process, lateral view. Scale bars = 100 (a); $50(\mathbf{b}, \mathbf{c}, \mathbf{d})$, and $10 \mu \mathrm{m}$ (e).

T. litteratus is not included in this key because it is known only by females. It may be distinguished from all other species of the genus by the $\mathrm{H}$-shaped equuleus, with sides rather dissociated but easel-body well-developed (which is the opposite of T. honda and T. kakera, in which the sides are well-developed and the body shows various degrees of dissociation, culminating with complete effacement. There are also unique secondary posterior island blots (Figure 5i,j). Also left out of this key, the male holotype of T. unapunctatus has not been duly examined for 
this study, only by two snapshots. The femur IV does not match the shape and armature of any other species, having a clear medial curve and a row of 15 small spines on the distal half.

1. Lateral margins of scutum with one strong spine on each side (Figure 21a); femur IV bipectinate: a little thicker in distal $2 / 3$ and with 2 (retro- and prolateral) combs of spines in distal half (Figure 21e,f,g) .... T. kakera

Lateral margin of scutum unarmed (e.g., Figure 22a); femur IV variedly armed and curved (e.g., Figure 22e), but never bipectinate or incrassate as above .... 2

2(1). Anal operculum with one or more well-developed processes (Figure 1a,b,c,f) .... 3

Anal operculum entirely unarmed (Figure 1d,e) .... 7

3(2). Equuleus butterfly-shaped (Figure 8a,b,c,d,e,f,g,h, $\mathrm{i}, \mathrm{j}, \mathrm{k}, \mathrm{l}, \mathrm{m}, \mathrm{n})$; apophyses of anal operculum + last sternite forming a trident (Figures 2a,d and 23a,d); patella IV densely covered with coarse acuminate tubercles, larger at distal edge (Figures $2 \mathrm{f}$ and 23f) .... 4

Equuleus easel-shaped; apophyses of anal operculum + last sternite variedly armed (e.g., Figure 24a, d), but never forming anything similar to a trident; patella IV mostly finely granular (Figure 24f, with stouter retrolateral granulation in T. osmari only, Figure 25f) .... 5

4(3). Scutal area III with two strong acuminate spines (Figure 2a,b,d); feet of equuleus rounded; horns of equuleus indistinct (Figure 8a,b,c,d,e,f,g) .... T. galaga

Scutal area III with two small acuminate tubercles (Figure 23a,b,d); feet of equuleus square; crown of equuleus fused medially, anterior outline of blot without notch (Figure 8h,i,j,k,l,m,n) .... T. rorschachi

5(3). Anal operculum of male with median stout blunt apophysis (Figures 1a,b, 24a,b,d, and 26a,b,d); sternites 7/8 unarmed (Figures 24b and 26b) .... 6

Anal operculum of male with fringe of 6 to 7 spines (Figures $1 \mathrm{f}, 25 \mathrm{~b}, \mathrm{~d}$ ); sternites $7 / 8$ with a pair of acuminate spines.... T. osmari

6(5). Apophysis of anal operculum globular (Figure 26a, $\mathrm{b}, \mathrm{d})$; femur IV with extreme dorso-ventral curvature and distal combs of few spines on both sides (Figure 26e,f,g) .... T. medinae

Apophysis of anal operculum elongated, with apex bifid (Figure 24a,b,d); femur IV only gently curved laterally and distal comb of few spines only prolateral (Figure 24e,f,g) .... T. spaceinvaders

$7(2)$. Area III with a pair of spiniform apophyses (Figure 27a,b,d); equuleus $\mathrm{H}$-shaped (Figure 5a,b,c,d,e, f,g,h); dorso-apical apophysis of coxa IV large, in situ extending well into trochanter IV (Figure 27a) .... T. honda

Area III with a pair of minute granules (Figure 28a,b,d); equuleus easel-shaped or two-heart-shaped (Figure 6a,b,c,d, e,f,g,h,i,j,k,l,m,n,o,p,q,r,s,t,u,v,w,x,y,z,aa,ab,ac,ad,ae,af,ag,ah,ai, aj,ak,al,am,an,ao,ap,aq,ar,as,at,au,av); dorso-apical apophysis of coxa IV smaller, in situ barely reaching anterior border of trochanter IV (Figure 28a) .... 8

8(7). Dorso-apical apophysis of coxa IV single; femur IV gently curved, with only a row of a few distal prolateral spines; scutum beta-elongated (Figure 9c); sternite 7/8 armed with coarse tubercles (Figure 1d,e) .... 9

Dorso-apical apophysis of coxa IV double; femur IV either with some sharp angle or clavate, provided with rows of numerous spines in varied positions (e.g., Figure 14f); scutum classical beta (Figure 9b); sternite $7 / 8$ entirely unarmed (e.g., Figure 22d) .... 10

$9(8)$. Ocularium normally wide (around $40 \%$ of carapace width, Figure 28a); tibia IV with retrolateral row of 12 small spines; horns and feet of equuleus mostly strongly reduced, resulting in a botuliform blot (Figures 6ae,af,ag, ah,ai and 28a) .... T. insperatus

Ocularium narrow (around 30\% of carapace width, Figure 29a), eyes large; tibia IV entirely unarmed; horns and feet of equuleus mostly whole, resulting in a more typical easel (Figure 6a,b,c,d,e,f,g,h,i,j,k,l) .... T. oblongatus

10(8). Tibia IV with only one subapical retrolateral spine/Mt IV unarmed; easel body with different degrees of dissociation resulting eventually in two separate blots in some specimens (Figure 6ak,al,am,an,ao,ap,aq,ar,as,at, $\mathrm{au}, \mathrm{av})$; femur IV clavate sub-basally with small comb of dorsal spines (Figure 30e,g) .... T. kawaiikei

Tibia IV with three to six retrolateral spines (Figure 31e), metatarsus IV with two retrolateral spines; easel always whole; femur IV neither clavate nor with dorso-basal row of spines (Figure 14f) .... 11

11(10). Femur IV with two acuminate retrolateral spines on basal fourth (Figure 22e); dorsal comb of 20 to 25 spines and without distal-prolateral comb (Figure 22g) .... T. juruensis

Femur IV without retrolateral spines, without dorsal comb, but with distal-prolateral comb of 10 to 12 spines (Figure 31e,f,g) .... T. serriperna.

\section{Characterization of the species Taito galaga sp. nov.}

The characterization of Taito galaga sp. nov. is shown in Figures 1c, 2a,b,c,d,e,f,g, 8a,b,c,d,e,f,g, 13a,b,c,d, 16j,k,l, and $18 \mathrm{a}, \mathrm{b}, \mathrm{c}, \mathrm{d}, \mathrm{e}$.

Etymology. Galaga (Japanese Gyaraga) is a fixed shooter arcade game developed and published by Namco in Japan, inspired by Space Invaders. It is referring to the shape of the alien insectoids which resemble the butterfly-shaped equuleus of this species.

Type data. Male (ठ) holotype (MNRJ 1949), BRAZIL, Amazonas, Humaitá, left margin of Madeira river, Igarapé do Banheiro, 13.iv.1975, VP Silva \& AJ Dillon leg.; 3 đ 1 female (q) paratypes (MNRJ 2399), Humaitá, Igarapé do Banheiro, 11.vi.1975, A Mantovan leg.; 2 ऽ 1 ㅇ paratypes (MNRJ 7549), Humaitá, 19.vi.1975, A Mantovan leg.; 1 đ paratype (MNRJ 2389), Humaitá, 


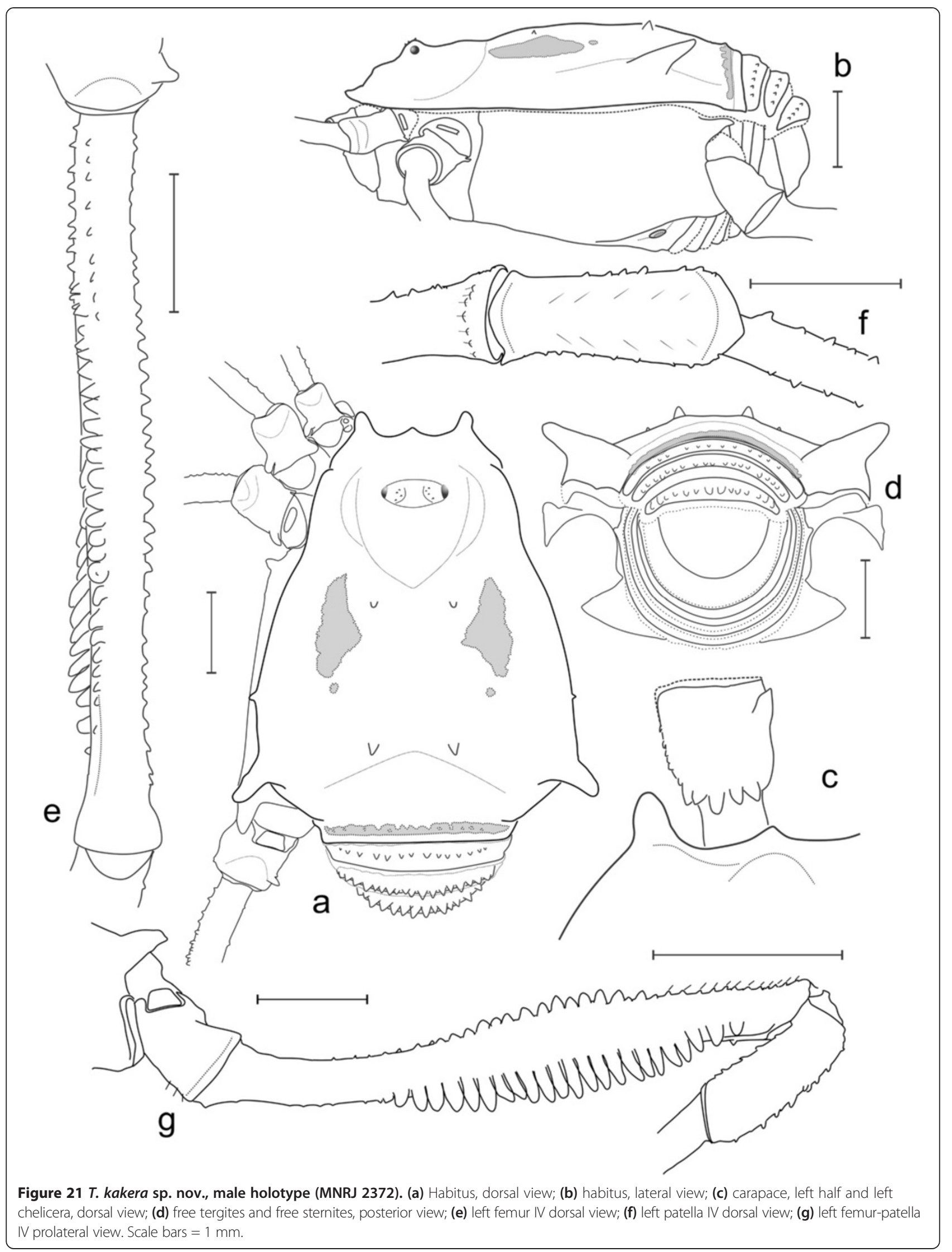




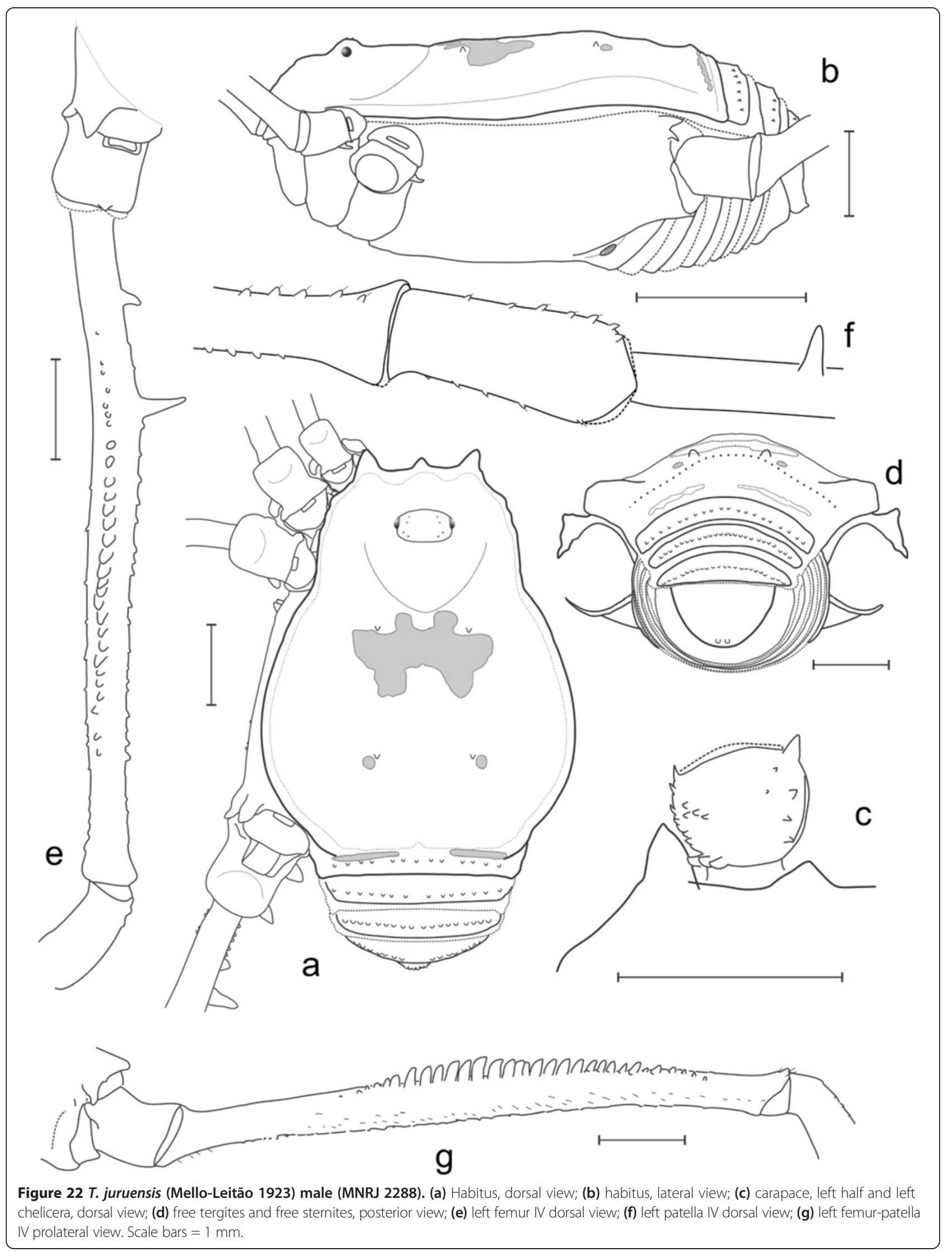




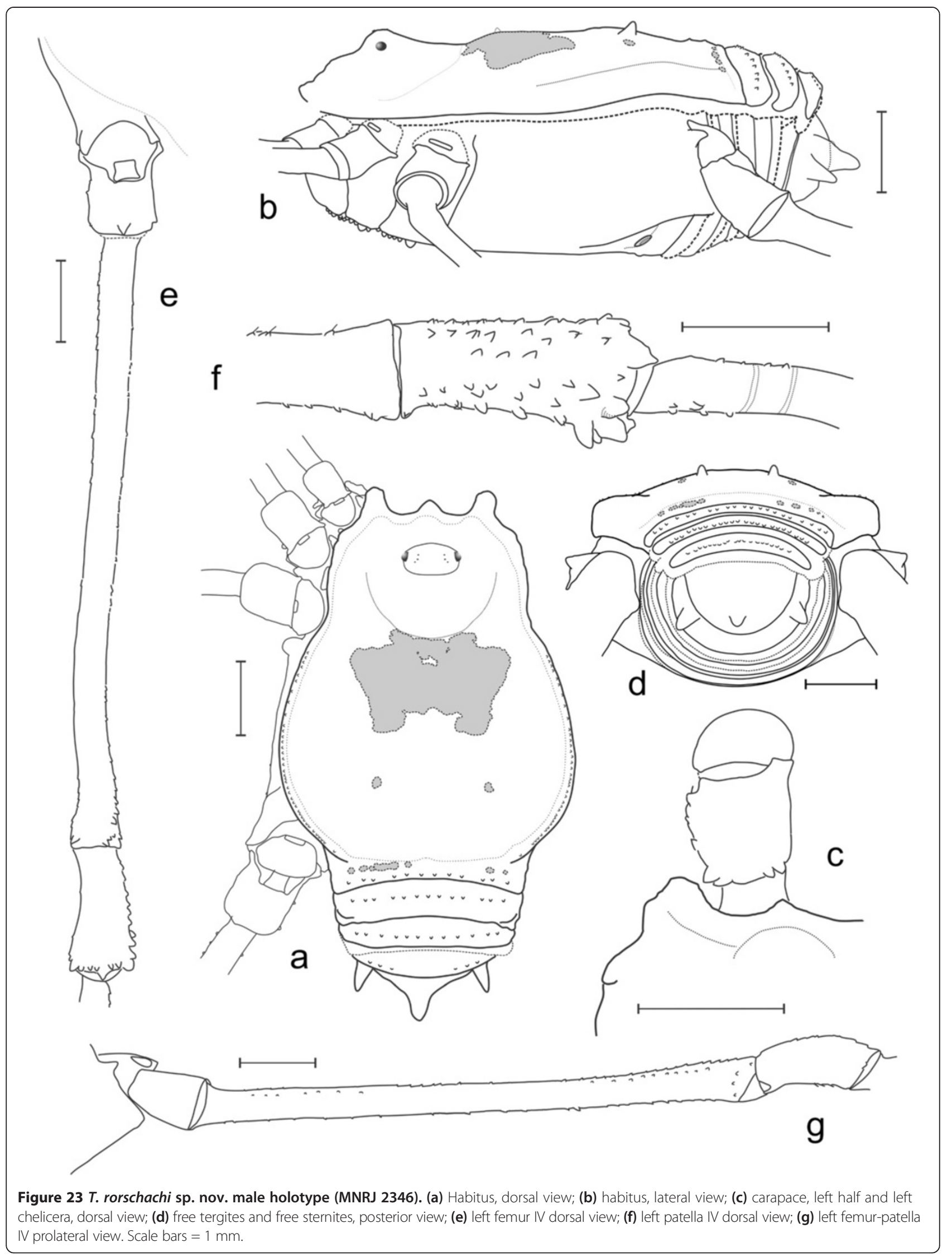




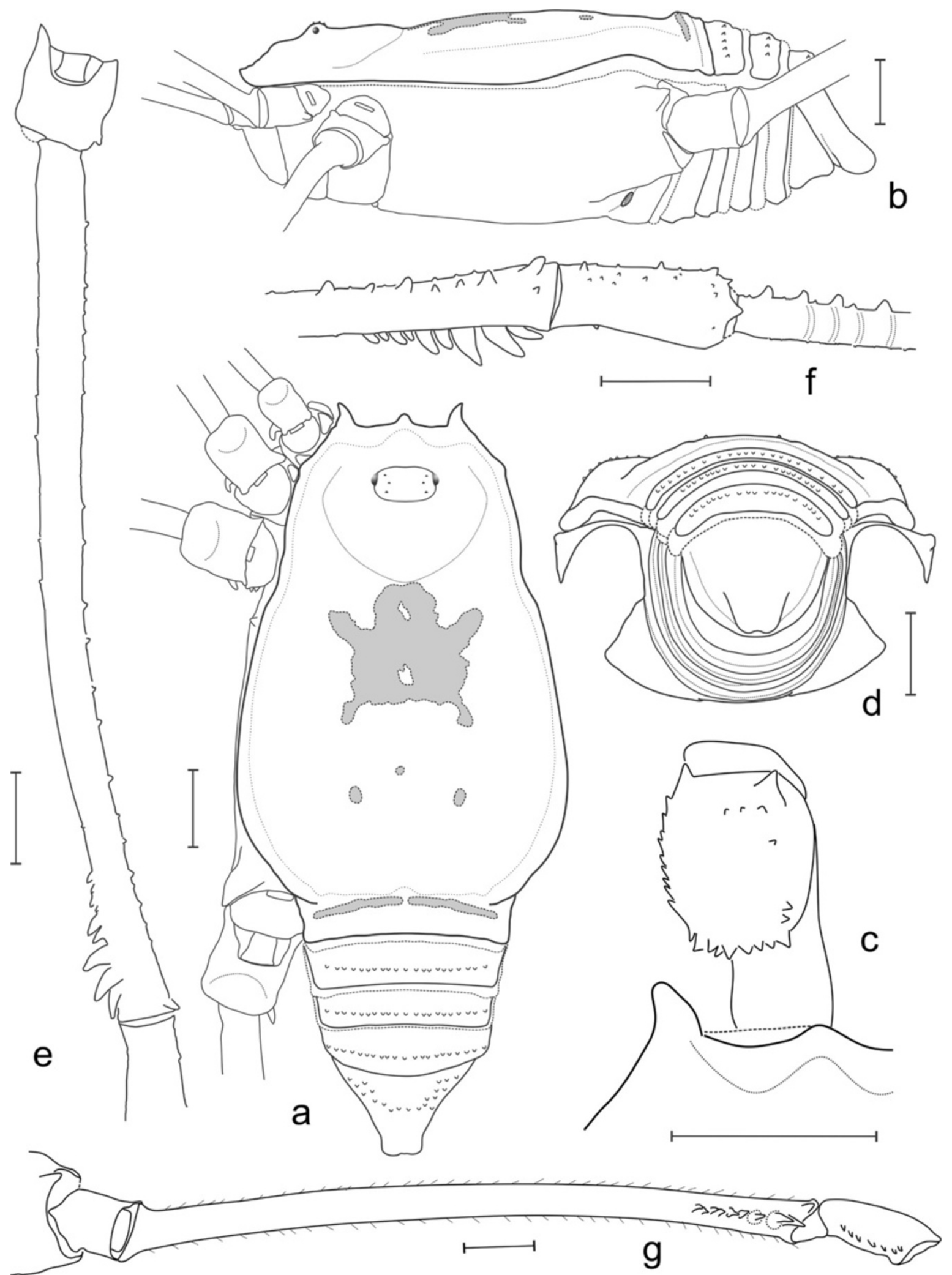

Figure 24 T. spaceinvaders sp. nov. male holotype (MNRJ 2357). (a) Habitus, dorsal view; (b) habitus, lateral view; (c) carapace, left half and left chelicera, dorsal view; (d) free tergites and free sternites, posterior view; (e) left femur IV dorsal view; (f) left patella IV dorsal view; (g) left femur-patella IV prolateral view. Scale bars $=1 \mathrm{~mm}$. 


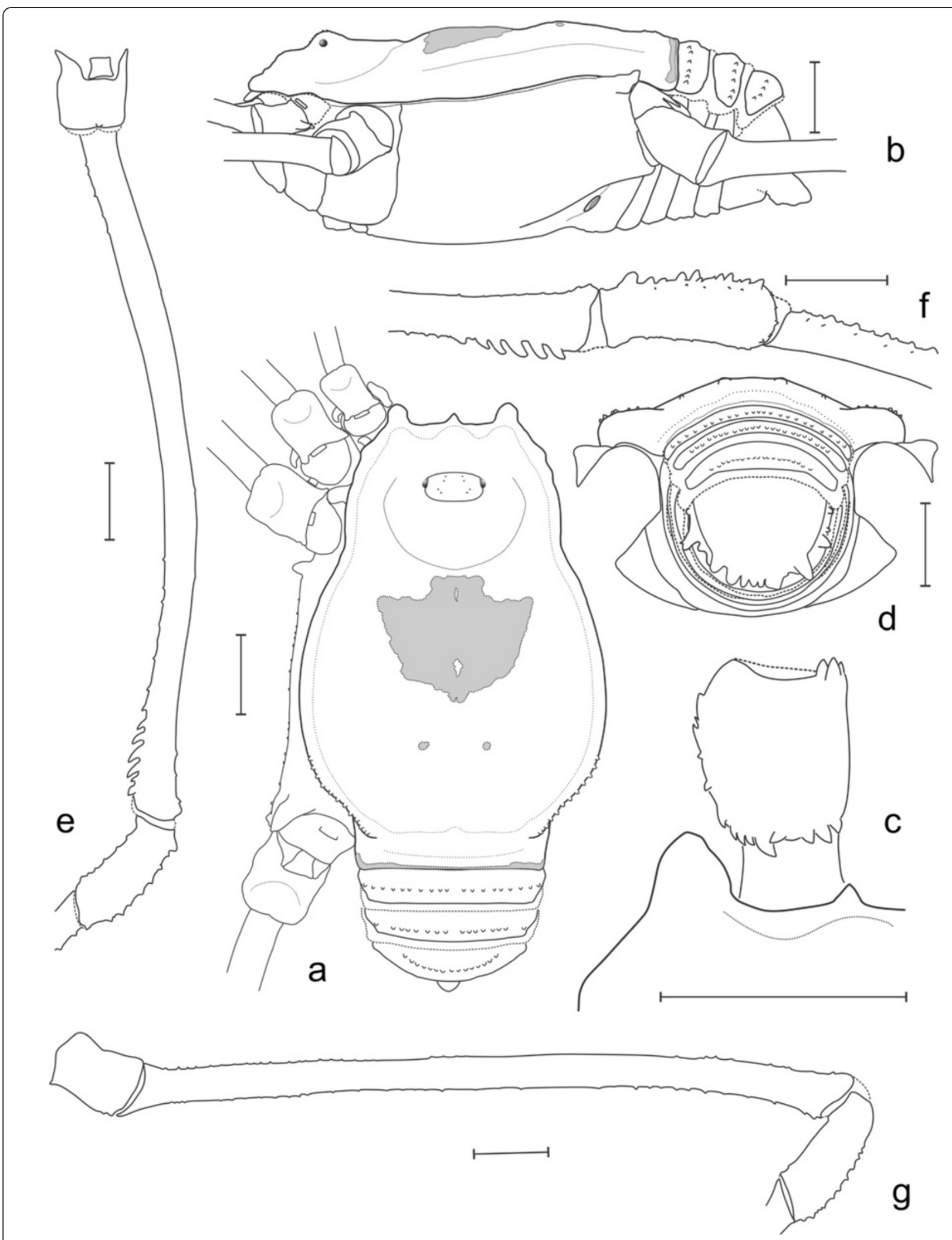

Figure 25 T. osmari sp. nov. male holotype (MNRJ 2362). (a) Habitus, dorsal view; (b) habitus, lateral view; (c) carapace, left half and left chelicera, dorsal view; (d) free tergites and free sternites, posterior view; (e) left femur IV dorsal view; (f) left patella IV dorsal view; (g) left femur-patella IV prolateral view. Scale bars $=1 \mathrm{~mm}$. 


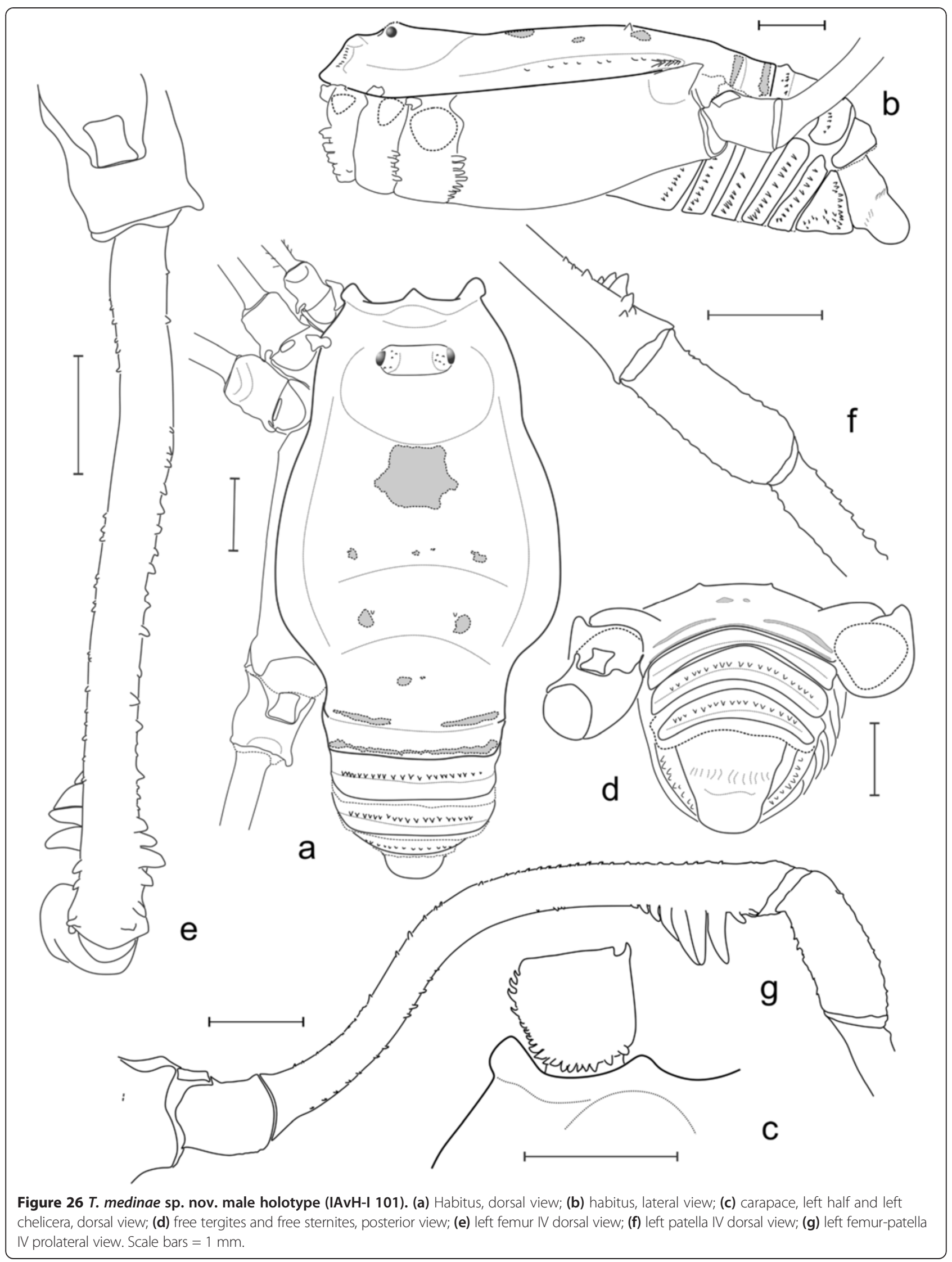




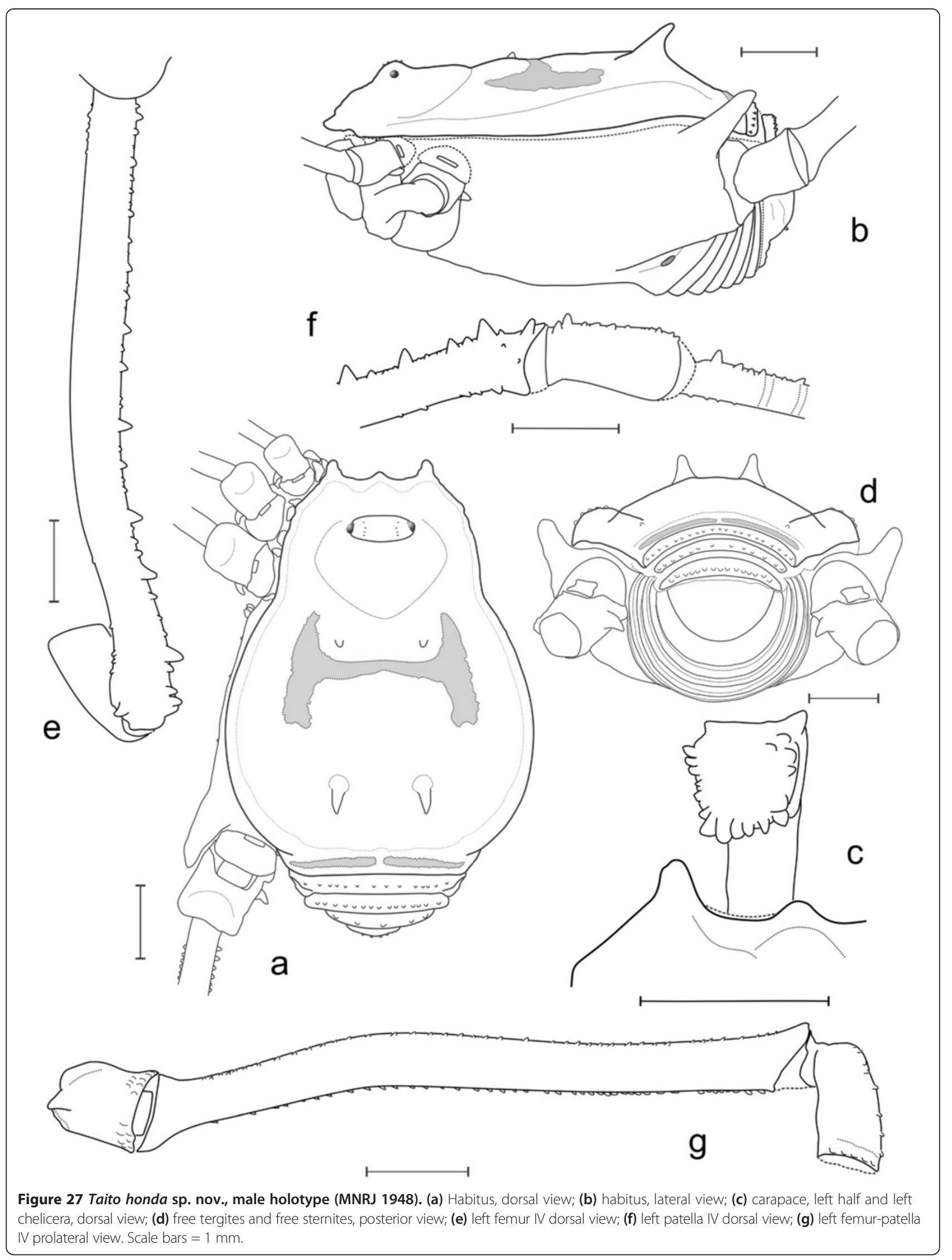




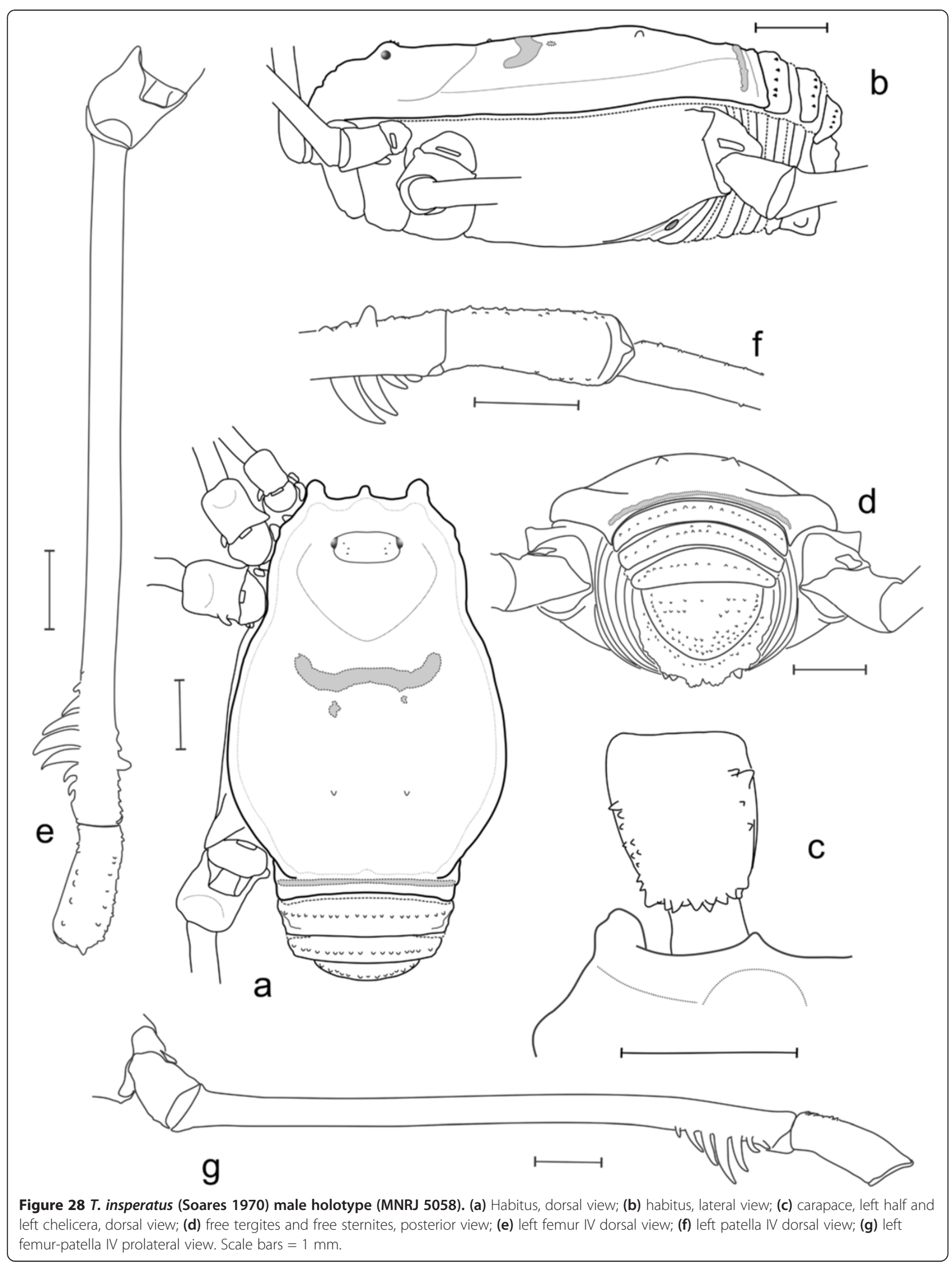




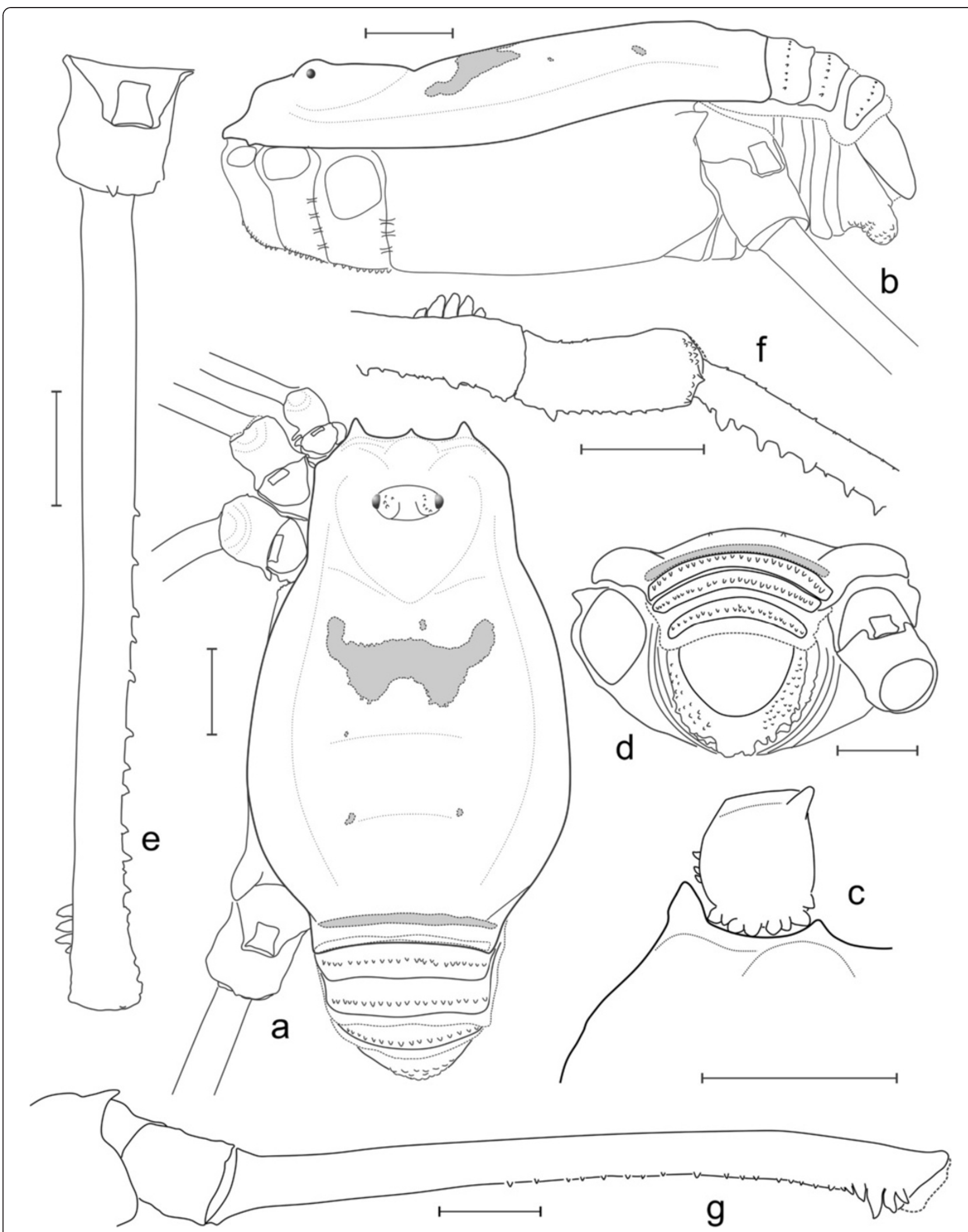

Figure 29 T. oblongatus (Roewer 1928), male (ICN-AO 213). (a) Habitus, dorsal view; (b) habitus, lateral view; (c) carapace, left half and left chelicera, dorsal view; (d) free tergites and free sternites, posterior view; (e) left femur IV dorsal view; (f) left patella IV dorsal view; (g) left femur-patella IV prolateral view. Scale bars $=1 \mathrm{~mm}$. 


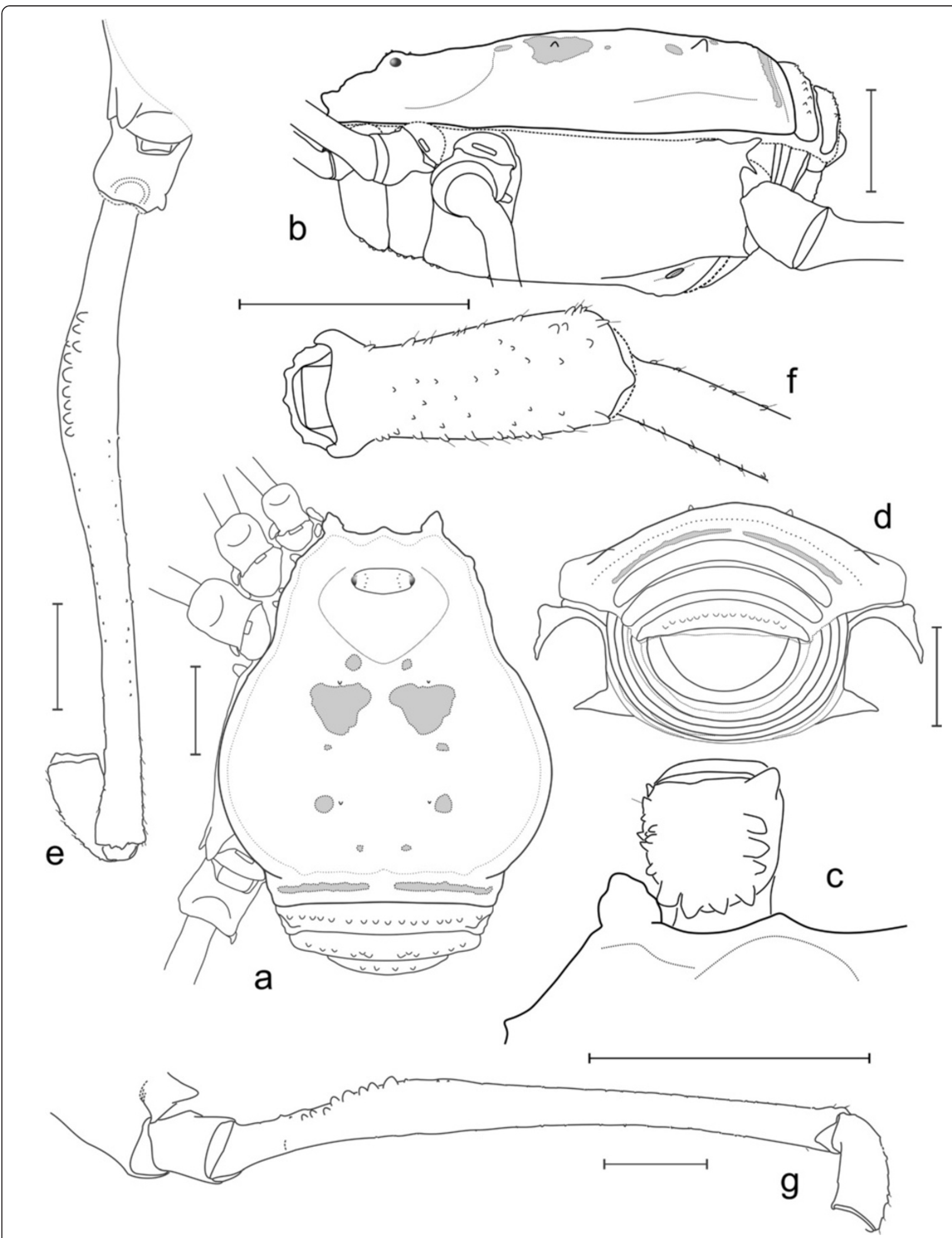

Figure 30 T. kawaiikei sp. nov. male holotype (MNRJ 2347). (a) Habitus, dorsal view; (b) habitus, lateral view; (c) carapace, left half and left chelicera, dorsal view; (d) free tergites and free sternites, posterior view; (e) left femur IV dorsal view; (f) left patella IV dorsal view; (g) left femur-patella IV prolateral view. Scale bars $=1 \mathrm{~mm}$. 


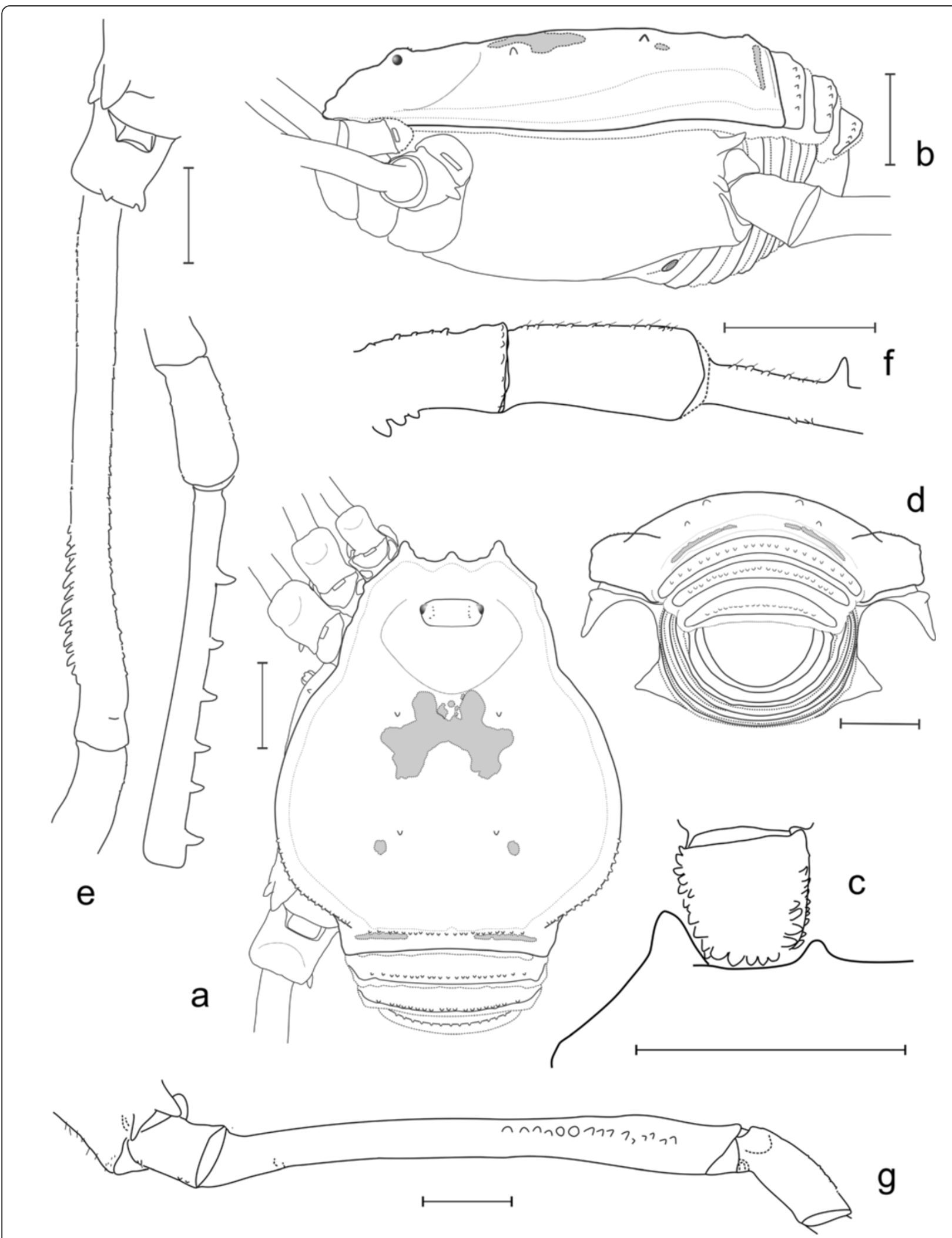

Figure 31 T. serriperna (Mello-Leitão 1932) male (MNRJ 1372). (a) Habitus, dorsal view; (b) habitus, lateral view; (c) carapace, left half and left chelicera, dorsal view; (d) free tergites and free sternites, posterior view; (e) left femur IV dorsal view; (f) left patella IV dorsal view; (g) left femur-patella IV prolateral view. Scale bars $=1 \mathrm{~mm}$. 
Igarapé do Banheiro, 02.i.1979, CM Carvalho leg.; 1 ภ 1 o paratypes (MNRJ 4580), Humaitá, Igarapé do Banheiro, 25.iii.1975, U Caramaschi \& CM Carvalho leg.; 1 đ paratype (MNRJ 4294) Amazonas, Conceição [do] Raimundo, Juruá River, vi.1950, JCM Carvalho \& A Viegas leg.; 1 đ paratype (MNRJ 7601) Rondônia, Monte Negro, 22-24.vii.2007, PI Silva Jr., R Bertani \& R Martins leg.

Diagnosis. Dorsal scutum of male moderately elongated (ratio ca. 1.34); scutal area III with two acuminate paramedian spines. Dorsal anal operculum of male with a robust central spiniform apophysis, sternite $7 / 8$ with two smaller paramedian spines. Dorso-apical apophysis of coxa IV as a single acuminate spine. Femur IV only breaking direction once, distally, dorsally unarmed, distal-prolateral unarmed. Patella IV densely covered with coarse acuminate granules concentrated distally. Equuleus compact, butterfly-shaped.

Distribution (Figure 32). BRAZIL, Amazonas, Conceição do Raimundo, WWF NT0133 (Juruá-Purus moist forests); Humaitá, WWF NT0141 (Monte Alegre Várzea); Rondônia, Monte Negro, WWF NT0135 (Madeira-Tapajós moist forests).

Measurements. $\mathrm{CL}=2.0, \mathrm{AL}=3.1, \mathrm{CW}=2.5, \mathrm{AW}=$ 4.0, FeIV $=8.0$, TiIV $=4.9$. Dorsum (Figure 2a,b,d). Dorsal scutum moderately elongated (ratio ca. 1.34), laterals convex, scutum widest at virtual area III, abruptly interrupted by the posterior constriction defining the posterior margin of scutum ('free tergite zero'). Area I with a pair of small tubercles, area III with a pair of moderately high spines, slightly bent backwards. Posterior margin of scutum slightly concave in dorsal view. Free tergites I and II with posterior margin straight and transverse marginal row of small granules, free tergite III with posterior margin strongly convex and a transverse row of small granules. Dorsal anal operculum with a robust central spiniform apophysis bearing a basal pair of very small accessory spines. Venter. Stigmatic area elongated, Y-shaped, anterior border (= posterior border of genital operculum) with a pair of lateral lobes. Sternites $7 / 8$ with a pair of latero-posterior spiniform apophyses smaller than the apophyses of anal operculum. Chelicerae (Figure 2c). Basichelicerite with ectal row of 12 small granules, posterior row of 7 strong acuminate tubercles. Two geminated stout tubercles on antero-mesal corner. Pedipalps (Figure 13a,b,c,d). Keels and ditch as in the genus. Femur with dorsal row of four small blunt setiferous tubercles and ventral row of nine flattened setiferous tubercle, median ones larger. Tibia with one ectal and one mesal apical setiferous tubercle. Legs (Figure 2a,e,f,g). Coxa IV with strong unbranched dorso-apical apophysis and surpassing scutum in dorsal view. Femur IV curved subdistally with two retrolateral rows of small acuminate tubercles. Patella IV curved and densely covered with coarse acuminate tubercles, larger meso-distally. Tibia IV with distal retrolateral row of four small acuminate spines, increasing distally. Tarsal counts: 6(3)-6

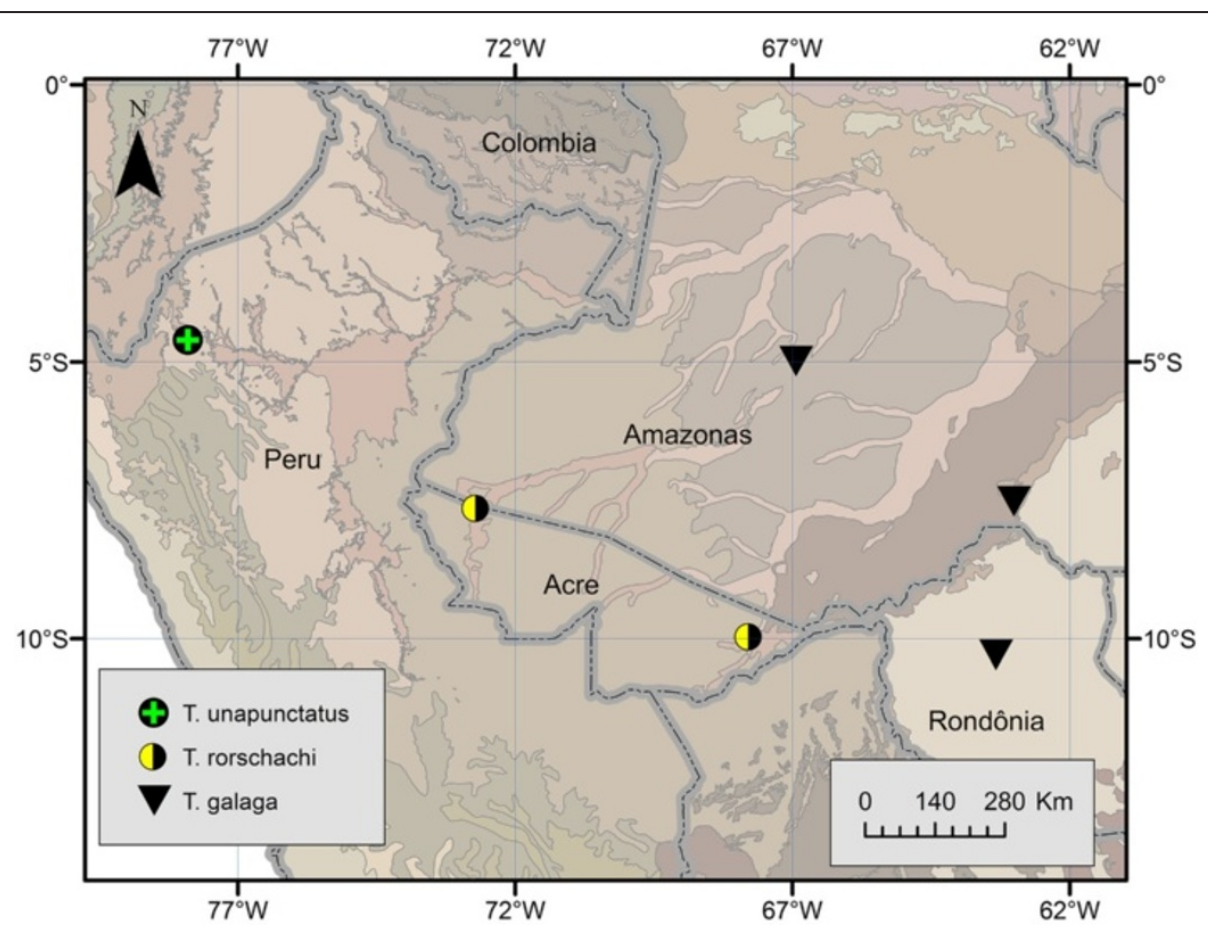

Figure 32 Northwestern South America, Upper Amazon Basin, showing distribution of species of Taito (part 1). Colored patches on the background represent WWF eco-regions. 
(3)/14(3)-14(3)/7-7/8-?. Color (in alcohol). Body and appendages uniformly brown, free sternites a little darker. Equuleus butterfly-shaped (Figure 8a,b,c,d,e,f,g), carapace, and scutum with 14 small rounded blots, mostly forming asymmetric pairs. Tibiae II and IV, metatarsi I to IV with many light rings. Genitalia (Figures $16 \mathrm{j}$, k,l, 16a,b,c,d,e). Truncus penis straight, without callus; ventral plate subrectangular concave at laterals; dorsal apophysis of glans conical, smooth; distal macrosetae moderately flattened; wattle very long, starting from base of stylus.

\section{Taito honda sp. nov.}

The characterization of Taito honda sp. nov. is shown in Figures 5a,b,c,d,e,f,g,h, 11a,b,c,d, 15g,h,i, and 27a,b,c,d,e,f,g.

Etymology. Honda Motor Company, Ltd. is a Japanese multinational corporation primarily known as a manufacturer of automobiles and motorcycles. The H-shaped equuleus of this species strongly resembles the current brand mark of Honda.

Type data. § holotype (MNRJ 1948) and 1 ๙ paratype (MNRJ 2358), BRAZIL, Amazonas, Humaitá, left margin of Madeira river, Igarapé do Banheiro, 13.iv.1975, VP Silva \& AJ Dillon leg.; 3 ô paratypes (MNRJ 7084), Humaitá, Igarapé do Banheiro, 25.iii.1975, JCM Carvalho \& U Caramaschi leg.; 1 q paratype (MNRJ 7086), Humaitá, Igarapé do Banheiro, 17.ii.1976, U Caramaschi leg.; 1 † 1 juv. paratypes (MNRJ 7085), Humaitá, Igarapé do Banheiro, 2.i.1979, LM Silva, A Silva \& JCM Carvalho leg.; 1 ㅇ paratype (MNRJ 17650), idem, 11.vi.1975, A Mantovan leg.; 1 đ paratype (MNRJ 7088) and 5 ○ 2 क paratypes (MNRJ 7087), Humaitá, Lago do Puruzinho, 19.ii.1977, U Caramaschi leg.; 1 q paratype (MNRJ 4823), idem, 30. xii.1975, Luis \& Angélica leg.; 1 q paratype (MNRJ 4295), Humaitá, 3.xi.1976.

Diagnosis. Dorsal scutum of male moderately elongated (ratio ca. 1.28). Scutal area III with two acuminate spines. Anal operculum of male unarmed. Dorso-apical apophysis of coxa IV as a single stout acuminate spine. Femur IV breaking direction once in each plan, distally, dorsally unarmed, distal-retrolateral with a few scattered short spines. Patella IV unarmed. Equuleus with long transverse axis and two lateral bars, forming an $\mathrm{H}$.

Distribution (Figure 33). BRAZIL, Amazonas, Humaitá, WWF NT0141 (Monte Alegre Várzea).

\section{Description of male holotype}

Measurements. $\mathrm{CL}=1.9, \mathrm{AL}=3.1, \mathrm{CW}=2.6, \mathrm{AW}=$ 4.1, FeIV $=6.2$, TiIV $=4.0$. Dorsum . Dorsal scutum moderately elongated (ratio ca. 1.28), without any trace of segmentation, except for carapace and abdominal scutum, areas 1 and 2 separated by shallow groove, laterals thickened and convex. Lateral areas of scutum with one longitudinal row of small tubercles. Area I with a pair of small

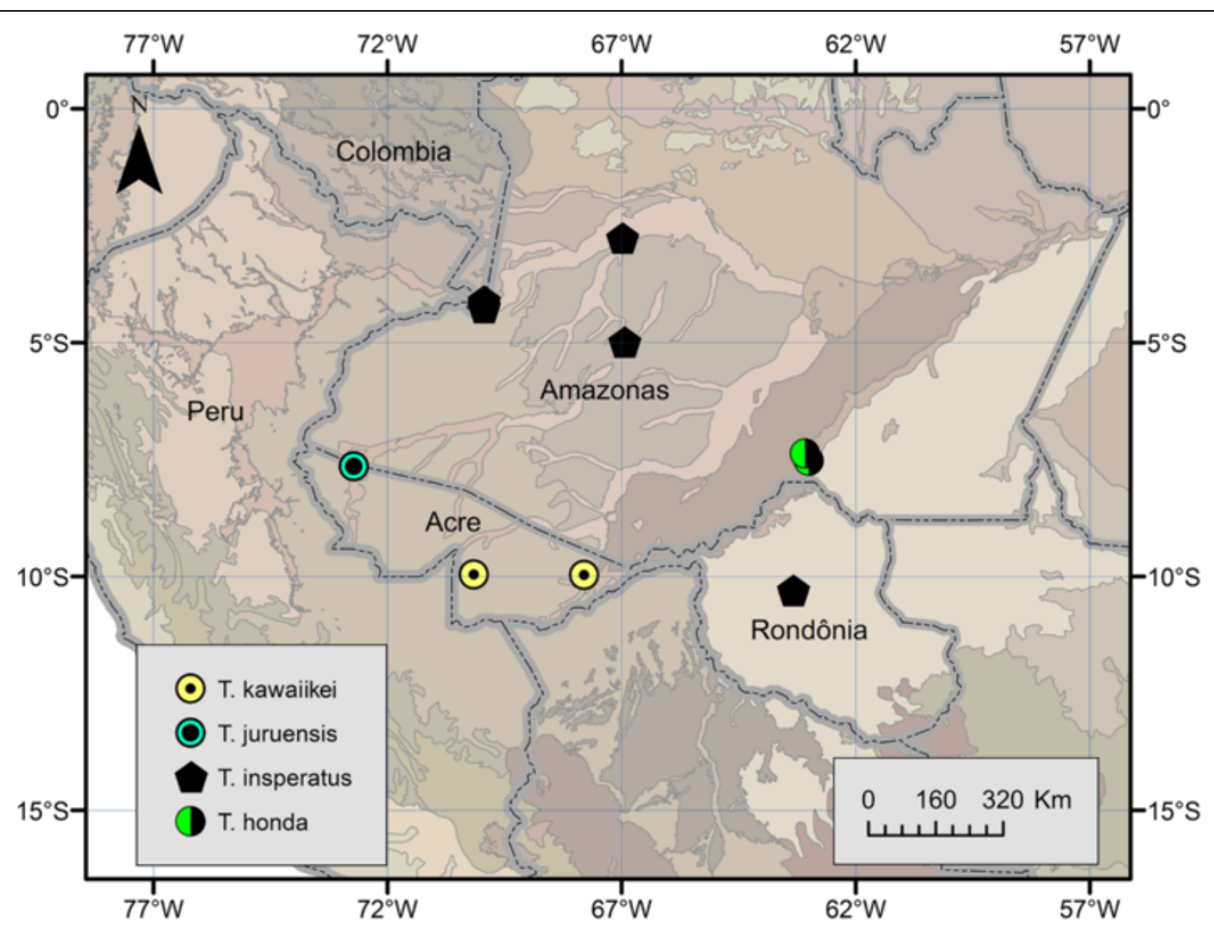

Figure 33 Northwestern South America, Upper Amazon Basin, showing distribution of species of Taito (part 2). Colored patches on the background represent WWF eco-regions. 
acuminated tubercles, area III with a pair of moderately high spines, slightly bent backwards. Posterior margin of scutum straight in dorsal view. Free tergites I and II with posterior margin straight and transverse marginal row of small granules, free tergite III with posterior margin strongly convex and a transverse row of small granules. Dorsal anal operculum densely covered by coarse granules. Venter. Coxa I subtriangular with two transverse rows of tubercles and a larger tubercle at posterior corner matching correspondent tubercle of coxa II. Coxa II subtriangular, unarmed, linked to coxa III by tubercular bridges, maxillary lobe as small rounded projection, inner anterior corners with 3 to 4 coarse tubercles. Chelicerae (Figure 27c). Basichelicerite with ectal row of five large granules, posterior row of eight strong broad tubercles. A single stout tubercle on antero-mesal corner. Pedipalps (Figure 11a,b,c,d). Femur with dorsal keel with four anterior teeth, ventral row of seven small flattened teeth, median larger. Tibia with meso-apical blunt apophysis and antero-ectal projection, ending in two setiferous tubercles. Legs. Femur IV twisted twice (halfway dorso-ventrally and latero-subdistal at distal fourth). Armed with two retrodistal rows of small acuminate tubercles. Patella IV substraight, finely granular, granulation coarser mesally. Tibia IV mostly unarmed, except for two small acuminate retrobasal tubercles. Articles of basitarsus I clearly larger than those of distitarsus, but not swollen. Tarsal counts: 6(3)-6 (3)/?-12(3)/7-7/8-8. Color (in alcohol). Body and appendages uniform mahogany brown, free sternites and also apophysis of coxa IV a little darker. H-shaped equuleus and transverse stripe on coda white. Genitalia (Figure 15g, $\mathrm{h}, \mathrm{i})$. Truncus penis slender, but growing steadily with subdistal bulge, forming a pair of attenuate calluses; ventral plate subrectangular concave at laterals; dorsal apophysis of glans square, bilobed, densely covered with tubercles; distal macrosetae cylindrical; wattle short, restricted to distal third of stylus.

\section{Taito insperatus (Soares 1970) comb. nov.}

The Taito insperatus (Soares 1970) comb. nov. is shown in Figures 6ae,af,ag,ah,ai, 17d,e,f, and 28a,b,c,d,e,f,g).

Cynorta insperata Soares 1970: 323, Figure 3; Kury 2003: 45.

Type data. ${ }^{\lambda}$ holotype (MNRJ 5058, examined), BRAZIL, Amazonas, Conceição [do] Raimundo, Juruá River, vi.1950, JCM Carvalho \& A Viegas leg.; 1 ○ (MNRJ 8269) Amazonas, Tabatinga, vi.1950, JCM Candido \& A Viegas leg.; 1 ô (INPA 007) Amazonas, Jutaí, Ilha Xibeco CN, 16.ix.2003, F do Rego leg.; 1 o paratype (MNRJ 7601) Rondônia, Monte Negro, 22-24.vii.2007, PI Silva Jr., R Bertani \& R Martins leg.; 1 ô 1 \& (MNRJ-HS 0719) (Cynortula oblongata Roewer, H Soares det. 1978), COLOMBIA, Amazonas, $1 \mathrm{~km}$ East Leticia, along path to Marco, 7.vii.1977, RM Shelley leg.; 1 우 (ICN AO 303)
Bosque Comunidad Indigena Monilla-Amena, $100 \mathrm{~m}$, among vines attached to standing tree, nocturnal collecting, II.xi.2001, E Florez leg.

Diagnosis. Dorsal scutum of male moderately elongated (ratio ca. 1.41). Scutal area III with two minute granules. Anal operculum of male unarmed. Dorso-apical apophysis of coxa IV as a single short acuminate spine. Femur IV substraight, only breaking direction once, distally, dorsally unarmed, distal-prolateral with a comb of 5 spines, distalretrolateral with a few small spines. Patella IV unarmed. Equuleus with long transverse axis, no feet and crown much reduced.

Distribution (Figure 33). BRAZIL, Amazonas, Conceição do Raimundo, WWF NT0133 (Juruá-Purus moist forests); Jutaí, WWF NT0156 (Purus Várzea); Rondônia, Monte Negro, WWF NT0135 (Madeira-Tapajós moist forests). COLOMBIA, Amazonas, Leticia, WWF NT0156 (Purus Várzea) and NT0163 (Solimoes-Japurá moist forest).

\section{Description of male holotype}

Measurements. $\mathrm{CL}=2.1, \mathrm{AL}=3.3, \mathrm{CW}=2.6, \mathrm{AW}=3.8$, FeIV $=7.7$, TiIV $=4.7$. Dorsum (Figure 28a,b). Dorsal scutum moderately elongated (ratio ca. 1.41). Areas I and III each with pair of very small acuminated tubercles. Posterior margin of scutum slightly concave in dorsal view. Free tergites I-II with posterior margin straight and transverse row of small granules, free tergite III with posterior margin slightly convex and a transverse row of small granules. Anal operculum finely granular. Venter (Figures 1d, and 28d). Sternites 3, 4, 5, and 6 each with a transverse row of acuminate tubercles. Sternite $7 / 8$ with a transverse row of clusters of coarse acuminate tubercles, the two paramedian much larger. Chelicerae (Figure 28c). Basichelicerite with ectal row of eight small granules, posterior row of ten stronger acuminate tubercles. Two stout tubercles subdistal to antero-mesal corner. Pedipalps. Femur with dorsal keel with 8 teeth, ventral row of 14 small flattened teeth. Legs (Figure 28e,f,g). Trochanter IV unarmed. Femur IV only slightly curved twice - dorso-ventrally on half and laterally on distal $1 / 4$. Armed with a comb of seven pro-subapical spines, the mid four much larger. Armed with 1 pro-subapical small spine. Patella substraight, finely granular, unarmed. Tibia and metatarsus IV unarmed. Tarsal counts: 6-?(3)/14-14(3)/7-?/8-8. Color. Body and appendages uniformly brown, free tergites and sternites a little darker, also coxa IV. Equuleus yellowish white, legs I-IV slightly lighter than body. Genitalia (Figure 17d,e,f). Truncus penis slender, but growing steadily with subdistal bulge, forming pair of attenuate calluses; ventral plate trapezoid; dorsal apophysis of glans square, bilobed, densely covered with tubercles; distal macrosetae spatulate; wattle short, restricted to distal third of stylus. 
Taito juruensis (Mello-Leitão 1923) comb. nov.

Taito juruensis (Mello-Leitão 1923) comb. nov. is shown in Figures 6m,n,o,p,q,r,s,t,u,v,w,x,y,z,aa,ab,ac,ad, 10a,b,c, d, 16a,b,c, and 22a,b,c,d,e,f,g.

Eucynortella juruensis Mello-Leitão 1923: 111, Figure 4; 1932: 54; Roewer 1928a: 579.

Cynortula juruensis: Soares 1944: 176; 1945: 342; 1946: 528, Figure 3.

Cynorta juruensis: Soares 1970: 324; Kury 2003: 45.

Type data. + holotype (MNRJ 5060, not examined, lost), 5 o paratypes (MNRJ-HS 0010, examined), BRAZIL, "Upper Juruá River", Acre or Amazonas State, xi.1950, H Sick leg.

Other material examined. 2 o 1 (MNRJ 2307) Acre, Cruzeiro do Sul, vi.2009, OS Torres leg.; 1 ㄱ 7 ㅇ (MNRJ 2288), Cruzeiro do Sul, vii.2009, OS Torres leg.; 3 o 4 우 (MNRJ 2313), Cruzeiro do Sul, vi.2009, OS Torres leg.;

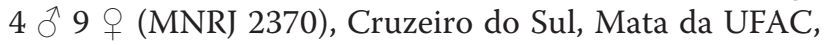
04.xi.2010, A Giupponi, F Madeira \& J Cruz leg.

Diagnosis. Dorsal scutum of male moderately elongated (ratio ca. 1.33). Scutal area III with two minute granules. Anal operculum of male virtually unarmed. Dorso-apical apophysis of coxa IV as a double spine. Femur IV, only breaking direction once, basally, dorsally with comb of 25 spines, distal-prolateral unarmed, basalretrolateral with two large spines. Patella IV unarmed. Equuleus typical easel, with each pair of arms, feet, and horns well-defined.

Distribution (Figure 33). BRAZIL, Acre, Cruzeiro do Sul, WWF NT0166 (Southwest Amazon moist forests).

Remarks. The collections examined were found to contain some specimens of cosmetids from the upper course of Juruá River (municipality Cruzeiro do Sul), here considered to be topotypes of E. juruensis, including the hitherto unknown male of this species. A comparison with the holotype of $C$. serriperna shows that they are two distinct species, although closely related.

\section{Description of male MNRJ 2288}

Measurements. $\mathrm{CL}=1.8, \mathrm{AL}=2.9, \mathrm{CW}=2.4, \mathrm{AW}=3.8$, FeIV $=6.7$, TiIV $=4.4$. Dorsum (Figures 22a,b and, 14a). Dorsal scutum moderately elongated (ratio ca. 1.33), areas I to III each with pair of minute granules. Posterior margin of scutum straight in dorsal view. All tergites finely granular and unarmed. Anal operculum with a pair of very small rounded tubercles. Venter (Figure 22b,d). Free sternites finely granular, unarmed. Chelicerae (Figure 22c). Basichelicerite with ectal row of seven small acuminate curved tubercles, posterior row of only three curved tubercles. A single stout acuminate tubercle on anteromesal corner. Pedipalps (Figure 10a,b,c,d). Femur without pronounced dorsal keel, but dorsally with six setiferous tubercles. Ventral row of 12 setiferous tubercles. Legs (Figures 14b,c,d,e,f and 22e,f,g). Trochanter
IV with spiniform apophyses, one retro-basal, one retro-distal. Femur IV curved to the outside in dorsal view, median portion somewhat incrassate in dorsoventral direction. Armed with two large spiniform apophyses on proximal third, one retrolateral row of small tubercles on distal $4 / 5 ; 1$ dorsal row of 25 setiferous tubercles on the mid 3/5. Patella IV substraight with very small setiferous tubercles. Tibia IV with three retrolateral spiniform apophyses, two on proximal half, one subapical. Metatarsus IV with two retrolateral spiniform apophyses on proximal fourth. Tarsal counts: 6-6/12-13/7-7/8-8. Color. Body and appendages dark brown. Easel white. Genitalia (Figure 16a,b,c). Truncus penis slender, abruptly widened forming pair of calluses; ventral plate rectangular straight; dorsal apophysis of glans square, bilobed, densely covered with tubercles; distal macrosetae spatulate; wattle very long.

\section{Taito kakera sp. nov.}

Taito kakera sp. nov. is shown in Figures 5k,l,m,n,o,p,q,r, s,t,u,v,w,x, 15j,k,l, 19a,b,c,d, and 21a,b,c,d,e,f,g).

Etymology. From Japanese kakera $=$ shard, because of the shape of the equuleus, reminiscent of the fragments of the Jewel of Four Souls in the Japanese manga 'InuYasha, a Feudal Fairy Tale', written and illustrated by Rumiko Takahashi.

Type data. సै holotype (MNRJ 2372), BRAZIL, Acre, Rio Branco, FEC, x.2010, OS Torres leg.; 1 ๙ 1 q paratypes (MNRJ 2345), same data; 2 paratypes (MNRJ 2369) Acre, Xapuri, área controle, xi.2009, OS Torres leg.; 4 đ 2 q paratypes (MNRJ 7623) Acre, Manoel Urbano, Parque Estadual Chandless, x.2011, OS Torres leg.; 1 त 10 q paratypes (MNRJ 7548) Amazonas, Humaitá, 19.vi.1975, A Mantovan leg.

Diagnosis. Dorsal scutum of male moderately elongated (ratio ca. 1.32). Lateral margins of scutum with one strong spine on each side (Figure 21a). Scutal area III armed with two acuminate tubercles. Anal operculum and free sternites unarmed. Dorso-apical apophysis of coxa IV as a single acuminate spine. Femur IV only breaking direction once, basally, with dorsal row of numerous tubercles, distal-prolateral armed with comb of some 20 increasing spines, medial retrolateral armed with comb of numerous tubercles (Figure 21e,g). Equuleus either $\mathrm{H}$-shaped or disjoint as two half diamonds.

Distribution (Figure 34). BRAZIL, Acre, Manoel Urbano; Rio Branco; Xapuri, all WWF NT0166 (Southwest Amazon moist forests); Amazonas, Humaitá, WWF NT0141 (Monte Alegre Várzea).

\section{Description of male holotype}

Measurements. $\mathrm{CL}=1.9, \mathrm{AL}=3.0, \mathrm{CW}=2.6, \mathrm{AW}=$ 3.9, FeIV $=5.2$, TiIV $=4.4$. Dorsum. Dorsal scutum 


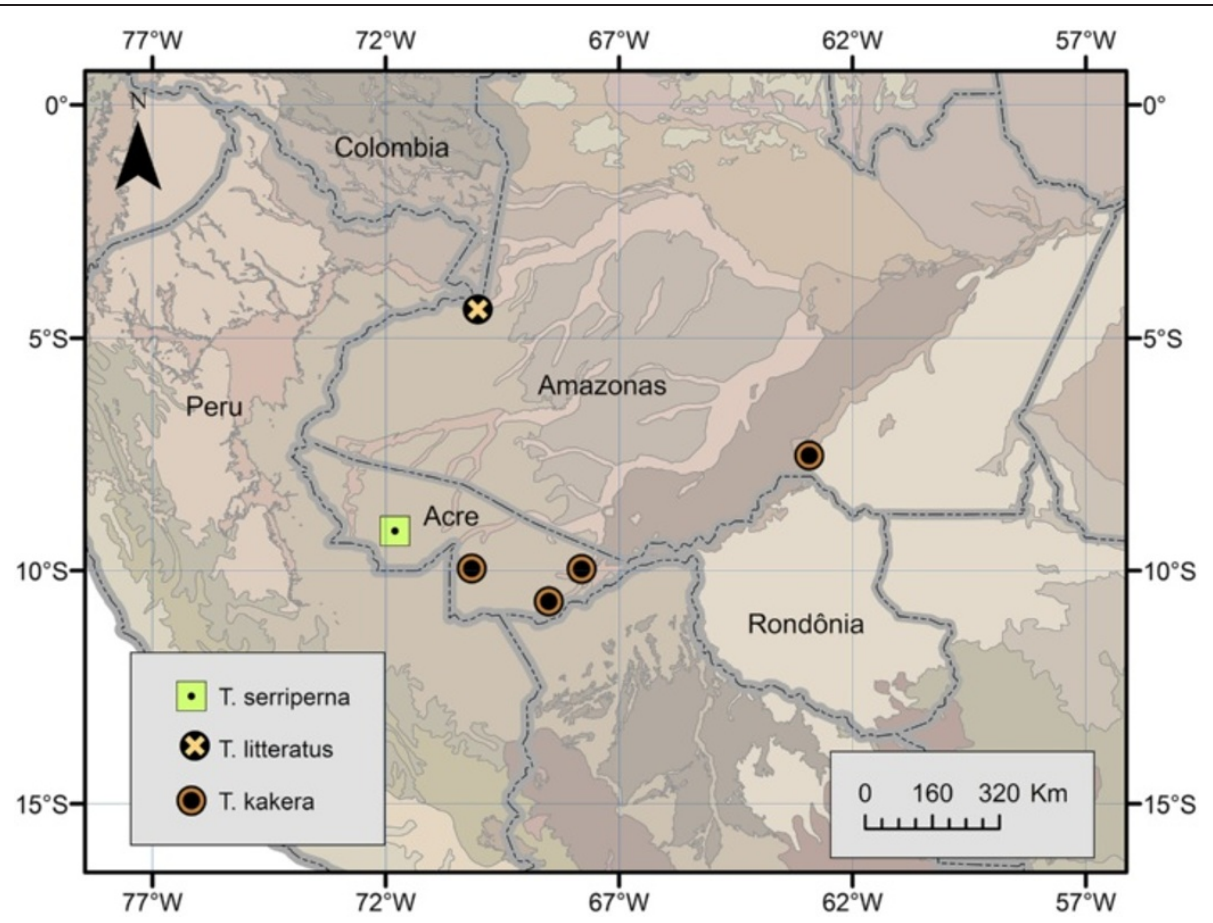

Figure 34 Northwestern South America, Upper Amazon Basin, showing distribution of species of Taito (part 3). Colored patches on the background represent WWF eco-regions.

moderately elongated (ratio ca. 1.32). Areas I to III each with pair of very small acuminated tubercles. Posterior margin of scutum straight in dorsal view. Free tergite II with transverse marginal row of small granules, free tergites II and III each with transverse row of robust tubercles. Dorsal anal operculum smooth and unarmed. Venter. Free sternites smooth and unarmed. Chelicerae (Figure 21c). Basichelicerite with ectal row of six minuscule granules, posterior row of five stout tubercles. A single stout acuminate tubercle on antero-mesal corner. Pedipalps. Femur with low dorsal keel with five setiferous tubercles and a row of eight ventral setiferous tubercles. Legs. Trochanter IV with small retro-subdistal setiferous tubercle. Femur IV sinuous, with dorsal and retrolateral rows of very small tubercles and a prolateral row of robust setiferous tubercles, larger in the middle (Figure 21e,g). Patella IV substraight with mesal row of small acuminate tubercles (Figure 21f). Tibia and metatarsus unarmed. Tarsal counts: ?-6/11-12/7-7/ 8-8. Color (in alcohol). Body and appendages uniformly brown, free sternites a little darker. Equuleus as two white diamonds and two small rounded accessory blots (Figure 21a), free tergite zero with white transverse stripe. Genitalia (Figures 15j,k,l and, 19a,b,c,d). Truncus penis slender, but growing steadily with subdistal bulge, forming pair of attenuate calluses; ventral plate trapezoid; dorsal apophysis of glans square, bilobed, densely covered with tubercles; distal macrosetae cylindrical; wattle short, restricted to distal third of stylus.

\section{Taito kawaiikei sp. nov.}

Taito kawaiikei sp. nov. is shown in Figures 6ak,al,am, an,ao,ap,aq,ar,as,at,au,av, 15d,e,f, 19e, and 30a,b,c,d,e,f,g.

Etymology. From Japanese noun kawaii-kei = カワイイ 系, a recently-made fashionable Japanese word that indicates an ensemble of cute things in Japanese popular culture, because of the easel shape of this species, which resembles a couple of hearts. 系 = 'kei' means 'group', 'series,' 'system'.

Type data. $\delta$ holotype, 1 q paratype (MNRJ 2347), BRAZIL, Acre, Rio Branco, FEC, x.2010, OS Torres leg.; 1 ๙ paratype (MNRJ 02353), idem, xi.2010; 5 ते 4 ㅇ paratypes (MNRJ 7622) Acre, Manoel Urbano, Parque Estadual Chandless, x.2011, OS Torres leg.

Diagnosis. Dorsal scutum of male sturdy (ratio ca. 1.15). Scutal area III with two minute paramedian granules. Anal operculum of male unarmed. Dorso-apical apophysis of coxa IV as a double spine. Femur IV, only breaking direction once, basally, where it has a club with a pro-dorsal row of nine setiferous tubercles, dorsally unarmed, distalprolateral unarmed (Figure 30e,f,g). Patella IV unarmed (Figure 30f). Equuleus easel-shaped often strongly dissociated, sometimes disjoint, composed of two heart-shaped spots (Figure 6ak,al,am,an,ao,ap,aq,ar,as,at,au,av). 
Distribution (Figure 33). BRAZIL, Acre, Manoel Urbano; Rio Branco all WWF NT0166 (Southwest Amazon moist forests).

\section{Description of male holotype}

Measurements. $\mathrm{CL}=1.5, \mathrm{AL}=2.5, \mathrm{CW}=2.5, \mathrm{AW}=3.6$, FeIV $=5.8$, TiIV $=4.2$. Dorsum. Dorsal scutum sturdy (ratio ca. 1.15), areas I and III each with a pair of minute tubercles. Posterior margin of scutum straight in dorsal view. Free tergites I and II with posterior margin straight and transverse marginal row of small tubercles, free tergite III with posterior margin strongly convex and a transverse row of small tubercles. Anal operculum unarmed. Venter. Sternites 7/8 smooth and unarmed (Figure 30d). Chelicerae (Figure 30c). Basichelicerite with ectal row of eight small granules, posterior row of four stout tubercles, mesal row of three large tubercles. A single stout blunt tubercle on antero-mesal corner. Pedipalps. Femur with low dorsal keel with a row of six setiferous tubercles, ventrally with a row of nine setiferous tubercles. Legs. Trochanter IV with two small retro-basal and retro-apical setiferous tubercles. Femur IV, only breaking direction once, basally, where it has a club with a pro-dorsal row of nine setiferous tubercles, dorsally unarmed, distal-prolateral unarmed (Figure 30e,f,g). Patella IV unarmed (Figure 30f). Tibia IV with one small retro-subapical setiferous tubercle. Metatarsus IV unarmed. Tarsal counts: 6-6/12-12/7-?/8-8. Color (in alcohol). Body and appendages uniformly brown, free sternites a little darker. Leg IV with patches of dense black mottling, especially in and around patella. Coxae I to IV ventrally all honeycombed in black and yellowish brown. Equuleus as two white heart-shaped blots and four pairs of rounded accessory blots (Figure 30a), free tergite zero with white transverse stripe interrupted in the middle. Genitalia (Figures 15d,e,f, and 19e). Truncus penis slender, abruptly widened forming pair of calluses; ventral plate rectangular straight; dorsal apophysis of glans square, bilobed, densely covered with tubercles; distal macrosetae spatulate; wattle short, restricted to distal third of stylus.

\section{Taito litteratus (Soares 1970) comb. nov.}

Taito litteratus (Soares 1970) comb. nov. is shown in Figure 5i,j.

Cynorta litterata Soares 1970b: 324, Figure 9; Kury 2003: 46.

Type data. + holotype (MNRJ 5061, examined), BRAZIL, Amazonas, Benjamin Constant, v.1950, JCM Carvalho \& A Viegas Filho leg; 1 q paratype (MNRJ-HS 0015) same data.

Diagnosis. Males so far unknown. Scutal area III with two minute granules. Equuleus with thick, long transverse axis of body and 2 lateral arches, roughly haltershaped or bat-shaped. Tarsal counts: 6-6/?-?/8-8/9-?

Female holotype. Measurements. $\mathrm{CL}=1.4, \mathrm{AL}=2.5$, $\mathrm{CW}=2.5, \mathrm{AW}=3.4, \mathrm{FeIV}=8.2, \mathrm{TiIV}=4.7$.
Distribution (Figure 34). BRAZIL, Amazonas, Benjamin Constant, WWF NT0166 (Southwest Amazon moist forests).

Taito medinae sp. nov.

Taito medinae sp. nov. is shown in Figures $1 \mathrm{a}, 17 \mathrm{j}, \mathrm{k}, \mathrm{l}$, 26a,b,c,d,e,f,g, and 35.

Etymology. Species name honors Claudia Alejandra Medina Uribe, head of the collections in the Instituto de Investigación de Recursos Biológicos Alexander von Humboldt (Villa de Leyva) for her effort in managing and preserving Colombian biodiversity.

Type data. $\widehat{\jmath}$ holotype (IAvH - I 101), COLOMBIA, Amazonas, Leticia, Reserva forestal del río Calderón, Estación biológica el Zafire, $150 \mathrm{~m}, 4^{\circ} 0^{\prime 2} 21^{\prime \prime S} 69^{\circ} 53^{\prime} 55^{\prime \prime W}$, varrillal trampa Winkler n 37, 2-4.xii.2007, LE Franco \& S Flórez leg. $1 \precsim 1$ q paratypes (MNRJ 8432) COLOMBIA, Amazonas, near Puerto Nariño (NW of Leticia), San Martín de Amacayacu, terra firme forest, 05-09.xii.2013, A Anker leg.

Diagnosis. Dorsal scutum of male extremely elongated (ratio ca. 1.67). Scutal area III with two minute tubercles. Anal operculum with huge median globular process, sternite7/8 unarmed (Figure 1a). Dorso-apical apophysis of coxa IV as a single acuminate spine. Femur IV with extreme dorso-ventral curvature and distal combs of few spines on both sides. Equuleus compact without feet, arms, and horns.

Distribution (Figure 36). COLOMBIA, Amazonas, Leticia, WWF NT0163 (Solimões-Japurá moist forest).

\section{Description of male holotype}

Measurements. $\mathrm{CL}=2.0, \mathrm{AL}=3.7, \mathrm{CW}=2.8, \mathrm{AW}=$ 3.7, FeIV $=5.8$, TiIV $=4.3$. Dorsum. Dorsal scutum extremely elongated (ratio ca. 1.67). Areas I and III each with paramedian pair of minute granules. Posterior margin of scutum straight in dorsal view. Free tergites I and II with posterior margin straight and transverse marginal row of small granules, free tergite III with posterior margin strongly convex and a transverse row of small granules. Anal operculum with huge median globular process (Figure 1a). Venter. Sternite7/8 unarmed, densely granular (Figure 1a). Chelicerae (Figure 26c). Basichelicerite with ectal row of 12 curved tubercles, posterior row of 7 stronger acuminate tubercles. One stout tubercle on anteromesal corner. Pedipalps. Femur with low dorsal keel with 7 setiferous tubercles and ventral row of 14 setiferous tubercles. Legs. Trochanter IV with one very small retrosubapical setiferous tubercle. Femur IV strongly curved dorso-ventrally in the middle (Figure 26g), with comb of seven pro-subapical curved teeth, of which three are much larger; with row of three retro-subapical small teeth. Patella to metatarsus IV unarmed. Tarsal counts: 6-6/14-12/7-7/8-8. Color (in alcohol). Body and appendages uniformly brown, free sternites a little darker. Leg IV with patches of dense black mottling, especially in and around patella. Equuleus as a 


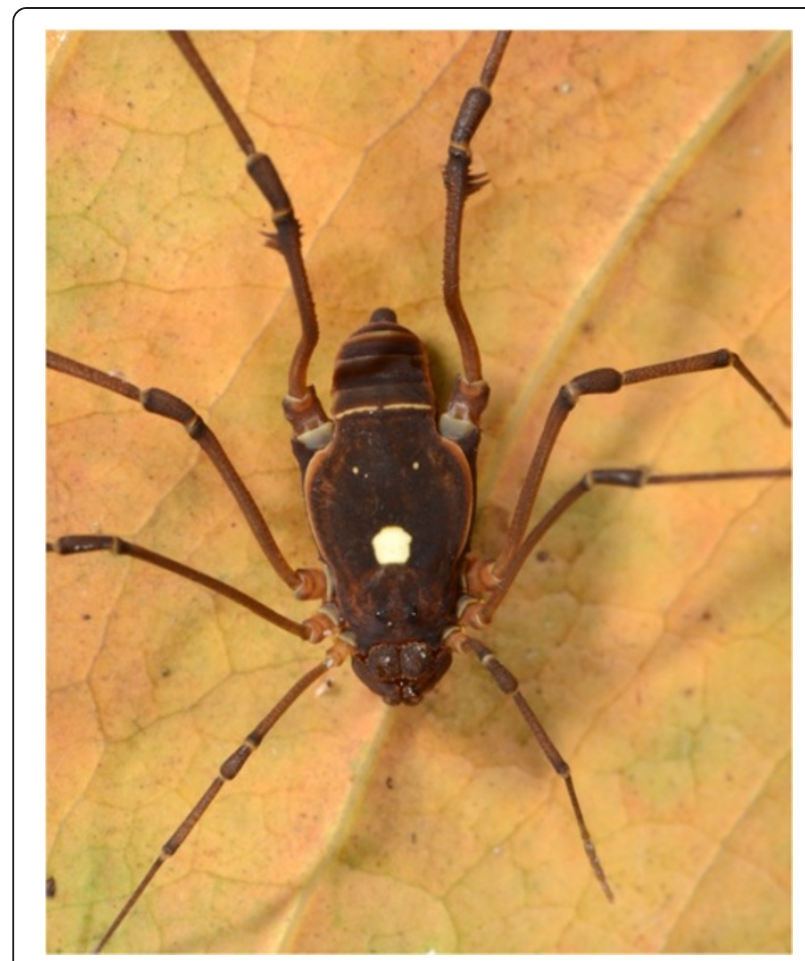

Figure 35 T. medinae sp. nov.. Male paratype (MNRJ 8432). Photograph taken by Arthur Anker, San Martín de Amacayacu. compact square blot and one pair of rounded accessory blots (Figure 26a), free tergite zero with white transverse stripe interrupted in the middle. Genitalia (Figure 17j,k,l). Truncus penis slender, abruptly widened forming pair of calluses; ventral plate subrectangular concave at laterals; dorsal apophysis of glans square, bilobed, densely covered with tubercles; distal macrosetae spatulate; wattle short, restricted to distal third of stylus.

\section{Taito oblongatus (Roewer 1928a) comb. nov.}

Taito oblongatus (Roewer 1928a) comb. nov. is shown in Figures 1e, 6a,b,c,d,e,f,g,h,i,j,k,l, 17a,b,c, and 29a,b,c,d,e,f,g.

Cynortula oblongata Roewer 1928a: 576, Figure 28; Mello-Leitão 1932: 58; Kury 2003: 52.

Type data. 1 ô 1 क syntypes (SMF RII 158/80, examined through photograph, courtesy R. Pinto-da-Rocha), ECUADOR, [Zamora-Chinchipe, Yantzaza], Zamora Valley.

Other material examined. 3 o 13 ㅇ (ICN-AO 213), COLOMBIA, Meta, [Mesetas], Puerto Marimba, Serrania de la Macarena, Rio Duda, vi.1994, A Calixto leg.

Diagnosis. Dorsal scutum of male extremely elongated (ratio ca. 1.60). Scutal area III with two minute tubercles. Dorsal anal operculum unarmed, sternite $7 / 8$ with a median stout blunt protuberance. Dorso-apical apophysis of coxa IV as a single acuminate spine. Femur IV sinuous, dorsally unarmed, distal-prolateral armed with comb of seven increasing spines. Equuleus compact with two well separate feet, arms, and crown prongs.

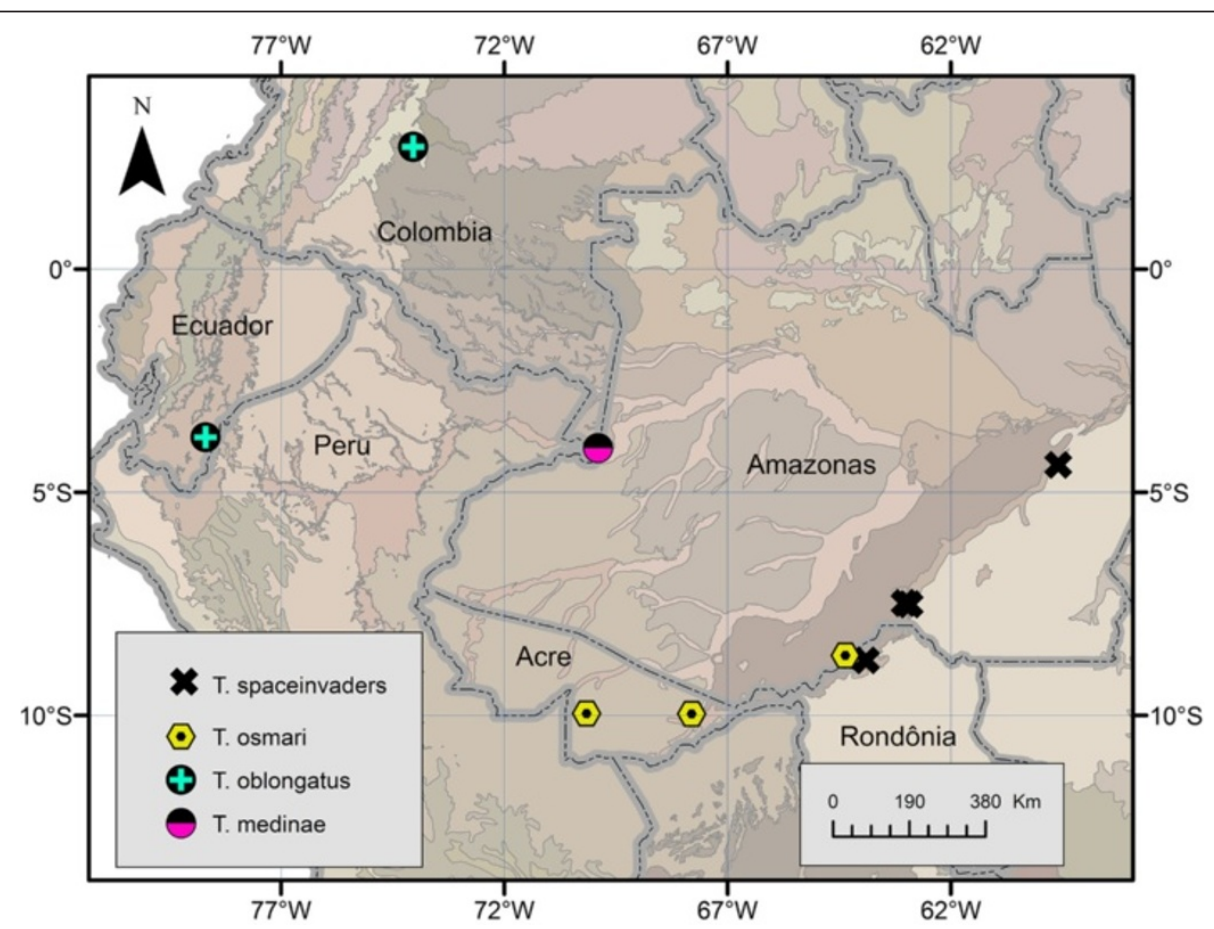

Figure 36 Northwestern South America, showing distribution of species of Taito (part 4). Colored patches on the background represent WWF eco-regions. 
Distribution (Figure 36). COLOMBIA, Meta, Mesetas, WWF NT0118 (Cordillera Oriental montane forests); ECUADOR, Zamora-Chinchipe, Yantzaza, WWF NT0121 (Eastern Cordillera real montane forests).

\section{Description of male ICN-AO 213}

Measurements. $\mathrm{CL}=2.0, \mathrm{AL}=3.9, \mathrm{CW}=2.5, \mathrm{AW}=3.8$, FeIV $=6.7$, TiIV $=4.2$. Dorsum (Figure 29a,b,d). Dorsal scutum extremely elongated (ratio ca. 1.60). Areas I and III each with pair of minute paramedian granules. Posterior margin of scutum slightly concave in dorsal view. Free tergites I and II with posterior margin sinuous and transverse marginal row of small granules, free tergite III with posterior margin strongly convex and a transverse row of small granules. Anal operculum unarmed (Figure 1e). Venter. Sternite $7 / 8$ with two main protuberances and many secondary coarse tubercles (Figure 1e). Chelicerae (Figure 29c). Basichelicerite with ectal row of only three small granules, posterior row of eight stout tubercles. One stout tubercle on antero-mesal corner. Pedipalps. Femur with low keel with row of 8 setiferous tubercles and ventral row of 12 setiferous tubercles. Legs. Trochanter IV with one very small retro-subapical setiferous tubercle. Femur IV only slightly curved dorsoventrally, with a few small retrolateral tubercles and a comb of five pro-subapical setiferous tubercles (Figure 29e,g). Patella (Figure 29f) and metatarsus IV unarmed. Tibia IV with row of 12 intercalate-sized retrolateral setiferous tubercles on proximal half (Figure 29f). Tarsal counts: 6-6/?-12/7-7/ 8-8. Color. Body and appendages uniformly brown, with white easel and white transverse stripe on free tergite zero. Genitalia (Figure 17a,b,c). Truncus penis slender, abruptly widened forming pair of calluses; ventral plate trapezoid; dorsal apophysis of glans square, bilobed, densely covered with tubercles; distal macrosetae spatulate; wattle short, restricted to distal third of stylus.

\section{Taito osmari sp. nov.}

Taito osmari sp. nov. is shown in Figures 1f, 8o,p,q,r,s,t, u,v, 15a,b,c, 25a,b,c,d,e,f,g.

Etymology. The species is named in honor of Osmar $\mathrm{S}$. Torres (UFAC), who assembled a nice collection of Opiliones from Acre, including, many specimens of species of Taito.

Type data. $\widehat{\alpha}$ holotype 2 q paratypes (MNRJ 2362) BRAZIL, Acre, Rio Branco, FEC, ix.2010, OS Torres leg.; 1 万ิ 2 ㅇ paratypes (MNRJ 7624) Acre, Parque Estadual Chandless, x.2011, OS Torres leg.; 1 त 1 \& paratypes (INPA-OP 0607), BRAZIL, Amazonas, Canutama, interfluve Madeira-Purus, projeto GEOMA, -08.65323 -064.35962; vii.2007, RS Ferreira leg.

Diagnosis. Dorsal scutum of male extremely elongated (ratio ca. 1.49). Scutal area III with two minute tubercles. Dorsal anal operculum with fringe of 6 to 7 small spines, ventral anal operculum with a pair of divergent spines. Dorso-apical apophysis of coxa IV as a single blunt spine. Femur IV sinuous, dorsally unarmed, distal-prolateral armed with comb of 7 increasing spines. Equuleus compact, boat-shaped.

Distribution (Figure 36). BRAZIL, Acre, Manoel Urbano; Rio Branco, both WWF NT0166 (Southwest Amazon moist forests); Amazonas, Canutama WWF NT0157 (PurusMadeira moist forests). Both eco-regions make part of the larger region Southwestern Amazonian moist forests.

\section{Description of male holotype}

Measurements. $\mathrm{CL}=1.9, \mathrm{AL}=3.5, \mathrm{CW}=2.5, \mathrm{AW}=3.7$, FeIV $=8.7$, TiIV $=4.9$. Dorsum (Figure 25a,b,c,d). Dorsal scutum extremely elongated (ratio ca. 1.49). Areas I and III each with paramedian pair of minute granules. Posterior margin of scutum slightly concave in dorsal view. Free tergites I and II with posterior margin straight and transverse marginal row of small granules, free tergite III with posterior margin strongly convex and a transverse row of small granules. Anal operculum with a cluster of spines, five larger, five smaller (Figures 1f, 25d). Venter. Coxa IV parallel to main body axis. Posterior margin of stigmatic area concave. Stigmata well detached from background by tegument fold. Sternite $7 / 8$ with a pair of widely separated spines (Figure 1f). Chelicerae (Figure 25c). Basichelicerite with ectal row of nine small granules, posterior row of six stronger acuminate tubercles. Two stout tubercles on antero-mesal corner. Pedipalps. Femur IV with 2 small tubercles on dorsal keel, a row of 11 ventral tubercles. Tibia ecto-apical with bifid tooth. Legs. Femur IV curved twice - in the middle and in the third fourth. With a distal row of five curved spines. Patella IV with a prolateral row of small acuminate tubercles. Tibia IV with row of 6 larger and 15 smaller acuminate tubercles intercalated. Tarsal counts: 6(3)-6(3)/?-12(3)/7-7/8-8. Color (in alcohol). Body and appendages very dark brown, appendages light brown mottled in black, metatarsi and tarsi IV pale yellow. Genitalia (Figure 15a,b,c). Truncus penis slender, but growing steadily with subdistal bulge, forming a pair of attenuate calluses; ventral plate subrectangular concave at laterals; dorsal apophysis of glans square, bilobed, densely covered with tubercles; distal macrosetae cylindrical; wattle short, restricted to distal third of stylus.

\section{Taito rorschachi sp. nov.}

Taito rorschachi sp. nov. is shown in Figures $8 \mathrm{~h}, \mathrm{i}, \mathrm{j}, \mathrm{k}, \mathrm{l}, \mathrm{m}, \mathrm{n}$, $16 \mathrm{~g}, \mathrm{~h}, \mathrm{i}$, and 23a,b,c,d,e,f,g).

Etymology. Named by the shape of the equuleus, which resembles the inkblots of the psychological Rorschach test.

Type data. $\delta$ holotype (MNRJ 2346), BRAZIL, Acre, Rio Branco, FEC, ix.2010, OS Torres leg.; 1 ๙ paratype 
(MNRJ 2380), same data; 5 त paratypes (MNRJ 02306) Acre, Cruzeiro do Sul, xi.2009, OS Torres leg.

Diagnosis. Dorsal scutum of male moderately elongated (ratio ca. 1.33). Scutal area III with two minute tubercles. Dorsal anal operculum of male with a robust central spiniform apophysis, ventral anal operculum with two smaller paramedian ones (absent in beta males). Dorso-apical apophysis of coxa IV as a single acuminate spine. Femur IV only breaking direction once, distally, dorsally unarmed, distal-prolateral unarmed. Patella IV densely covered with acuminate tubercles. Equuleus compact, butterfly-shaped.

\section{Description of male holotype}

Distribution (Figure 32). BRAZIL, Acre, Cruzeiro do Sul; Rio Branco, both WWF NT0166 (Southwest Amazon moist forests).

Measurements. $\mathrm{CL}=1.7, \mathrm{AL}=3.0, \mathrm{CW}=2.5, \mathrm{AW}=3.8$, FeIV $=7.4$, TiIV $=4.5$. Dorsum. Dorsal scutum moderately elongated (ratio ca. 1.33). Areas I and III each with a pair of small acuminate tubercles. Posterior margin of scutum concave in dorsal view. Free tergites I and II with posterior margin straight and transverse marginal row of small granules, free tergite III with posterior margin strongly convex and a transverse row of small granules. Anal operculum with median robust spiniform apophysis. Venter. Sternite 7/8 with a pair of paramedian robust spiniform apophyses. Chelicerae (Figure 23c). Basichelicerite with ectal row of four small granules, posterior row of four strong acuminate tubercles. Two entirely fused tubercles on antero-mesal corner. Pedipalps. Femur with dorsal keel fused with indistinct setiferous tubercles, and ventral row of nine setiferous tubercles. Legs. Trochanter, tibia and metatarsus IV unarmed. Femur IV slightly sinuous only in distal third, entirely unarmed. Patella IV armed with coarse retrolateral setiferous tubercles. Tarsal counts: 6-6/11-11/7-7/8-8. Color (in alcohol). Body and appendages uniformly dark brown. Equuleus white butterfly-shaped, with a pair of rounded accessory blots. White transverse stripe on free tergite zero strongly dissociated. Genitalia (Figure 16g,h,i). Truncus penis straight, without callus; ventral plate subrectangular concave at laterals; dorsal apophysis of glans conical, smooth; distal macrosetae moderately flattened; wattle very long, starting from base of stylus.

Taito serriperna (Mello-Leitão 1932) comb. nov., revalidated Revalidated Taito serriperna (Mello-Leitão 1932) comb. nov. is shown in Figures 16d,e,f and 31a,b,c,d,e,f,g.

Cynortula serriperna Mello-Leitão 1932: 442, fig. suppl. 3, [junior subjective synonym of Eucynortella juruensis Mello-Leitão 1923 by Soares (1944)].

Type data. O holotype (MNRJ 1372, examined), 'Rio Janinana' [BRAZIL, Acre, Jaminuá River, latitude 9.15', longitude $71.8^{\circ}$, municipality Jordão], B Carvalho leg.
Diagnosis. Dorsal scutum of male sturdy (ratio ca. 1.19). Scutal area III with a pair of minute tubercles. Anal operculum unarmed. Dorso-apical apophysis of coxa IV as a bifid short spine. Femur IV gently sinuous, dorsally unarmed, distal-prolateral armed with comb of 12 spines. Equuleus compact with two well separate feet, arms, and crown prongs.

Distribution (Figure 34). BRAZIL, Acre, Jordão, WWF NT0166 (Southwest Amazon moist forests).

\section{Description of male holotype}

Measurements. $\mathrm{CL}=1.6, \mathrm{AL}=3.0, \mathrm{CW}=2.6, \mathrm{AW}=4.1$, FeIV $=5.4$, TiIV $=3.8$. Dorsum (Figure 31a,b,d). Dorsal scutum sturdy (ratio ca. 1.19). Areas I and III each with a pair of small acuminate tubercles. Posterior margin of scutum straight in dorsal view. Free tergites I and II with posterior margin straight and transverse marginal row of small granules, free tergite III with posterior margin slightly convex and a transverse row of small granules. Anal operculum smooth and unarmed. Venter (Figure 31d). Sternite 7/8 smooth and unarmed. Chelicerae (Figure 31c). Basichelicerite with ectal row of 12 small granules, posterior row of 5 strong acuminate tubercles, mesal row of 4 strong acuminate tubercles. One stout blunt tubercle on antero-mesal corner. Pedipalps. Femur with low dorsal keel with six setiferous tubercles, ventral row of nine setiferous tubercles. Legs (Figure 31e,f,g). Trochanter IV with 1 small retrosubapical tubercle. Femur IV gently sinuous, changing the direction towards retrolateral at about $3 / 4$ of its length, without noticeable incrassation. Armed with prolateral row of 12 curved tubercles. Tibia IV armed with row of six retrolateral spines. Metatarsus IV lacking. Tarsal counts (tarsalia destroyed, original Mello-Leitão's number given): 6/7/7/9. Color (in alcohol). Body and appendages uniformly brown. Equuleus white, easel-shaped. White transverse stripe on free tergite zero strongly dissociated. Genitalia (Figure 16d,e,f). Truncus penis slender, abruptly widened forming a pair of calluses; ventral plate rectangular straight; dorsal apophysis of glans square, bilobed, densely covered with tubercles; distal macrosetae spatulate; wattle short, restricted to distal third of stylus.

\section{Taito spaceinvaders sp. nov.}

Taito spaceinvaders sp. nov. is shown in Figures 1b, 7a,b, c,d,e,f,g,h,i,j,k,l,m,n,o,p,q,r,s,t,u,v,w,x,y,z,aa,ab,ac,ad,ae,af, 12a,b,c,d, 17g,h,i, 20a,b,c,d,e, and 24a,b,c,d,e,f,g.

Etymology. Space Invaders (Japanese Supûsu Inbêdâ) is an arcade video game manufactured and sold by Taito and very successful and popular worldwide in the 1980s.

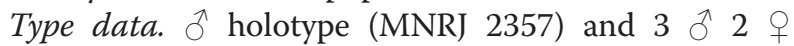
paratypes (MNRJ 1947), BRAZIL, Amazonas, Humaitá, left margin of Madeira river, Igarapé do Banheiro, 13. iv.1975, VP Silva \& AJ Dillon leg.; 2 11 q paratypes 
(MNRJ 2300), Humaitá, Igarapé do Banheiro, 24.ii.1976, U Caramaschi leg.; 3 đ̊ paratypes (MNRJ 4462), Humaitá, Igarapé do Banheiro, 10-11.iii.1976, U Caramaschi leg.; 6 đ 1 q paratypes (MNRJ 4570), Humaitá, Igarapé do Banheiro, 4.iv.1975, JCM Carvalho \& U Caramaschi leg.; 1 ô 6 q paratypes (MNRJ 4620), Humaitá, Igarapé do Banheiro, 17.ii.1976, U Caramaschi leg.; 1 q paratype (MNRJ 4401), Humaitá, Igarapé do Banheiro, 02.i.1979, LM Silva, A Silva \& CM de Carvalho leg.; 3 \ $7 q$ paratypes (MNRJ 17646), Humaitá, Igarapé do Banheiro, 11. vi.1975, A Mantovan leg.; 1 đo 5 q paratypes (MNRJ 4579), Humaitá, Igarapé do Banheiro, 25.iii.1975, CM de Carvalho \& U Caramaschi leg.; 4 ô 1 † paratypes (MNRJ 17387), Humaitá, Igarapé do Banheiro, 02.i.1979, CM de Carvalho leg.; 3 ô paratypes (MNRJ 17386), Humaitá,

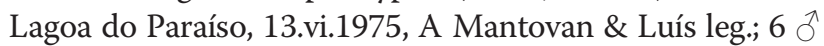
1 q paratypes (MNRJ 4816), Humaitá, São João do Crato, 15.ii.1977, MT Almeida \& LM Silva leg.; 4 đ 3 q paratypes (MNRJ 4821), Humaitá, Lagoa Puruzinho, 30. xii.1975, Luís \& Angélica leg; 2 đ 6 q paratypes (MNRJ 7547), Humaitá, 19.vii..1975, A Mantovan leg.; 1 ઈ paratype (MZUSP 18302) Amazonas, Borba, Boca do Matupiri, R. Madeira, 09.xii.1975, E.P.A.; 1 ते paratype (MNRJ 7580) Rondônia, Porto Velho, Campus da UNIR, aleatória, noturna, 28.vii.2008, PI Silva Jr., R. Bertani, R Martins \& CS Fukushima leg.; 2 ते paratype (MNRJ 7510), Porto Velho, Parque Natural Municipal de Porto Velho, 5.ii.2011, G Miranda leg.

Diagnosis. Dorsal scutum of male extremely elongated (ratio ca. 1.58). Scutal area III with two minute tubercles. Anal operculum with a stout median blunt protuberance, very slightly bifid only at the tip (Figure 24a,b,d). Dorso-apical apophysis of coxa IV as a single acuminate spine (Figure 24a). Femur IV only gently curved, dorsally unarmed, distal-prolateral armed with comb of seven curved spines (Figure 24e,f,g). Equuleus compact with two well separate feet and arms but crown prongs coalesced.

Distribution (Figure 36). BRAZIL, Amazonas, Borba; Humaitá; Rondônia, Porto Velho. WWF Monte Alegre Várzea (NT0141).

\section{Description of male holotype}

Measurements. $\mathrm{CL}=2.0, \mathrm{AL}=3.9, \mathrm{CW}=2.9, \mathrm{AW}=4.1$, FeIV $=9.2$, TiIV $=5.5$. Dorsum (Figure 24a,b,d). Dorsal scutum extremely elongated (ratio ca. 1.58). Areas I and III each with a paramedian pair of minute granules. Posterior margin of scutum slightly concave in dorsal view. Free tergites I and II with posterior margin straight and transverse marginal row of small granules, free tergite III with posterior margin convex and a transverse row of small granules. Anal operculum with a stout median blunt protuberance, very slightly bifid only at the tip (Figure 24a,b,d). Venter. Sternite 7/8 unarmed (Figure 1b). Chelicerae (Figure 24c). Basichelicerite with ectal row of nine small tubercles, posterior row of nine stronger acuminate tubercles. One stout tubercle on antero-mesal corner, displaced a little internally. Pedipalps (Figure 12a,b,c,d). Femur with low dorsal keel with 6 setiferous tubercles, and ventral row of 10 setiferous tubercles. Legs. Dorsoapical apophysis of coxa IV as a single acuminate spine (Figure 24a). Trochanter IV with very small retrosubapical tubercle. Femur IV only gently curved on distal $1 / 3$, dorsally unarmed, distal-prolateral armed with comb of seven curved spines (Figure 24e,f,g). Patella IV substraight, finely granular. Tibia IV with retrolateral row of 13 very small setiferous tubercles. Metatarsus IV unarmed. Tarsal counts: 6-6/13-13/8-8/ 9-9. Color. Body and appendages uniformly brown, free sternites only a little darker. White markings: equuleus easel-shaped (Figure 24a), scutum with three small rounded blots, coda with transverse stripe. Tibiae II and IV, metatarsi I to IV with many light rings. Genitalia (Figure 17g,h,i). Truncus penis slender, abruptly widened forming a pair of calluses; ventral plate trapezoid; dorsal apophysis of glans square, bilobed, densely covered with tubercles; distal macrosetae spatulate; wattle short, restricted to distal third of stylus. Variation (paratypes). Tarsal counts: 6(3)/12-14(3)/8/9-10.

\section{Taito unapunctatus (Goodnight and Goodnight 1943) comb. nov.}

Taito unapunctatus (Goodnight and Goodnight 1943) comb. nov. is shown in Figure 8x.

Cynortula unapunctata Goodnight and Goodnight 1943c: 4, Figures 7, 8; Kury 2003: 52.

Type data. $\widehat{o}$ holotype $q$ paratype $(\mathrm{AMNH}$, examined only through photograph, courtesy $\mathrm{R}$ Pinto-da-Rocha), PERU, [Amazonas, Provincia de Condorcanqui], between Cenipa and Nieva rivers, Upper Marañon, 10-24.ix.1924, Klug leg.

Diagnosis. Dorsal scutum of male moderately elongated (ratio ca. 1.28). Scutal area III with two small tubercles. Anal operculum unarmed. Dorso-apical apophysis of coxa IV as a single acuminate spine. Femur IV substraight in dorsal view, curved in lateral view, dorsally unarmed, distal-prolateral armed with comb of 20 spines, larger in the middle. Equuleus extremely compact, square, without discrete feet, arms and horns.

Distribution (Figure 32). PERU, Amazonas, Condorcanqui, WWF NT0174 (Ucayali moist forests).

\section{Discussion and conclusions}

Distribution of the species of Taito. The 14 species of Taito are known from the Upper Amazon Basin up the eastern slope of the Andes, being absent of mid-course moist forest such as Japurá-Solimões-Negro and UatumaTrombetas. Due to the scarcity of material in the collections, many of the species of Taito are known from only 
one locality. As it is common in Amazonia, the species are widely sympatric, so we were forced to split the graphical representation of the distribution into four maps to avoid superposition. We may recognize four basic nuclei of distribution of the species: (1) Eastern Andean slope (montane forests) of Colombia and Ecuador - with T. oblongatus only. (2) Ucayali moist forests, non-floodable lowland in Peru - only T. unapunctatus. (3) Southwest Amazon lowlands - these are the species which occur in the Acre state, all in the WWF eco-region NT0166 T. juruensis, T. kawaiikei, T. rorschachi, and T. serriperna. (4) The interfluves Juruá-Purus-Madeira, also in lowlands, while many of the species are exclusive to the Várzeas (seasonal floodplain forests inundated by white water rivers). T. honda and T. spaceinvaders are endemic from the Monte Alegre Várzea (NT0141), other species, such as $T$. galaga and T. insperatus occur both in the Várzea and in the non-floodable moist forests. T. litteratus and $T$. medinae each is known from only one point between Iquitos and Purus Várzeas. T. kakera and T. osmari are the only two species which break this fourfold exclusion pattern, because besides occurring in the SW, they were also found respectively in Monte Alegre Várzea and Purus-Madeira moist forests, that is, both belong to our groups 3 and 4 . Some important eco-regions which lie within the known limits of Taito's distribution and have similar physiognomy, such as Napo Moist Forests are expected to harbor more representatives of the genus.

Cosmetidae from Acre. The Brazilian state of Acre is a 'knowledge-wasteland' regarding Opiliones (Kury 2003), but the operation of inventory projects by local arachnologists such as Osmar Torres is expected to steeply increase the known diversity of the region. The only previous record of Cosmetidae from Acre in the literature is that of Roewer (1912), who described Cynorta vestita from 'Suriname, Paramaribo' and 'Brasilien, Rio Branco'. Rio Branco is a fairly common name of forsaken places in Brazil, although by far the most famous is the one in Acre state. It is well possible that Roewer referred to Rio Branco in Acre. It seems strange to have a harvestman species distributed in Suriname and Acre, and the possible explanations are (1) misidentification - they are not the same species, (2) misplacing - they are the same species, but the labels somehow got mixed up, and (3) the species really has an unusual wide distribution. There are other records for this C. vestita from Brazil, Guyana, and Peru, forming an unlikely large distribution area. By the above discussed, it is clear that the present records of Cosmetidae are the first reliable ones for the Brazilian state of Acre.

Species groups in Taito and monophyly of the genus. Refined knowledge about morphology of Cosmetidae is only available for a few species. Most genera are very poorly known and do not represent natural groups. In the absence of a rigorous test of the monophyly of this genus, that could only be achieved by a phylogenetic analysis, the status of Taito as a clade in uncertain. Significance of character state distribution is currently hard to access. Our taxonomic decision to create the new genus Taito is based on morphological gaps that allow a definition of Taito as dark colored cosmetids with some sexual dimorphic elongation of dorsal scutum, which can be extreme in some species; legs much longer than in Vononoides; equuleus with horns never forming anvilshaped crown; pedipalpal tibia with deep mesal ditch; pedipalpal tarsus beveled mesally; truncus penis mostly slender, but abruptly widening at VP forming a pair of calli; dorsal process of glans bilobed square.

The 'bump-scales' of the glans are being here described for the first time. They are clearly absent in Cosmetus (unpublished data) and Roquettea (as seen in Ferreira and Kury 2010) and present in Cynorta (unpublished data) as well as in all species of Taito for which male genitalia is examined on SEM. The specialized square bilobed dorsal process and the concave ring of the calli are also new discoveries, and they seem to be restricted to species of Taito. In this respect, Cynortopyga and Eucynortella show more generalized genitalia. But again, it takes SEM imagery to understand the subtle genital morphological features in this family.

Hitherto there is not a single character state which can be confidently interpreted as a synapomorphy for all species of Taito, the extreme elongation of the body is not universal within the genus, and there are similar equulei in other related genera such as Vononoides and Eucynortella. The best candidate for a synapomorphy would be the unique square-bilobed shape of dorsal process of gland penis, but it is absent in T. galaga and T. rorschachi. The equulei in Taito are varied, but in general, they conform with the prototypic shape as described above, except for the subgroup with $\mathrm{H}$-shaped equuleus, such as $T$. honda. These are different from the filamentous equuleus of Cynortopyga and the anvilshaped crown of Vononoides and Eucynortella.

The pedipalpus of Taito species bears notable features, such as (1) mesal flange on patella, (2) mesal ditch occupying all length of tibia, and (3) mesally beveled tarsus. All of these occur variedly outside the genus, but there is no comparative study on pedipalp morphology to allow more extensive assessment.

Judging only by external morphology, there seem to be at least two main facies of Taito species - (1) the elongated, bumpy reared, with few pro-distal spines on femur IV (such as T. medinae, T. spaceinvaders) and (2) the shorter-bodied, smooth-reared, comb-spiny legged (such as T. juruensis, T. kawaiikei). But not even these two would-be subgroups are clear-cut - there are intermediates such as T. honda. Genital morphology is not clear-cut either, the thin-shafted//callus-bearer group 
of T. spaceinvaders is not universal, but again there are intermediates between this facies and the thick-shafted species, such as T. galaga.

Based on the shape/armature of femur IV of male and the presence of an equuleus, Taito seems to be closely related to Cynortopyga, Eucynortella, Vononoides, and a large number of small meaningless Andean genera, which will probably be mostly fused into each other in the future. Distribution of groin warts in Cosmetidae seems to be much wider, and also includes genera such as Flirtea, which in contrast possesses the primitive states of swollen chelicerae in male and well-marked scutal grooves.

Subtle separation of species. This was a contentious point during the early stages of the project of both pairs T. galaga/rorschachi and T. insperatus/oblongatus; are they really separate species which represent points in a cline? There is no doubt that they are at least very closely related species. For T. galaga/rorschachi, the trident armature of anal operculum and sternites 7/8 differ only in degree, and even the male genitalia is extremely similar to one another, strongly deviating from the Taito pattern. Our ability to always tell to which morphotype an individual belongs (also using spines of area III and details of equuleus and chelicera) has led us to decide for creating two separate species. For $T$. insperatus/ oblongatus, the differences are still subtler - insperatus has (1) equuleus more deteriorated, frankly botuliform, (2) ocularium normally wide, (3) tibia IV armed retrolateral, (4) truncus penis thicker, with neck less abrupt.

Taxonomic recognition of variation in Opiliones. With this name, Goodnight and Goodnight (1953b) published observations on variable features, concluding that many of the characters used in taxonomy (they notably used Cosmetidae and Stygnommatidae) are 'subject to considerable variation'. Based on that, but without giving any alternative treatment, they proposed a great number of specific and generic synonymies in both families (Goodnight and Goodnight 1951; 1953a). These authors failed to employ other characters from the great number of potential ones that occur in Opiliones and thus failed to perceive and arrange the diversity of the group (Kury 2003). We understand that Linnean categories are arbitrary conventions, but choosing exclusively tarsal segmentation to discriminate groups is hardly a wise move. In Stygnommatidae, the 'everything-is-variation' approach resulted in the fusion of a wide variety of biodiversity into a single extremely variable species, Stygnomma fuhrmanni, which made the knowledge in this family to retrocede immensely (Pérez-González A: Revisão sistemática e análise filogenética de Stygnommatidae (Arachnida, Opiliones), unpublished).

\section{Competing interests}

The authors declare that they have no competing interests.

\section{Authors' contributions}

ABK conceived of the study and participated in its design and coordination, prepared illustrations and drafted the manuscript. CMLB participated in the final ID of the samples (delimitation of the species) and of the species descriptions and prepared illustrations. Both authors read and approved the final manuscript.

\section{Authors' information}

ABK is currently professor and senior curator of arachnids in the National Museum (Rio). CMLB is currently assistant curator in the National Museum (Rio).

\section{Acknowledgements}

We would like to thank Denis Pedroso (MNRJ) for coming up with the name of $T$. honda and for calling our attention to the free tergite zero and to Nobuo Tsurusaki for help with the name of T. kawaiikei. Cláudio Ferreira (ex-graduate-student of MNRJ) took part in the very early stages of the project before leaving zoology for good. Osmar S. Torres (Universidade Federal do Acre - UFAC) kindly sent a collection of Opiliones from Acre State for study. Alessandro Giupponi (FIOCRUZ) made a small expedition to Acre and got some Taito of his own. Ulisses Caramaschi (MNRJ) collected many specimens of Taito in Humaitá. Ricardo Pinto-da-Rocha (MZSP) generously shared his own photographs of the types of Cosmetidae in AMNH and SMF and hand-carried the type of E. pauper from IBSP. Andrés García (ICN-UNAL) provided valuable company in the field and specially lab work in Colombia 2011. Elvert Danny Vélez and Luis Edier Franco, assistant curators in IAvH, spent many days sorting Opiliones material with ABK in Leyva, 2011, while Claudia Medina patiently tried to explain over the phone to an astonished ABK the absence of an airport in that small village. Eduardo Flórez (ICNUNAL), in spite of being crazy hosting a congress, gave a great deal of attention to ABK in Bogotá 2011. Ana Lúcia Tourinho (INPA) was a congenial host to ABK in Manaus 2012. Sidclay Dias, Willians Porto, and Lidianne Salvatierra were attentive co-hosts to ABK at INPA. Arthur Anker graciously contributed one of his fantastic photographs of a living Taito specimen. The collection curators - Eduardo Flórez (ICN-UNAL), Claudia Medina (IAvH), Ricardo Pinto-da-Rocha (MZSP), and Ana Lúcia Tourinho (INPA) - are gratefully acknowledged for the loan of material which served as comparison and partly became types. Our 'second family' in the arachno-lab of Museu Nacional provided excellent environment for research. Criticism from Nobuo Tsurusaki and an unknown referee improved the quality of the text. A conscious effort is being made by us to reinforce the significance of local South American collections (for example, in Colombia and Ecuador), by depositing type material there - this is only the second type of Opiliones to be deposited in IAvH. This study has been supported by grant \# 562149/2010-4 (PROTAX - OPESC project) and scholarship \# 302116/2010-9 (PQ - AMMA project) from the Conselho Nacional de Desenvolvimento Científico e Tecnológico (CNPq).

Received: 24 December 2013 Accepted: 18 April 2014

Published online: 28 May 2014

\section{References}

Ferreira CP, Kury AB (2010) A review of Roquettea, with description of three new Brazilian species and notes on Gryne (Opiliones, Cosmetidae, Discosomaticinae). Zoological Science 27:697-708

Goodnight CJ, Goodnight ML (1943) Phalangida from South America. Am Mus Novit 1234:1-19

Goodnight CJ, Goodnight ML (1951) The genus Stygnomma (Phalangida). Am Mus Novit 1491:1-20

Goodnight CJ, Goodnight ML (1953a) The opilionid fauna of Chiapas, Mexico, and adjacent areas (Arachnoidea, Opiliones). Am Mus Novit 1610:1-81

Goodnight CJ, Goodnight ML (1953b) Taxonomic recognition of variation in Opiliones. Syst Zool 2(4):173-179

Kury AB (2003) Annotated catalogue of the Laniatores of the New World (Arachnida, Opiliones). Revista Ibérica de Aracnología especial monográfico $1: 1-337$

Kury AB (2012) A new genus of Cranaidae from Ecuador (Opiliones: Laniatores). Zootaxa 3314:31-44

Kury AB (2013) Order Opiliones Sundevall, 1833. In: Zhang, ZQ (Ed.) Animal biodiversity: an outline of higher-level classification and survey of taxonomic richness (Addenda 2013). Zootaxa 3703(1):27-33 
Kury AB, Costa CS, Villarreal MO (2007) Redescription of the type species of Cynorta Koch, 1839 (Arachnida, Opiliones, Cosmetidae). J Arachnology 35(2):325-333

Mello-Leitão CF (1923) Opiliones Laniatores do Brasil. Archivos do Museu Nacional 24:107-197

Mello-Leitão CF (1932) Opiliões do Brasil. Revista do Museu Paulista 17(2):1-505, 61 pls

Piza Jr ST (1938) Novos Opiliões do Brasil. Boletim Biológico (Nova Série) $3(3 / 4): 135-146$

Roewer CF (1912) Die Familie der Cosmetiden Opiliones-Laniatores. Archiv für Naturgeschichte, Abt A, Original-Arbeiten 78(10):1-122, + Taf. 1-2

Roewer CF (1928) Weitere Weberknechte II. (2. Ergänzung der Weberknechte der Erde, 1923). Abhandlungen der Naturwissenschaftlichen Verein zu Bremen 26 (3):527-632, ["1927"], 1 plate

Roewer CF (1947) Diagnosen neuer Gattungen und Arten der Opiliones

Laniatores (Arachn.) aus C.F. Roewer's Sammlung im Senckenberg-Museum.

1. Cosmetidae. [Weitere Weberknechte XII]. Senckenbergiana 28(1/3):7-57

Soares BAM (1944) Notas sobre opiliões da coleção do Museu Nacional do Rio de Janeiro. Papéis avulsos do Departamento de Zoologia 6(15):163-180

Soares HEM (1970) Novas espécies de opiliões da Região Amazônica (Opiliones, Cosmetidae, Gonyleptidae, Phalangiidae, Stygnidae). Rev Bras Biol 30(3):323-338

\section{doi:10.1186/s40555-014-0024-4}

Cite this article as: Kury and Barros: A new genus and eight new species of Amazonian cosmetines (Opiliones, Laniatores, Cosmetidae). Zoological Studies 2014 53:24.

\section{Submit your manuscript to a SpringerOpen ${ }^{\circ}$ journal and benefit from:}

- Convenient online submission

- Rigorous peer review

- Immediate publication on acceptance

- Open access: articles freely available online

- High visibility within the field

- Retaining the copyright to your article 